\title{
Fibrillar A $\beta$ triggers microglial proteome alterations and dysfunction in Alzheimer mouse models
}

$$
\begin{aligned}
& \text { Laura Sebastian Monasor }{ }^{1,10 *} \text {, Stephan A. Müller }{ }^{1 *} \text {, Alessio Colombo }{ }^{1} \text {, Jasmin König }{ }^{1,2} \text {, Stefan } \\
& \text { Roth }^{3} \text {, Arthur Liesz }{ }^{3,4} \text {, Anna Berghofer }{ }^{5} \text {, Takashi Saito }{ }^{6,7} \text {, Takaomi C. Saido }{ }^{6} \text {, Jochen Herms }{ }^{1,4,8} \text {, } \\
& \text { Michael Willem }{ }^{9} \text {, Christian Haass }{ }^{1,4,9} \text {, Stefan F. Lichtenthaler }{ }^{1,4,5 \#} \& \text { Sabina Tahirovic }^{1 \#}
\end{aligned}
$$

${ }^{1}$ German Center for Neurodegenerative Diseases (DZNE) Munich, 81377 Munich, Germany

${ }^{2}$ Faculty of Chemistry, Technical University of Munich, Garching, Germany

${ }^{3}$ Institute for Stroke and Dementia Research (ISD), Ludwig-Maximilians Universität München, 81377 Munich, Germany

${ }^{4}$ Munich Cluster for Systems Neurology (SyNergy), Munich, Germany

${ }^{5}$ Neuroproteomics, School of Medicine, Klinikum Rechts der Isar, Technical University of Munich, Munich, Germany

${ }^{6}$ Laboratory for Proteolytic Neuroscience, RIKEN Center for Brain Science Institute, Wako, Saitama 351-0198, Japan

${ }^{7}$ Department of Neurocognitive Science, Nagoya City University Graduate School of Medical Science, Nagoya, Aichi 467-8601, Japan

${ }^{8}$ Center for Neuropathology and Prion Research, Ludwig-Maximilians-Universität München, 81377 Munich, Germany

${ }^{9}$ Biomedical Center (BMC), Ludwig-Maximilians Universität München, 81377 Munich, Germany

${ }^{10}$ Graduate School of Systemic Neuroscience, Ludwig-Maximilians-University Munich, Munich, Germany.

${ }^{*}$ Contributed equally

\#Correspondence: Sabina.Tahirovic@dzne.de and Stefan.Lichtenthaler@dzne.de

\section{Running title:}

Microglial proteomic signatures of AD

Keywords: Alzheimer's disease / microglia / proteomic signatures / neuroinflammation / phagocytosis 


\section{Abstract}

34 Microglial dysfunction is a key pathological feature of Alzheimer's disease (AD), but little is known 35 about proteome-wide changes in microglia during the course of AD pathogenesis and their functional 36 consequences. Here, we performed an in-depth and time-resolved proteomic characterization of 37 microglia in two mouse models of amyloid $\beta(\mathrm{A} \beta)$ pathology, the overexpression APPPS1 and the 38 knock-in APP-NL-G-F (APP-KI) model. We identified a large panel of Microglial A $\beta$ Response 39 Proteins (MARPs) that reflect a heterogeneity of microglial alterations during early, middle and 40 advanced stages of $A \beta$ deposition. Although both mouse models display severe microglial alterations 41 at late stages of amyloid pathology, MARP signatures occur earlier in the APPPS1 mice. Strikingly, 42 the kinetic differences in proteomic profiles correlated with the presence of fibrillar $\mathrm{A} \beta$, rather than 43 dystrophic neurites, suggesting that fibrillar $\mathrm{A} \beta$ aggregates are the main drivers of the AD-associated 44 microglial phenotype and the observed functional decline. The identified microglial proteomic 45 fingerprints of $\mathrm{AD}$ provide a valuable resource for functional studies of novel molecular targets and 46 potential biomarkers for monitoring AD progression or therapeutic efficacy. 


\section{Introduction}

Microglia play fundamental roles in a variety of neurodegenerative diseases, including AD (McQuade and Blurton-Jones, 2019). Changes in brain immunity, together with extracellular A $\beta$ deposition and neurofibrillary tangles, are major pathological culprits in AD (Gjoneska et al., 2015; Guillot-Sestier and Town, 2013; Holtzman et al., 2011; Shi and Holtzman, 2018). The importance of microglia in $\mathrm{AD}$ pathogenesis is well illustrated by the increasing number of identified AD risk genes which are expressed in microglia and have functions in brain immunity (Cuyvers and Sleegers, 2016; Guerreiro et al., 2013; Jansen et al., 2019; Jonsson et al., 2013; Karch and Goate, 2015; Lambert et al., 2009; Naj et al., 2011; Sims et al., 2017). For example, the triggering receptor expressed on myeloid cells 2 (Trem2) and apolipoprotein E (ApoE) are major genetic risk factors for sporadic AD that are expressed by plaque-associated microglia and involved in A $\beta$ clearance (Bradshaw et al., 2013; Castellano et al., 2011; Kleinberger et al., 2014; Parhizkar et al., 2019; Reddy et al., 2009; Wang et al., 2015). It has also been shown that microglial phagocytosis decays over the course of AD (Hickman et al., 2008; Koellhoffer et al., 2017; Orre et al., 2014a; Solito and Sastre, 2012; Zuroff et al., 2017). Along these lines, $\mathrm{A} \beta$ clearance was found reduced in sporadic $\mathrm{AD}$ and it is assumed to be a key factor in the pathogenesis (Mawuenyega et al., 2010; Saido, 1998; Wildsmith et al., 2013). Importantly, A $\beta$ clearance defects in AD microglia are reversible (Daria et al., 2017) and enhancing microglial phagocytic function has been explored as a therapeutic approach since substantial reduction of A $\beta$ burden appears to correlate with cognitive benefits (Bacskai et al., 2001; Bard et al., 2000; Bohrmann et al., 2012; Janus et al., 2000; Lathuiliere et al., 2016; Morgan et al., 2000; Nicoll et al., 2006; Nicoll et al., 2003; Schenk et al., 1999; Schilling et al., 2018; Sevigny et al., 2016; Wilcock et al., 2004). However, when and how microglia change along AD progression is still not clear. Thus, understanding molecular alterations of microglia at different stages of $\mathrm{AD}$ is crucial and a pre-requisite for developing safe and efficacious therapy.

Transcriptional expression profiles for microglia were previously revealed under physiological, neurodegenerative or neuroinflammatory conditions (Butovsky et al., 2014; Galatro et al., 2017; Gosselin et al., 2017; Gotzl et al., 2019; Grabert et al., 2016; Holtman et al., 2015; Kamphuis et al., 2016; Krasemann et al., 2017; Mazaheri et al., 2017; Orre et al., 2014a; Orre et al., 2014b; Wang et al., 2015; Yin et al., 2017). Transcriptional signatures were also recently reported at single-cell resolution, demonstrating regional and functional heterogeneity of brain myeloid cells (Hammond et al., 2019; Jordao et al., 2019; Keren-Shaul et al., 2017; Mathys et al., 2017; Sala Frigerio et al., 2019). In neurodegenerative mouse models, two major profiles have been proposed along the spectrum of 
microglial alterations. One is the homeostatic microglial signature that occurs under physiological conditions and is characterized by the expression of several genes, including P2ry12, Tmem119 and Cx3crl. The other key signatures, referred to as disease-associated microglia (DAM), microglial neurodegenerative phenotype $(\mathrm{MGnD})$ or activated response microglia (ARM) are observed under neurodegenerative conditions (Keren-Shaul et al., 2017; Krasemann et al., 2017; Sala Frigerio et al., 2019) and characterized by increased expression of ApoE, Trem2, Cd68, Clec7a and Itgax (Cd11c), among others. These changes were quantified using RNA transcripts, but transcript levels do not necessarily reflect protein levels which ultimately control cell function (Bottcher et al., 2019; Mrdjen et al., 2018; Sharma et al., 2015). Importantly, a recent study postulated that transcriptomic profiles of microglia from another AD mouse model (5xFAD) do not correlate well with proteomic changes (Rangaraju et al., 2018), suggesting the existence of additional translational or post-translational regulation mechanisms in AD microglia. Additionally, little is known about $A \beta$-associated changes in the microglial proteome in a time-resolved manner, or which proteome alterations underscore microglial dysfunction. Accordingly, we analyzed the microglial proteome at distinct stages of A $\beta$ pathology in two commonly used mouse models of amyloidosis; the APPPS1 (Radde et al., 2006), and the APP-KI mice (Saito et al., 2014). In contrast to the APPPS1 mouse model that overexpresses mutated human amyloid precursor protein (APP) and presenilin-1 (PS1), the APP-KI model bears endogenous levels of APP with a humanized A $\beta$ sequence containing three AD mutations (NL-G-F), and has no alterations of PS1 (Radde et al., 2006; Saito et al., 2014).

Our study determines the proteome of microglia from APPPS1 and APP-KI mice in a time resolved manner, starting from pre-deposition to early, middle and advanced stages of amyloid deposition and reveals a panel of MARPs that progressively change throughout $A \beta$ accumulation. Although both mouse models display severe microglial alterations at late stages of $A \beta$ pathology, the occurrence of MARP signatures differs and appears earlier in the APPPS1 mice. Strikingly, the kinetic differences in proteomic profiles correlated with the presence of fibrillar $A \beta$, rather than dystrophic neurites, suggesting that fibrillar $\mathrm{A} \beta$ aggregates are the main drivers of the AD-associated microglial phenotype and corresponding functional decline. The time-resolved microglial profiles may serve as benchmark proteomic signatures for investigating novel microglial targets or monitoring the efficacy of future pre-clinical studies aiming at microglial repair. 


\section{Results}

112 APPPS1 microglia develop an AD-associated proteomic signatures earlier compared to the APP-

\section{KI microglia}

114 To facilitate proteomic analysis, we first optimized the microglial isolation procedure. CD11b positive 115 microglia were isolated from mouse cerebrum using MACS technology. The purity of the CD11benriched fraction was controlled by fluorescence activated cell sorting (FACS), revealing that a $97 \%$ of isolated cells were CD11b positive (Suppl. Fig 1A). Of note, only $0.49 \%$ of CD11b positive cells were detected in the CD11b-depleted fraction (Suppl. Fig 1B), demonstrating high isolation efficiency. Next, we optimized the data acquisition method for microglial proteome analysis (Suppl. Fig 2A; Suppl. Table 1). Recently, it was shown that Data Independent Acquisition (DIA) for labelfree quantification (LFQ) of proteins identifies and quantifies consistently more peptides and proteins across multiple samples, compared to Data Dependent Acquisition (DDA) (Bruderer et al., 2015). Thus, we first evaluated the performance of DDA vs. DIA (Suppl. Table 2) using microglial lysates from WT and APPPS1 mice. DDA identified 53912 peptides on average compared to 74281 peptides identified by DIA, representing a $37.8 \%$ increase in detection by DIA method (Suppl. Table 2). Overall, the main advantage of DIA was the improved consistency of protein quantifications among the replicates and the identification of proteins with lower abundance, leading to $29 \%$ increase of relatively quantified proteins from 4412 with DDA to 5699 with DIA (Suppl. Table 2; Suppl. Fig 2B and C). We therefore selected DIA for further proteomic characterization of APPPS1 and APP-KI microglia. Notably, we also detected a consistent relative quantification of proteins with an overlap of $93.5 \%$ between the two mouse models (Suppl. Fig 2D), supporting our selection of DIA as a robust method for microglial proteomic analysis.

Amyloid plaque deposits appear at similar ages (between 6-8 weeks) in APPPS1 and APP-KI mouse models (Radde et al., 2006; Saito et al., 2014). To reveal the dynamics of microglial proteomic alterations across different amyloid stages, we analyzed microglia from 1, 3, 6 and 12 month old APPPS1 and APP-KI mice and their corresponding age-matched wild-type (WT) mice (Suppl. Fig 2A). For our proteomic analysis, we have set as a threshold a $\log 2$ fold change larger than 0.5 or smaller than -0.5 compared to the WT with a p-value less than 0.05, and significance after False Discovery Rate (FDR) correction. No data imputation was performed.

According to $A \beta$ burden in both mouse models, we refer to one month of age as a predeposition stage, and to 3, 6 and 12 months of age as early, middle and advanced stages of amyloid

142 pathology, respectively (Suppl. Fig 3). At the pre-deposition stage (1 month), microglial proteomes 
143 of APPPS1 and APP-KI mice did not show significant alterations compared to WT (Fig 1A and B), 144 demonstrating that microglia are not affected prior to development of A $\beta$ pathology. At 3 months of 145 age, microglia in APPPS 1 mice already displayed a significant up-regulation of 332 proteins and 146 down-regulation of 678 proteins, compared to WT microglia (Fig 1C; Suppl. Table 3A). In contrast, 147 APP-KI microglia were hardly affected at 3 months of age (Fig 1D; Suppl. Table 3B), which is

148 particularly surprising because both mouse models show comparable amyloid burden at this stage 149 (Suppl. Fig 3). At 6 months of age, microglia in APPPS1 mice displayed 309 up-regulated and 261 150 down-regulated proteins, compared to WT microglia (Fig 1E; Suppl. Table 3A). In contrast to 3 months of age (Fig 1D), APP-KI mice at 6 months of age displayed a substantial alteration of their 152 microglial proteome, illustrated by 140 up-regulated and 151 down-regulated proteins (Fig 1F; Suppl. 153 Table 3B). Still, microglial alterations in 6 month old APP-KI mice were less pronounced compared 154 to the proteome of APPPS1 mice (Fig 1E and F). Noteworthy, by 12 months of age, APPPS1 microglia 155 revealed a significant up-regulation of 776 proteins and down-regulation of 633 proteins, while APP156 KI microglia displayed 704 up-regulated and 666 down-regulated proteins (Fig 1G and H; Suppl. 157 Table 3A and B). This indicates comparable changes in APPPS1 and APP-KI mice at advanced stages 158 of $\mathrm{A} \beta$ pathology. Overall, our data show that amyloid plaque accumulation triggers microglial progression towards an $\mathrm{AD}$-associated phenotype in both mouse models, but that response dynamics are different in APPPS1 and APP-KI microglia.

\section{Identification of MARPs as signatures of early, middle and advanced amyloid stages}

163 Next, we determined protein alterations that first appear in early, middle or advanced stages of $164 \mathrm{~A} \beta$ deposition and remain altered thought all analyzed stages, thus following amyloid accumulation. 165 To this end, we selected the APPPS1 mouse model as a reference since it displays earlier changes and 166 thus provides a better time resolution of protein alterations to amyloid response, compared to the APP-

167 KI model (Fig 2A). Correspondingly, we defined early (proteins changed at 3, 6, and 12 months), 168 middle (proteins changed only at 6 and 12 months) and advanced (proteins changed only at 12 months) 169 MARPs. Only proteins with a consistent quantification in all samples of an age group were used for 170 relative quantification. Furthermore, in order to determine robust and model-independent A $\beta$ triggered microglial alterations, we only selected MARPs that were altered with a significantly 172 changed abundance in both mouse models (even if in APP-KI microglia changes appear later). This 173 analysis identified 90 early, 176 middle, and 435 advanced MARPs (Suppl. Fig 4A). The most strongly regulated MARPs with early, middle and advanced response are displayed in corresponding 
175 heatmaps (Fig 2B-D). In addition, we compared MARP signatures with the previously delineated 176 RNA signatures of 5xFAD mice (Keren-Shaul et al., 2017) to visualize the overlap, as well as differences, between proteomic and transcriptomic microglial profiles.

Early MARPs included several of the previously identified transcriptional DAM markers (Keren-Shaul et al., 2017) such as ITGAX (CD11c), APOE, CLEC7a, LGALS3 (Galectin-3) and CD68, which were found with an increased abundance (Fig 2B). Moreover, proteins involved in antigen presentation such as CD74, H2-D1, TAP2, TAPBP and H2-K1 were revealed as up-regulated early MARPs. In addition, we discovered prominent changes in interferon signaling represented by the up-regulation of early MARPs, including MNDA, OAS1A, IFIT3, ISG15, GVIN1, STAT1 and 2 (Fig 2B). Even though early MARPs were mainly up-regulated, we also identified early MARPs with a decreased abundance, including KRAS, a protein involved in cell proliferation and the endocytosis regulator EHD2 among others (Fig 2B). A gene ontology (GO) cluster enrichment analysis of early MARPs revealed that up-regulated proteins were enriched for immune and viral response, interferon beta and cytokine response, antigen processing and presentation as well as biotic and lipid response (Fig 3A; Suppl. Fig 5A und D). Thus, these processes represent first molecular alterations that progressively follow $\mathrm{A} \beta$ plaque pathology.

The middle MARPs included the up-regulated proteins FABP3, FABP5, CD63, TREM2, MIF and GUSB (Fig 2C), demonstrating a progressive conversion of the microglial proteome towards a disease state that accompanies $A \beta$ accumulation. Importantly, middle MARPs also reveal downregulation of the proposed homeostatic markers such as CX3CR1, TMEM119 and P2RY12 (Fig 2C). Among the down-regulated middle MARPs, we identified additional chemotaxis and cell migration related proteins like SYK, FER, CX3CL1, and BIN2 (Fig 2C; Suppl. Table 4), underscoring a loss of key homeostatic functions of microglia throughout AD progression.

Advanced MARPs represent proteins that were only altered upon extensive amyloid pathology and show a high correlation between the two models (Suppl. Fig 4B). This group included upregulation of proteins involved in calcium ion binding such as NCAN, MYO5A, HPCAL4, TTYH1 and GCA and down-regulation of proteins that play a role in the endocytosis/lysosomal system such as TFEB, TFE3 and BIN1 (Fig 2D; Suppl. Table 4). In addition, different G protein-coupled receptor signaling proteins, including GNG2, GNG5 and GNG10, also displayed a decreased abundance (Fig 2D).

A GO cluster enrichment analysis of middle and advanced MARPs identified down-regulation 
and proliferation (Fig 3B and C; Suppl. Fig 5B, C, E and F). Conversely, we found an up-regulation of protein glycosylation and carbohydrate metabolism (Fig 3C; Suppl. Fig 5E and F). Additionally, alterations in ion transport processes involving ion homeostasis and $\mathrm{pH}$ regulation were also detected (Fig 3C). These findings indicate that after an initial inflammatory response, several cellular processes related to chemotaxis and phagocytosis are progressively dysregulated upon increased $A \beta$ deposition. genetic risk factors of $\mathrm{AD}$ (Karch and Goate, 2015), including significantly increased levels of APOE, TREM2, and INPP5D, and decreased levels of PLCG2, ABI3, and BIN1 in both mouse models (Suppl. Table 5A and B).

The overlap of consistently quantified proteins and a previously published transcriptome study (Keren-Shaul et al., 2017) was 38.4\%, whereas 2152 and 2841 gene products were only quantified on protein and transcript level, respectively (Suppl. Fig 4C). Single cell transcriptomics (Keren-Shaul et al., 2017) has demonstrated a similar regulation of a number of early MARPs while we found less overlap for middle and advanced MARPs (Fig 2B-D). We also identified proteins with an inverse regulation compared to transcriptomic signatures such as the early MARP RPL38, middle MARPs MCM3 and GFPT1 or advanced MARPs CDC88A, GALNT2, EIF4B and CHMP6 (Fig 2B-D; Suppl.

Table 4). Furthermore, the advanced MARP HEXB showed a consistent up-regulation in our proteomic analysis, despite being previously anticipated as a homeostatic gene (Suppl. Table 4).

Overall, our study presents a robust and reliable method to track microglial proteome and provides a resource that maps changes in brain immunity during different phases of $\mathrm{A} \beta$ accumulation.

\section{Proteomic changes are detected in plaque-associated microglia}

Next, we validated proteomic changes by western blot analysis using isolated microglia from 12 month old APPPS1 and APP-KI mice. This analysis confirmed the pronounced increase of the early MARPs APOE and CD68, the middle MARPs TREM2 and FABP5, as well as reduced levels of the middle MARP CSF1R (Suppl. Fig 4D) in both transgenic mouse models compared to WT mice. Furthermore, proteomic changes were also validated by immunohistochemistry in order to visualize spatial distribution of altered microglial proteins in APPPS1 and APP-KI mice. Immunohistological analysis of 3 month old APPPS1 mice already revealed increased immunoreactivity of selected MARPs such as CLEC7a (Fig 4), TREM2 (Suppl. Fig 6) and APOE (Suppl. Fig 7) that mark initial stages of microglial activation in $\mathrm{AD}$. This increase was detected in IBA1 positive microglia that were 
agreement with our proteomic data - less pronounced in 3 month old APP-KI mice. Accordingly, at 12 months, both APPPS1 and APP-KI mice showed a similar increase in the levels of selected MARPs such as CLEC7a (Fig 5) and decreased levels of TMEM119 (Fig 6) compared to the WT mice, once again in microglia surrounding amyloid plaques. Taken together, we validated selected microglial proteomic alterations from our dataset by applying biochemical and immunohistochemical methods. In addition, we confirmed the kinetic differences in AD-associated proteomic signatures of APPPS1 and APP-KI microglia. Our data suggest that interaction between microglia and A $\beta$ is likely triggering the proteomic changes as they could be observed in plaque-associated microglial population.

\section{APPPS1 and APP-KI mice show similar dynamics of amyloid plaque deposition, but differ in} plaque fibrillization

The magnitude of proteomic microglial changes was found to correlate with $\mathrm{A} \beta$ plaque accumulation throughout disease progression. However, the appearance of MARP signatures differed between the models and occurred earlier in the APPPS1 mice (Fig 1C and D; Fig 2A) despite the comparable plaque load observed in both mouse models (Suppl. Fig 3). Thus, it appears possible that the nature of amyloid plaques is different between the APPPS1 and APP-KI mice. To examine this, we analyzed amyloid plaques in 3, 6 and 12 month old APPPS1 and APP-KI mice by immunohistochemistry. We used the anti-A $\beta$ antibody NAB228 (Abner et al., 2018) to detect amyloid plaques, and Thiazine red to visualize fibrillar amyloid plaque cores (Daria et al., 2017) (Fig 7A). In agreement with amyloid plaque pathology reported in this model (Radde et al., 2006), APPPS1 mice contained fibrillar amyloid plaque cores already at 3 months of age. In contrast, fibrillar A $\beta$ was barely detectable in APP-KI mice at 3 months of age (Fig 7A). The amount of fibrillar A $\beta$ in APP-KI mice increased at 6 and 12 months, but overall still remained lower compared to the APPPS1 mice. This result was also confirmed by biochemical analysis in which fibrillar $A \beta$ was specifically detected via immunoblot of the insoluble brain fraction (Fig 7B). Therefore, we excluded differences in the detection and binding properties of Thiazine red to be the underlying cause for the observed reduction in the levels of fibrillar $\mathrm{A} \beta$ in APP-KI mice. Taken together, although immunohistochemistry revealed comparable A $\beta$ plaque coverage in APPPS1 and APP-KI mice, the amount of fibrillar A $\beta$ was significantly lower in APP-KI mice. 


\section{Microglial recruitment is triggered by fibrillar $A \beta$ and not by dystrophic neurites}

271 To determine what triggers microglial reactivity in $\mathrm{AD}$, we first quantified microglial recruitment to $272 \mathrm{~A} \beta$ plaques in both mouse models. This analysis was done at the early pathological stage (3 months), 273 where we identified prominent differences in the proteome regulation (Fig 1C and D; Fig 2A) as well 274 as in the amount of fibrillar $\mathrm{A} \beta$ (Fig 7A and $\mathrm{B}$ ) between the two AD mouse models. 275 Immunohistochemical analysis revealed IBA1 positive, amoeboid microglia recruited to large, 276 Thiazine red positive, fibrillar A $\beta$ plaque cores in APPPS1 mice. Of note, we observed intracellular 277 fibrillar A $\beta$ in APPPS1 microglia in close contact to the plaque core (Fig 8A) as previously reported 278 (Bolmont et al., 2008). Despite the significantly smaller fibrillar A $\beta$ plaque core in APP-KI mice, we could observe IBA1 positive microglia polarized towards the fibrillar $A \beta$, rather than to the surrounding non-fibrillar A $\beta$ positive material (Fig 8A). Quantification analysis revealed increased clustering of IBA1 positive microglia around A $\beta$ plaques in APPPS 1 compared to the APP-KI mice (Fig 8B), which display overall larger A $\beta$ plaque size (Fig 8C). Likewise, we observed increased CD68 immunoreactivity around A $\beta$ plaques in the APPPS1 compared to the APP-KI mice (Fig 8D and E). However, CD68 signal per individual microglial cell in the plaque vicinity was similar in both models (Fig 8F), suggesting that differences in $\mathrm{AD}$-associated microglial proteins are due to the number of recruited microglia rather than differences in their individual CD68 protein levels.

Besides $\mathrm{A} \beta$, microglial recruitment has also been associated with neuritic damage (dystrophic neurites) (Hemonnot et al., 2019). Accordingly, we analyzed dystrophic neurite pathology in 3 month old APPPS1 and APP-KI mice, using an antibody against APP that accumulates in these structures (Cummings et al., 1992; Sadleir et al., 2016). As previously reported (Radde et al., 2006), amyloid plaques in the APPPS1 mice were surrounded by prominent dystrophic neurites (Fig 8G). Interestingly, despite the reduced load of fibrillar $\mathrm{A} \beta$, we readily detected dystrophic neurites in the APP-KI mice (Fig 8G). Moreover, our quantification analysis revealed a trend towards an increased dystrophic neurite area in the APP-KI compared to the APPPS1 mice (Fig 8H). Therefore, the differences in early microglial recruitment to APPPS1 plaques and the consecutive proteomic changes are less likely to be triggered by dystrophic neurites.

Altogether, we hypothesize that microglial recruitment is primarily triggered by the fibrillar 


\section{Phagocytic impairments correlate with the occurrence of MARP signatures}

302 The differences observed in the dynamics of microglial response to amyloid in the APPPS1 and the APP-KI mice prompted us to examine the association between microglial phagocytic function and the appearance of MARP signatures. To this end, we assessed the phagocytic capacity of microglia from 3 and 6 month old APPPS1 and APP-KI mice compared to the corresponding age-matched WT microglia using the E.coli-pHrodo uptake assay (Gotzl et al., 2019; Kleinberger et al., 2014). We already detected phagocytic dysfunction in 3 month old APPPS1 microglia, which was reflected by a prominent decrease in the amount of intracellular E.coli particles (Fig 8I; Suppl. Fig 8A) and a reduced number of CD11b positive cells that were capable of E.coli uptake (Fig 8J; Suppl. Fig 8B). Notably, APPPS1 phagocytic impairment did not change further in 6 month old microglia, suggesting that microglial functional deficits, as measured by the E.coli uptake assay, were fully established already at 3 months of age and characterized by early MARPs. In contrast, APP-KI microglia remained functional at 3 months, but at 6 months displayed similar impairments as seen in APPPS1 microglia (Fig 8I and J). Overall, we observed different kinetics of microglial dysfunction among mouse models which correlate with the appearance of MARPs and, in turn, with the presence fibrillar A $\beta$.

\section{Discussion}

This study presents an in-depth and time-resolved proteome of microglia isolated across different stages of A $\beta$ accumulation in the APPPS1 and APP-KI mouse models, resulting in the identification of early, middle, and advanced MARPs. Importantly, we demonstrated that the structure of amyloid plaques (fibrillar versus non-fibrillar) is a major determinant driving the molecular alterations of microglia. Key microglial signatures encompass proteins with a central function in microglial biology and AD pathogenesis. Moreover, our functional analysis shows that early MARP signatures already reflect microglial phagocytic dysfunction.

To achieve robust and reproducible relative quantification of microglial proteins from single mice, we improved the yield of acutely isolated microglia to an average of $2 \times 10^{6}$ cells per mouse brain, compared to recently published protocols (Flowers et al., 2017; Rangaraju et al., 2018). Next, by establishing the more sensitive DIA method for protein quantification, we improved the number of consistently identified proteins by $29.3 \%$ and obtained on average 5699 (APPPS1) and 5698 (APPKI) relatively quantified proteins. Notably, our analysis enhanced the detection of low abundance proteins and does not require data imputation. The advancement to previous studies (Rangaraju et al., 
334 known microglial homeostatic markers TMEM119 or P2RY12. We also measured alterations in 335 proteins that were postulated to be only altered at the transcriptional level in AD microglia (Rangaraju 336 et al., 2018), including up-regulation of middle MARPs FABP3, FABP5, MIF and PLP2. In summary, 337 our study achieved a major improvement in quantitative proteomic analysis of rodent microglia 338 (Flowers et al., 2017; Rangaraju et al., 2018; Thygesen et al., 2018). This methodological advance enabled us to map microglial changes across diverse stages of $A \beta$ pathology in two widely explored pre-clinical models of amyloidosis. Generated proteomic profiles characterize microglia under diseased conditions and can be used as a resource to track changes upon microglial therapeutic modification, such as A $\beta$ immunotherapy. Such studies would facilitate discovery of clinically relevant molecular alterations that are necessary for microglial functional repair, monitoring disease progression and therapeutic efficacy.

The TREM2/APOE axis plays a key role in the regulation of the microglial transcriptional program and guides the homeostatic/DAM signature switch (Jay et al., 2017; Keren-Shaul et al., 2017; Krasemann et al., 2017). Our time-resolved proteomic analysis observed major rearrangements of the microglial proteomic landscape in both APPPS1 and APP-KI mice and revealed a partial overlap between MARPs and transcriptional profiles of DAM and homeostatic microglia (Keren-Shaul et al., 2017), but also identified additional microglial marker proteins throughout different stages of A $\beta$ deposition.

Early MARPs include proteins of the interferon response, which is consistent with the recently identified interferon-responsive microglial sub-population in AD mice (Sala Frigerio et al., 2019). Numerous up-regulated early MARPs, including CD74, CTSZ, HEXA, CTSH, GLB1, CD68, NPC2, CLN3 and PI4K2A, reflect alterations in endo-lysosomal homeostasis as an early pathological insult in AD microglia (Van Acker et al., 2019). Additionally, factors of the fatty acid and cholesterol metabolism are altered throughout all pathological phases. Up-regulated are the early (APOE, ACACA, and SOAT1) middle (FABP3, FABP5, NCEH1, APOD, AACS, ACOX3, HACD2) and advanced MARPs (ACOT11, ACSBG1, ECHS1, ELOVL1, and FASN) and down-regulated are several middle and advanced MARPs (NAAA, FAM213B, HPGD, HPGDS, and PRKAB1), linking microglial lipid dyshomeostasis and AD pathology.

An inflammatory response in $\mathrm{AD}$ is suggested by the significant up-regulation of early MARPs LGALS3 and its binding protein (LGALS3BP). Recent findings suggested that the LGALS3/TREM2 signalling pathway, that acts as an inflammatory regulator of amyloid plaque formation, may also be of relevance for AD pathology in humans (Boza-Serrano et al., 2019). Further evidence that some of 
366 the presented proteomic alterations of rodent microglia may be relevant for human disease is given by 367 the detection of up-regulated early/middle microglial MARPs, including CD68, TREM2 and ITGAX 368 in microglia surrounding amyloid plaques in postmortem AD brains (Hopperton et al., 2018). As 369 microglia emerge as a promising therapeutic target in AD, additional MARP signatures should be 370 validated in human tissue. In particular, early MARPs that are strongly increased in both AD mouse 371 models may serve as a resource to identify novel AD biomarkers and more specific microglial positron 372 emission tomography (PET) tracers that are urgently needed to monitor microglial reactivity in vivo 373 (Edison et al., 2018; Hemonnot et al., 2019). Middle and late MARPs reveal a decrease of microglial 374 homeostatic functions affecting chemotaxis, cell migration and phagocytosis (e.g., CX3CR1, SYK, 375 P2RY12, BIN2, TFEB and TFE3) and thus mark AD progression.

376 It is still being discussed which is the main trigger for microglial recruitment to amyloid 377 plaques and their molecular switch from a homeostatic to a neurodegenerative phenotype (Hemonnot 378 et al., 2019; Jung et al., 2015; Krasemann et al., 2017). Our study proposes that microglial recruitment 379 to $\mathrm{A} \beta$ deposits and their corresponding disease-associated proteomic alterations are triggered by 380 fibrillar $\mathrm{A} \beta$, rather than by dystrophic neurites. We observed more diffuse amyloid plaque morphology with less fibrillar A $\beta$ and prominent neuritic dystrophies in the APP-KI mice. Similar plaque morphology, with less fibrillar $\mathrm{A} \beta$, is also observed in AD mice deficient for TREM2 or APOE that also have less microglial cells recruited to amyloid plaques and display prominent neuritic dystrophies (Parhizkar et al., 2019; Sala Frigerio et al., 2019; Ulrich et al., 2018; Wang et al., 2015; Yuan et al., 2016). APOE may have a dual role and control the transcriptional/translational response of microglia to amyloid as well as amyloid plaque compactness that directs microglial recruitment and thus creates a regulatory feedback-loop. These findings are also strengthened by the relevance of ApoE and Trem2 as genetic risk factors of AD (Karch and Goate, 2015). Fibrillar A $\beta$ as the trigger for microglial recruitment is also supported by the human pathology where neuritic plaques in AD brains were found surrounded by microglia. In contrast, microglial clustering was not detected at diffuse plaques lacking fibrillar A $\beta$ core (D'Andrea et al., 2004).

Although DAM signatures have been suggested as a protective response, there is still a lack of direct experimental evidence linking specific transcriptomic or proteomic profiles to improved microglial function. Importantly, our study demonstrates a functional link between proteomic changes and reduced phagocytosis by AD microglia. APPPS1 microglia start acquiring early MARPs at the age of 3 months, which is already accompanied by reduced phagocytic function. In contrast, less 
398 function. Pronounced MARP signatures that appeared later in APP-KI microglia (6 months) were subsequently in accordance with phagocytic impairments. Therefore, differences in plaque fibrillization in both mouse models did not only affect microglial recruitment and activation, but also the phagocytic function of microglia.

Reduced phagocytosis of AD microglia might be related to observed proteomic alterations in lysosomal proteins or cell receptors. TREM2, which was found to be increased in both mouse models, plays an important role in phagocytosis as mutations of TREM2 related to AD and FTLD impair phagocytic activity of microglia (Kleinberger et al., 2014). However, up-regulation of the TREM2/APOE axis involves up-regulation of many lysosomal proteins (e.g., cathepsins or CD68) that are part of MARPs and altered in APPPS1 and APP-KI microglia. This may reflect a compensatory mechanism initiated as a response of microglia to $\mathrm{A} \beta$ accumulation in order to enhance phagocytic function. Eventually this frustrated microglial response fails to translate into improved $A \beta$ clearance capability.

Phagocytosis might also be altered through differential regulation of toll like receptors (TLR). Among the TLRs, TLR2, an A $\beta$ binding receptor (Liu et al., 2012; McDonald et al., 2016), showed the strongest increase with age while TLR9 was significantly reduced in APPPS1 and APP-KI mice. Along these lines, TLR2 deficiency reduced the inflammatory response of microglia to A $\beta 42$, but increased A $\beta$ phagocytosis in cultured microglia (Liu et al., 2012) while TLR9 is associated with improved A $\beta$ clearance (Scholtzova et al., 2009). Thus, differential regulation of TLRs might contribute to the reduced phagocytic activity of aged APPPS1 microglia (Daria et al., 2017).

Additionally, many purinergic receptors (e.g., P2RX7, P2RY12 or P2RY13), which are important regulators of chemotaxis, phagocytosis, membrane polarization, and inflammatory signaling and thus emerged as possible microglial targets in AD (Calovi et al., 2019; Hemonnot et al., 2019), were found to be down-regulated in both AD mouse models. P2RY12 is regarded as a marker for ramified non-inflammatory microglia (Mildner et al., 2017) that is reduced in response to A $\beta$ plaques and therefore represents a homeostatic microglial marker (Keren-Shaul et al., 2017; Krasemann et al., 2017). In contrast, P2RX4, a purinergic receptor that is likely to be involved in shifting microglia towards a pro-inflammatory phenotype (Calovi et al., 2019) or myelin phagocytosis (Zabala et al., 2018) had an increased abundance in both AD models. Taken together, our data emphasize alterations of purinergic receptor signaling in $\mathrm{AD}$ microglia that may regulate a morphological change towards amoeboid microglia with reduced motility and increased proinflammatory activity. 
Our study confirms that both mouse models are valuable tools for studying $A \beta$-induced pathological changes of microglia that are remarkably comparable at advanced stages of amyloidosis. However, the observed differences in the dynamics of early, middle and late MARPs in APPPS1 and APP-KI mice should be considered for the design of pre-clinical studies of microglial repair and will require different time windows for microglial modulation.

In conclusion, we tracked pathological alterations of microglia in two AD mouse models using a proteomic approach. Our work demonstrates that microglial alterations are triggered as a response to $A \beta$ deposition as pre-deposition stages do not reveal proteomic alterations. The conversion to MARPs is supported by changes in TREM2-APOE regulation mechanism. AD microglia display pronounced interferon stimulation, increased antigen presentation, alterations in cell surface receptors, lipid homeostasis and metabolism. Those proteomic changes in microglia occur as a response to fibrillar $\mathrm{A} \beta$ and are reflected in amoeboid microglial morphology and impaired phagocytic capacity. Finally, our proteomic dataset serves a valuable research resource providing information on microglial alterations over different stages of $\mathrm{A} \beta$ deposition that can be used to monitor therapeutic efficacy of microglial repair strategies.

\section{Materials and Methods}

\section{Animals}

448 Male and female mice of the hemizygous APPPS1 mouse line overexpressing human APPKM670/671NL and PS1L166P under the control of the Thy-1 promoter (Radde et al., 2006), homozygous App ${ }^{N L-G-F}$ mouse line (Saito et al., 2014) and the C57BL/6J (WT) line were used in this study. Mice were group housed under specific pathogen-free conditions. Mice had access to water and standard mouse chow (Ssniff® Ms-H, Ssniff Spezialdiäten GmbH, Soest, Germany) ad libitum and were kept under a 12/12 h light-dark cycle in IVC System Typ II L-cages $\left(528 \mathrm{~cm}^{2}\right)$ equipped with solid floors and a layer of bedding. All animal experiments were performed in compliance with the German animal welfare law and have been approved by the government of Upper Bavaria.

\section{Isolation of primary microglia}

458 Primary microglia were isolated from mouse brains (cerebrum) using MACS Technology (Miltenyi 459 Biotec) according to manufacturer's instructions and as previously described (Daria et al., 2017). 460 Briefly, olfactory bulb, brain stem and cerebellum were removed and the remaining tissue (cerebrum) 461 was freed from meninges and dissociated by enzymatic digestion using a Neural Tissue Dissociation 
462 Kit P (Miltenyi Biotec). Subsequently, mechanical dissociation was performed by using 3 fire463 polished glass Pasteur pipettes of decreasing diameter. CD11b positive microglia were magnetically 464 labelled using CD11b MicroBeads, loaded onto a MACS LS Column (Miltenyi Biotec) and subjected 465 to magnetic separation, resulting in CD11b-enriched (microglia-enriched) and CD11b-depleted 466 (microglia-depleted) fractions. Obtained microglia-enriched pellets were either washed twice with 467 HBSS (Gibco) supplemented with $7 \mathrm{mM}$ HEPES, frozen in liquid nitrogen and stored at $-80^{\circ} \mathrm{C}$ for 468 biochemical or mass spectrometry analysis or resuspended in microglial culturing media and used for 469 phagocytosis assay as described below.

470

Sample preparation for mass spectrometry

472 Microglia-enriched pellets were lysed in $200 \mu \mathrm{L}$ of STET lysis buffer (50 mM Tris, $150 \mathrm{mM} \mathrm{NaCl,} 2$ $473 \mathrm{mM}$ EDTA, $1 \%$ Triton, $\mathrm{pH} 7.5$ ) at $4^{\circ} \mathrm{C}$ with intermediate vortexing. The samples were centrifuged for $4745 \mathrm{~min}$ at $16000 \mathrm{xg}$ at $4^{\circ} \mathrm{C}$ to remove cell debris and undissolved material. The supernatant was 475 transferred to a LoBind tube (Eppendorf) and the protein concentration estimated using the Pierce 660 $476 \mathrm{~nm}$ protein assay (ThermoFisher Scientific). A protein amount of $15 \mu \mathrm{g}$ was subjected to tryptic 477 protein digestion applying the the filter aided sample preparation protocol (FASP) (Wisniewski et al., 478 2009) using Vivacon spin filters with a $30 \mathrm{kDa}$ cut-off (Sartorius). Briefly, proteins were reduced with $47920 \mathrm{mM}$ dithiothreitol and free cystein residues were alkylated with $50 \mathrm{mM}$ iodoacetamide (Sigma 480 Aldrich). After the urea washing steps, proteins were digested with $0.3 \mu \mathrm{g}$ LysC (Promega) for $16 \mathrm{~h}$ 481 at $37^{\circ} \mathrm{C}$ followed by a second digestion step with $0.15 \mu \mathrm{g}$ trypsin (Promega) for $4 \mathrm{~h}$ at $37^{\circ} \mathrm{C}$. The 482 peptides were eluted into collection tubes and acidified with formic acid (Sigma Aldrich). Afterwards, 483 proteolytic peptides were desalted by stop and go extraction (STAGE) with self-packed C18 tips 484 (Empore C18 SPE, 3M) (Rappsilber et al., 2003). After vacuum centrifugation, peptides were 485 dissolved in $20 \mu \mathrm{L} 0.1 \%$ formic acid (Biosolve) and indexed retention time peptides were added (iRT Kit, Biognosys).

\section{Liquid chromatography - tandem mass spectrometry analysis}

For LFQ of proteins, peptides were analyzed on an Easy nLC 1000 or 1200 nanoHPLC (Thermo Scientific) which was coupled online via a Nanospray Flex Ion Source (Thermo Sientific) equipped with a PRSO-V1 column oven (Sonation) to a Q-Exactive HF mass spectrometer (Thermo Scientific). An amount of $1.3 \mu \mathrm{g}$ of peptides was separated on in-house packed C18 columns $(30 \mathrm{~cm} \times 75 \mu \mathrm{m}$ ID, 
494

495

496

497

498

499

500

501

502

503

504

505

506

507

508

509

510

511

512

513

514

515

516

517

518

519

520

521

522

523

524

525

acetonitrile (B) supplemented with $0.1 \%$ formic acid $(0$ min., 2\% B; 3:30 min., 5\% B; 137:30 min., $25 \% \mathrm{~B} ; 168: 30 \mathrm{~min} ., 35 \% \mathrm{~B} ; 182: 30 \mathrm{~min} ., 60 \% \mathrm{~B})$ at $50^{\circ} \mathrm{C}$ column temperature.

For DDA, full MS scans were acquired at a resolution of 120000 (m/z range: 300-1400; AGC target: $3 \mathrm{E}+6)$. The 15 most intense peptide ions per full MS scan were selected for peptide fragmentation (resolution: 15000; isolation width: $1.6 \mathrm{~m} / \mathrm{z}$; AGC target: 1E+5; NCE: 26\%). A dynamic exclusion of $120 \mathrm{~s}$ was used for peptide fragmentation.

For DIA, one scan cycle included a full MS scan (m/z range: 300-1400; resolution: 120000; AGC target: 5E+6 ions) and $25 \mathrm{MS} / \mathrm{MS}$ scans covering a range of 300-1400 m/z with consecutive m/z windows (resolution: 30000; AGC target: 3E+6 ions; Suppl. Table 1). The maximum ion trapping time was set to "auto". A stepped normalized collision energy of $26 \% \pm 2.6 \%$ was used for fragmentation.

Microglia from APPPS1 mice were analyzed using DDA and DIA for method establishement. Microglia from APPPS1 and APP-KI mice were compared using DIA as it outperformed DDA.

\section{Mass spectrometric $L F Q$ and data analysis}

For data acquired with DDA, the data was analyzed with the software Maxquant (maxquant.org, MaxPlanck Institute Munich) version 1.6.1.0 (Cox et al., 2014). The MS data was searched against a reviewed canonical fasta database of Mus musculus from UniProt (download: November the $1^{\text {st }} 2017$, 16843 entries) supplemented with the sequence of human APP with the Swedish mutant and the iRT peptides. Trypsin was defined as a protease. Two missed cleavages were allowed for the database search. The option first search was used to recalibrate the peptide masses within a window of $20 \mathrm{ppm}$. For the main search peptide and peptide fragment mass tolerances were set to 4.5 and $20 \mathrm{ppm}$, respectively. Carbamidomethylation of cysteine was defined as static modification. Acetylation of the protein $\mathrm{N}$-term as well as oxidation of methionine was set as variable modification. The FDR for both peptides and proteins was set to $1 \%$. The "match between runs" option was enabled with a matching window of $1.5 \mathrm{~min}$. LFQ of proteins required at least one ratio count of unique peptides. Only unique peptides were used for quantification. Normalization of LFQ intensities was performed separately for the age groups because LC-MS/MS data was acquired in different batches.

A spectral library was generated in Spectronaut (version 12.0.20491.11, Biognosys) (Bruderer et al., 2015) using the search results of Maxquant of the APPPS1 dataset. The library includes 122542 precursor ions from 91349 peptides, which represent 6223 protein groups. The DIA datasets of both mouse models were analyzed with this spectral library (version 12.0.20491.14.21367) with standard 
settings. Briefly, the FDR of protein and peptide identifications was set to $1 \%$. LFQ of proteins was performed on peptide fragment ions and required at least one quantified peptide per protein. Protein quantification was performed on maximum three peptides per protein group. The data of APPPS1 microglia was organized in age dependent fractions to enable separate normalization of the data. All LC-MS/MS runs of the APP-KI dataset were normalized against each other because all samples were analyzed in randomized order in one batch. al., 2016). The protein LFQ intensities were $\log 2$ transformed and $\log 2$ fold changes were calculated between transgenic and wild type samples separately for the different age groups and mouse models. statistical testing. A two-sided Student's t-test was applied to evaluate the significance of proteins with changed abundance. Additionally, a permutation based FDR estimation was used (Tusher et al., 2001). A $\log 2$ fold change larger than 0.5 , or smaller than -0.5 , a p-value less than 0.05 , and significant regulation after FDR filtering were defined as regulation thresholds. The same thresholds were used for the comparison with transcriptomics data.

541 Gene ontology enrichment analysis was performed with the web-tool DAVID (version 6.8) (Huang 542 da et al., 2009a, b) using GO_FAT terms. Up- and down-regulated early, middle and advanced

543 MARPs were clustered separately for biological process, cellular component, and molecular function with all 5500 proteins, consistently quantified in APPPS1 and APP-KI microglia, as a customized background. A medium classification stringency was applied. An enrichment score of 1.3 was defined as threshold for cluster enrichment.

\section{Biochemical characterization of brain tissue and isolated microglia}

549 RIPA lysates were prepared from brain hemispheres, centrifuged at $100000 \times \mathrm{g}\left(60 \mathrm{~min}\right.$ at $\left.4^{\circ} \mathrm{C}\right)$ and the remaining pellet was homogenized in $0.5 \mathrm{~mL} 70 \%$ formic acid. The formic acid fraction was neutralized with $20 \times 1 \mathrm{M}$ Tris- $\mathrm{HCl}$ buffer at $\mathrm{pH} 9.5$ and used for $\mathrm{A} \beta$ analysis. For $\mathrm{A} \beta$ detection, proteins were separated on Tris-Tricine (10-20\%, Thermo Fisher Scientific) gels, transferred to nitrocellulose membranes $(0.1 \mu \mathrm{m}$, GE Healthcare) which were boiled for $5 \mathrm{~min}$ in PBS and subsequently incubated with the blocking solution containing $0.2 \%$ I-Block (Thermo Fisher Scientific) and $0.1 \%$ Tween 20 (Merck) in PBS for 1 hour, followed by overnight incubation with 
using the corresponding anti-HRP conjugated secondary antibody (Santa Cruz) and chemiluminescence detection reagent ECL (Thermo Fisher Scientific).

Microglia-enriched pellets were resuspended in $100 \mu \mathrm{L}$ of STET lysis buffer (composition as described above for mass spectrometry, supplemented with proteinase and phosphatase inhibitors), kept on ice for $20 \mathrm{~min}$ and then sonicated for 4 cycles of 30 seconds. Cell lysates were then centrifugated at $9600 \mathrm{xg}\left(5 \mathrm{~min}\right.$. at $\left.4^{\circ} \mathrm{C}\right)$ and pellets discarded. Protein concentration was quantified using Bradford assay (Biorad) according to manufacturer instructions. $10 \mu \mathrm{g}$ per sample using two independent microglial lysates per genotype were loaded on a bis-tris acrylamide gel (8\% or $12 \%$ ) and subsequently blotted onto either a PVDF or nitrocellulose membrane (Millipore) using the following antibodies: TREM2 (1:10, clone 5F4,(Xiang et al., 2016)); APOE (1:1000, AB947 FABP5 (1:400, AF1476, R\&DSystems). Blots were developed using horseradish peroxidaseconjugated secondary antibodies (Promega) and the ECL chemiluminescence system (Amersham) or SuperSignal ${ }^{\mathrm{TM}}$ West Pico PLUS (Thermo Scientific). An antibody against GAPDH (1:2000, ab8245, Abcam) was used as loading control.

572

\section{Immunohistochemistry}

5743 and 12 month old mice from the APPPS1 and APP-KI transgenic lines were anesthetized i.p. with 575 a mixture of Ketamine $(400 \mathrm{mg} / \mathrm{kg})$ and Xylazine $(27 \mathrm{mg} / \mathrm{kg})$ and transcardially perfused with cold 0.1M PBS for 5 minutes followed by 4\% Paraformaldehyde (PFA) in 0.1 M PBS for 15 minutes. Brains were isolated and postfixed for 20 minutes in 4\% PFA in $0.1 \mathrm{M} \mathrm{PBS}$ and transferred to $30 \%$ sucrose in 0.1 M PBS for cryopreservation. Brains were embedded in optimal cutting temperature compound (O.C.T./ Tissue-Tek, Sakura), frozen on dry ice and kept at $-80^{\circ} \mathrm{C}$ until sectioning. $30 \mu \mathrm{m}$ coronal brain sections were cut using a cryostat (CryoSTAR NX70, Thermo Scientific) and placed in 0.1 M PBS until staining. Alternatively, sections were kept in anti-freezing solution (30\% Glycerol, $30 \%$ Ethylenglycol, $10 \% 0.25 \mathrm{M} \mathrm{PO}_{4}$ buffer, $\mathrm{pH} 7.2-7.4$ and $30 \% \mathrm{dH}_{2} \mathrm{O}$ ) at $-20^{\circ} \mathrm{C}$ and briefly washed in $0.1 \mathrm{M}$ PBS before staining. Briefly, free-floating sections were permeabilized with $0.5 \%$ TritonPBS (PBS-T) for $30 \mathrm{~min}$, blocked either in 5\% normal Goat Serum or 5\% Donkey Serum in PBS-T for 1 hour and incubated overnight at $4^{\circ} \mathrm{C}$ in blocking solution with the following primary antibodies: IBA1 (1:500, 019-19741,Wako), IBA1 (1:500, ab5076, Abcam) NAB228 (1:2000, sc-32277, Santa Cruz), CD68 (1:500, MCA1957GA, AbDserotec), TREM2 (1:50, AF1729, R\&DSystems), APP- 
ab209064, Abcam), APOE-biotinilated (HJ6.3, 1:100, (Kim et al., 2012)) and 3552 (1:5000, (Yamasaki et al., 2006)). After primary antibody incubation, brain sections were washed 3 times with PBS-T and incubated with appropriate fluorophore-conjugated or streptavidine-fluorophore conjugated (for APOE biotinylated antibody) secondary antibodies (1:500, Life Technologies) together with nuclear stain Hoechst 33342 (1:2000, H3570,ThermoFisher), for two hours at room temperature (RT). Fibrillar dense core plaques were stained with Thiazine red (Sigma Aldrich, $2 \mu \mathrm{M}$ solution in PBS) for $20 \mathrm{~min}$ in the dark at RT (after secondary antibody staining). Sections were subsequently washed three times with PBS-T mounted onto glass slides (Thermo Scientific), dried in the dark for at least 30 min, mounted using Gel Aqua Mount media (Sigma Aldrich) and analyzed by confocal microscopy.

\section{Image acquisition, analysis and quantifications}

6003 month old APPPS1 and APP-KI mice were used for the analysis of dystrophic neurites, microglial 601 recruitment to amyloid plaques and CD68 coverage area. All quantification analysis included 3 mice 602 per genotype. $30 \mathrm{z}$-stack images $(\sim 10 \mu \mathrm{m}$ thick) of single cortical plaques were acquired per experiment using a confocal microscope $(63 \mathrm{X}$ water objective with $2 \mathrm{x}$ digital zoom, $600 \mathrm{~Hz}$, Leica TCS SP5 II) from 6 brain slices (5 plaques per slice) for the microglial recruitment and dystrophic neurite analysis, or from 3 brain slices (10 plaques per slice) for CD68 coverage area analysis. Microscopy acquisition settings were kept constant within the same experiment. Maximal intensity projection pictures from every z-stack were created using ImageJ software and for every image, a defined region of interest (ROI) was manually drawn around every plaque (including microglia recruited -in contact- to the plaque). APP (Y188 antibody) and CD68 coverage area were quantified using the "Threshold" and "Analyze Particles" (inclusion size of 1-Infinity) functions from ImageJ software (NIH) within the ROI. The area covered by CD68 was normalized to the total A $\beta$ plaque area (NAB228 antibody) or was divided by the number of microglia (IBA1 positive cells) recruited to the plaque within the ROI. The absolute values of area covered by neuritic dystrophies or A $\beta$ plaques are represented in square micrometers $\left(\mu \mathrm{m}^{2}\right)$. Microglial recruitment to plaques was quantified by counting the number of microglia (IBA1 positive cells) around amyloid plaques through the zstack images within the defined ROI using the cell counter function of ImageJ software. Number of microglial cells at amyloid plaques was normalized to the area covered by A $\beta$ (NAB228 antibody) and expressed as number of microglial cells per $\mu \mathrm{m}^{2}$ of $\mathrm{A} \beta$ plaque. 
619 Representative images from microglial recruitment analysis (IBA1 positive cells and CD68 coverage) 620 were taken using the confocal microscope (63X water objective with 2x digital zoom, $400 \mathrm{~Hz}$, Leica 621 TCS SP5 II). Representative picture of microglia polarized towards amyloid cores was taken using a $62263 \mathrm{X}$ confocal water objective with $3 \mathrm{x}$ digital zoom.

623 For immunohistological validation of the proteome analysis and amyloid pathology, representative 624 pictures in similar regions were taken by confocal microscopy using the same settings for all three 625 different genotypes (WT, APPPS1 and APP-KI). Low magnification pictures were taken with 20X 626 dry confocal objective with $2 \mathrm{x}$ digital zoom and higher magnification ones with 63X confocal water 627 objective with $3 x$ digital zoom. Images of A $\beta$ pathology (NAB228 antibody) were taken with a tile 628 scan system covering similar brain regions (10X confocal dry objective). Representative images of $629 \mathrm{~A} \beta$ composition (NAB228, ThR and IBA1) were taken with a confocal 20X dry objective.

630

\section{Microglial phagocytosis of E.coli particles}

632 Microglial phagocytosis was performed similarly as previously described (Kleinberger et al., 2014). 633 Microglia isolated from 3 or 6 month old APPPS1, APP-KI and WT mice were plated onto 24 well 634 plate at a density of $2 \times 10^{5}$ cells per well and cultured for 24 hours in a humidified $5 \% \mathrm{CO}_{2}$ incubator 635 at $36.5^{\circ} \mathrm{C}$ in DMEM/F12 media (Invitrogen) supplemented with $10 \%$ heat inactivated FCS (Sigma), $6361 \%$ Penicillin-Streptomycin (Invitrogen) and $10 \mathrm{ng} / \mathrm{mL}$ GM-CSF (R\&DSystems). After 24 hours, 637 plating media were replaced with fresh media. After 5 days in culture, microglia were incubated with $63850 \mu \mathrm{L}$ of E.coli particle suspension (pHrodo ${ }^{\mathrm{TM}}$ Green E.coli BioParticles ${ }^{\mathrm{TM}}$, P35366, Invitrogen ${ }^{\mathrm{TM}}$ ) for $60 \mathrm{~min}$. Cytochalasin D (CytoD, $10 \mu \mathrm{M}$, from $10 \mathrm{mM}$ stock in DMSO) was used as phagocytosis inhibitor and added 30 min prior to addition of bacterial particles. Bacteria suspension excess was washed 4 times with PBS (on ice) and microglia that were attached to the plate were incubated with CD11b-APC-Cy7 antibody (1:200, clone M1/70, 557657, BD) in FACS buffer (PBS supplemented with $2 \mathrm{mM}$ EDTA and $1 \% \mathrm{FBS}$ ) for $30 \mathrm{~min}$ at $4^{\circ} \mathrm{C}$. Microglia were then washed twice with PBS, scraped off the wells in FACS buffer and analyzed by flow cytometry. For the analysis of 3 month old mice, 3 independent experiments were performed per genotype, and each experiment included a minimum of 3 technical replicates with the exception of CytoD condition ( 2 technical replicates). For the analysis of 6 month old mice, 2 independent experiments were performed per genotype, and each experiment included a minimum of 4 technical replicates with the exception of CytoD condition $(2$ technical replicates). 
651

652 For the microglial isolation quality control, around 12000 cells from a CD11b-enriched and CD11b653 depleted fractions were stained in suspension with CD11b-APC-Cy7 antibody (1:200, clone M1/70, $654557657, \mathrm{BD})$ in FACS buffer for 30 minutes at $4^{\circ} \mathrm{C}$. After several washes with PBS, microglia were 655 resuspended in FACS buffer for analysis. Propidium Iodide (PI) staining was done 10 minutes prior 656 657 658 659

660 661 662 663 664 665 666 667 668 669

\section{FACS analysis}

FACS analysis. Flow cytometric data was acquired on a BD FACSverse flow cytometer by gating according to single stained and unstained samples and analyzed using FlowJo software (Treestar). Mean fluorescent intensity (MFI) is represented as the geometric mean of the according fluorochrome.

\section{Statistical analysis}

The data are presented as mean \pm standard deviation of the mean $( \pm$ SD) from 3 independent experiments with the exception of the phagocytic assay in 6 month old mice (Fig 8) were 2 independent experiments were performed. For the microglial recruitment and analysis of dystrophic neurites, statistical significance ( $\mathrm{P}$ value) was calculated using the unpaired two-tailed Student's $t$ test. Phagocytic assay was analyzed by the Dunnett's multiple comparison test of the Two-way ANOVA. Both statistical analysis were performed in GraphPad Prism. P value of <0.05 was considered to be statistically significant (*; $\mathrm{P}<0.05$, **; $\mathrm{P}<0.01$ and $* * * ; \mathrm{P}<0.001$, n.s. $=$ not significant).

\section{Data Availability}

The mass spectrometry proteomics data have been deposited to the ProteomeXchange Consortium via the PRIDE partner repository (Perez-Riverol et al., 2019) with the dataset identifier PXD016075.

\section{Acknowledgements}

We thank Allison Morningstar and Matthias Prestel for critically reading the manuscript. The authors are grateful to Mathias Jucker (Hertie-Institute for Clinical Brain Research, University of Tübingen, Germany) for providing the APPPS1 mice and David Holtzman (Washington University School of Medicine, St Louis, Missouri, USA) for providing the ApoE antibody. We thank Haike Hampel for excellent technical assistance. Funds have been provided by the Alzheimer Forschung Initiative e.V. This work was also supported by the Deutsche Forschungsgemeinschaft (German Research Foundation) within the framework of the Munich Cluster for Systems Neurology (EXC 2145 SyNergy), the European Research Council (ERC-StG 802305) and the Vascular Dementia Research 
683 Foundation. C.H. is supported by a Koselleck Project of the DFG (HA1737/16-1) and the Helmholtz684 Gemeinschaft (Zukunftsthema "Immunology and Inflammation" (ZT-0027)).

685

686

687

688

689

690

691

692

693

694

695

696

697

698

699

700

\section{Author Contributions}

S.T. and S.F.L. designed and supervised the study. S.T., S.F.L., S.A.M., L.S.M. wrote the manuscript with input of all co-authors. L.S.M. performed animal experiments including microglial isolation, target validation and functional studies. A.C. assisted in isolation of primary microglia. S.A.M., J.K., and A.B. performed the proteomic analysis. S.R., L.S.M. and A.L. performed FACS analysis. T.S. and T.C.S. provided the APP-KI mouse model. J.H. contributed to amyloid plaque analysis. L.S.M., M.W., and C.H. contributed to biochemical analysis. Correspondence and requests for materials should be addressed to S.T. or S.F. L.

\section{Competing Interests}

C.H. collaborates with Denali Therapeutics, participated on one advisory board meeting of Biogen, and received a speaker honorarium from Novartis and Roche. C.H. is chief advisor of ISAR Bioscience. All other authors declare that they have no competing interests. 


\section{References}

702

703

704

705

706

707

708

709

710

711

712

713

714

715

716

717

718

719

720

721

722

723

724

725

726

727

728

729

730

731

732

733

734

735

736

737

738

739

740

741

742

743

744

745

746

747

Abner, E.L., Neltner, J.H., Jicha, G.A., Patel, E., Anderson, S.L., Wilcock, D.M., Van Eldik, L.J., and Nelson, P.T. (2018). Diffuse Amyloid-beta Plaques, Neurofibrillary Tangles, and the Impact of APOE in Elderly Persons' Brains Lacking Neuritic Amyloid Plaques. Journal of Alzheimer's disease : JAD 64, 1307-1324. doi: 10.3233/JAD-180514.

Bacskai, B.J., Kajdasz, S.T., Christie, R.H., Carter, C., Games, D., Seubert, P., Schenk, D., and Hyman, B.T. (2001). Imaging of amyloid-beta deposits in brains of living mice permits direct observation of clearance of plaques with immunotherapy. Nature medicine 7, 369-372. doi: $10.1038 / 85525$.

Bard, F., Cannon, C., Barbour, R., Burke, R.L., Games, D., Grajeda, H., Guido, T., Hu, K., Huang, J., Johnson-Wood, K., et al. (2000). Peripherally administered antibodies against amyloid beta-peptide enter the central nervous system and reduce pathology in a mouse model of Alzheimer disease. Nature medicine 6, 916-919. doi: 10.1038/78682.

Bohrmann, B., Baumann, K., Benz, J., Gerber, F., Huber, W., Knoflach, F., Messer, J., Oroszlan, K., Rauchenberger, R., Richter, W.F., et al. (2012). Gantenerumab: a novel human anti-Abeta antibody demonstrates sustained cerebral amyloid-beta binding and elicits cell-mediated removal of human amyloid-beta. Journal of Alzheimer's disease : JAD 28, 49-69. doi: 10.3233/JAD-2011-110977.

Bolmont, T., Haiss, F., Eicke, D., Radde, R., Mathis, C.A., Klunk, W.E., Kohsaka, S., Jucker, M., and Calhoun, M.E. (2008). Dynamics of the microglial/amyloid interaction indicate a role in plaque maintenance. The Journal of neuroscience : the official journal of the Society for Neuroscience 28 , 4283-4292. doi: 10.1523/JNEUROSCI.4814-07.2008.

Bottcher, C., Schlickeiser, S., Sneeboer, M.A.M., Kunkel, D., Knop, A., Paza, E., Fidzinski, P., Kraus, L., Snijders, G.J.L., Kahn, R.S., et al. (2019). Human microglia regional heterogeneity and phenotypes determined by multiplexed single-cell mass cytometry. Nature neuroscience 22, 78-90. doi: 10.1038/s41593-018-0290-2.

Boza-Serrano, A., Ruiz, R., Sanchez-Varo, R., Garcia-Revilla, J., Yang, Y., Jimenez-Ferrer, I., Paulus, A., Wennstrom, M., Vilalta, A., Allendorf, D., et al. (2019). Galectin-3, a novel endogenous TREM2 ligand, detrimentally regulates inflammatory response in Alzheimer's disease. Acta neuropathologica 138, 251-273. doi: 10.1007/s00401-019-02013-z.

Bradshaw, E.M., Chibnik, L.B., Keenan, B.T., Ottoboni, L., Raj, T., Tang, A., Rosenkrantz, L.L., Imboywa, S., Lee, M., Von Korff, A., et al. (2013). CD33 Alzheimer's disease locus: altered monocyte function and amyloid biology. Nature neuroscience 16, 848-850. doi: 10.1038/nn.3435.

Bruderer, R., Bernhardt, O.M., Gandhi, T., Miladinovic, S.M., Cheng, L.Y., Messner, S., Ehrenberger, T., Zanotelli, V., Butscheid, Y., Escher, C., et al. (2015). Extending the limits of quantitative proteome profiling with data-independent acquisition and application to acetaminophen-treated threedimensional liver microtissues. Molecular \& cellular proteomics : MCP 14, 1400-1410. doi: 10.1074/mcp.M114.044305.

Butovsky, O., Jedrychowski, M.P., Moore, C.S., Cialic, R., Lanser, A.J., Gabriely, G., Koeglsperger, T., Dake, B., Wu, P.M., Doykan, C.E., et al. (2014). Identification of a unique TGF-beta-dependent molecular and functional signature in microglia. Nature neuroscience 17, 131-143. doi: 10.1038/nn.3599.

Calovi, S., Mut-Arbona, P., and Sperlagh, B. (2019). Microglia and the Purinergic Signaling System. Neuroscience 405, 137-147. doi: 10.1016/j.neuroscience.2018.12.021.

Castellano, J.M., Kim, J., Stewart, F.R., Jiang, H., DeMattos, R.B., Patterson, B.W., Fagan, A.M., Morris, J.C., Mawuenyega, K.G., Cruchaga, C., et al. (2011). Human apoE isoforms differentially regulate brain amyloid-beta peptide clearance. Sci Transl Med 3, 89ra57. doi: 10.1126/scitranslmed.3002156. 
Cox, J., Hein, M.Y., Luber, C.A., Paron, I., Nagaraj, N., and Mann, M. (2014). Accurate proteomewide label-free quantification by delayed normalization and maximal peptide ratio extraction, termed MaxLFQ. Molecular \& cellular proteomics : MCP 13, 2513-2526. doi: 10.1074/mcp.M113.031591. Cummings, B.J., Su, J.H., Geddes, J.W., Van Nostrand, W.E., Wagner, S.L., Cunningham, D.D., and Cotman, C.W. (1992). Aggregation of the amyloid precursor protein within degenerating neurons and dystrophic neurites in Alzheimer's disease. Neuroscience 48, 763-777. doi: 10.1016/03064522(92)90265-4.

Cuyvers, E., and Sleegers, K. (2016). Genetic variations underlying Alzheimer's disease: evidence from genome-wide association studies and beyond. Lancet Neurol 15, 857-868. doi: 10.1016/S14744422(16)00127-7.

D'Andrea, M.R., Cole, G.M., and Ard, M.D. (2004). The microglial phagocytic role with specific plaque types in the Alzheimer disease brain. Neurobiology of aging 25, 675-683. doi: 10.1016/j.neurobiolaging.2003.12.026.

761 Daria, A., Colombo, A., Llovera, G., Hampel, H., Willem, M., Liesz, A., Haass, C., and Tahirovic, S. (2017). Young microglia restore amyloid plaque clearance of aged microglia. The EMBO journal 36, 583-603. doi: 10.15252/embj.201694591.

Edison, P., Donat, C.K., and Sastre, M. (2018). In vivo Imaging of Glial Activation in Alzheimer's Disease. Front Neurol 9, 625. doi: 10.3389/fneur.2018.00625. Flowers, A., Bell-Temin, H., Jalloh, A., Stevens, S.M., Jr., and Bickford, P.C. (2017). Proteomic anaysis of aged microglia: shifts in transcription, bioenergetics, and nutrient response. J Neuroinflammation 14, 96. doi: 10.1186/s12974-017-0840-7.

Galatro, T.F., Holtman, I.R., Lerario, A.M., Vainchtein, I.D., Brouwer, N., Sola, P.R., Veras, M.M., Pereira, T.F., Leite, R.E.P., Moller, T., et al. (2017). Transcriptomic analysis of purified human cortical microglia reveals age-associated changes. Nature neuroscience 20, 1162-1171. doi: 10.1038/nn.4597.

Gjoneska, E., Pfenning, A.R., Mathys, H., Quon, G., Kundaje, A., Tsai, L.H., and Kellis, M. (2015). Conserved epigenomic signals in mice and humans reveal immune basis of Alzheimer's disease. Nature 518, 365-369. doi: 10.1038/nature14252.

Gosselin, D., Skola, D., Coufal, N.G., Holtman, I.R., Schlachetzki, J.C.M., Sajti, E., Jaeger, B.N., O'Connor, C., Fitzpatrick, C., Pasillas, M.P., et al. (2017). An environment-dependent transcriptional network specifies human microglia identity. Science. doi: 10.1126/science.aal3222.

Gotzl, J.K., Brendel, M., Werner, G., Parhizkar, S., Sebastian Monasor, L., Kleinberger, G., Colombo, A.V., Deussing, M., Wagner, M., Winkelmann, J., et al. (2019). Opposite microglial activation stages upon loss of PGRN or TREM2 result in reduced cerebral glucose metabolism. EMBO molecular medicine 11. doi: 10.15252/emmm.201809711.

Grabert, K., Michoel, T., Karavolos, M.H., Clohisey, S., Baillie, J.K., Stevens, M.P., Freeman, T.C., Summers, K.M., and McColl, B.W. (2016). Microglial brain region-dependent diversity and selective regional sensitivities to aging. Nature neuroscience 19, 504-516. doi: 10.1038/nn.4222.

Guerreiro, R., Wojtas, A., Bras, J., Carrasquillo, M., Rogaeva, E., Majounie, E., Cruchaga, C., Sassi, C., Kauwe, J.S., Younkin, S., et al. (2013). TREM2 variants in Alzheimer's disease. N Engl J Med 368, 117-127. doi: 10.1056/NEJMoa1211851.

Guillot-Sestier, M.V., and Town, T. (2013). Innate immunity in Alzheimer's disease: a complex affair. CNS Neurol Disord Drug Targets 12, 593-607. doi:

Hammond, T.R., Dufort, C., Dissing-Olesen, L., Giera, S., Young, A., Wysoker, A., Walker, A.J., Gergits, F., Segel, M., Nemesh, J., et al. (2019). Single-Cell RNA Sequencing of Microglia throughout the Mouse Lifespan and in the Injured Brain Reveals Complex Cell-State Changes. Immunity 50, 253271 e256. doi: 10.1016/j.immuni.2018.11.004. 
Hemonnot, A.L., Hua, J., Ulmann, L., and Hirbec, H. (2019). Microglia in Alzheimer Disease: Well-

Known Targets and New Opportunities. Front Aging Neurosci 11, 233. doi: 10.3389/fnagi.2019.00233.

798 Hickman, S.E., Allison, E.K., and El Khoury, J. (2008). Microglial dysfunction and defective betaamyloid clearance pathways in aging Alzheimer's disease mice. The Journal of neuroscience : the official journal of the Society for Neuroscience 28, 8354-8360. doi: 10.1523/JNEUROSCI.061608.2008.

802

803

804

805

Holtman, I.R., Raj, D.D., Miller, J.A., Schaafsma, W., Yin, Z., Brouwer, N., Wes, P.D., Moller, T., Orre, M., Kamphuis, W., et al. (2015). Induction of a common microglia gene expression signature by aging and neurodegenerative conditions: a co-expression meta-analysis. Acta neuropathologica communications 3, 31. doi: 10.1186/s40478-015-0203-5.

806

807

Holtzman, D.M., Morris, J.C., and Goate, A.M. (2011). Alzheimer's disease: the challenge of the second century. Sci Transl Med 3, 77sr71. doi: 10.1126/scitranslmed.3002369.

808

809

810 Hopperton, K.E., Mohammad, D., Trepanier, M.O., Giuliano, V., and Bazinet, R.P. (2018). Markers of microglia in post-mortem brain samples from patients with Alzheimer's disease: a systematic review. Molecular psychiatry 23, 177-198. doi: 10.1038/mp.2017.246.

811

812

Huang da, W., Sherman, B.T., and Lempicki, R.A. (2009a). Bioinformatics enrichment tools: paths toward the comprehensive functional analysis of large gene lists. Nucleic Acids Res 37, 1-13. doi:

813

814

815 10.1093/nar/gkn923.

Huang da, W., Sherman, B.T., and Lempicki, R.A. (2009b). Systematic and integrative analysis of large gene lists using DAVID bioinformatics resources. Nature protocols 4, 44-57. doi: 10.1038/nprot.2008.211.

817 Jansen, I.E., Savage, J.E., Watanabe, K., Bryois, J., Williams, D.M., Steinberg, S., Sealock, J., Karlsson, I.K., Hagg, S., Athanasiu, L., et al. (2019). Genome-wide meta-analysis identifies new loci and functional pathways influencing Alzheimer's disease risk. Nat Genet. doi: 10.1038/s41588-0180311-9.

820

821

822

823

824

825

826

827

Janus, C., Pearson, J., McLaurin, J., Mathews, P.M., Jiang, Y., Schmidt, S.D., Chishti, M.A., Horne, P., Heslin, D., French, J., et al. (2000). A beta peptide immunization reduces behavioural impairment and plaques in a model of Alzheimer's disease. Nature 408, 979-982. doi: 10.1038/35050110.

Jay, T.R., Hirsch, A.M., Broihier, M.L., Miller, C.M., Neilson, L.E., Ransohoff, R.M., Lamb, B.T., and Landreth, G.E. (2017). Disease Progression-Dependent Effects of TREM2 Deficiency in a Mouse Model of Alzheimer's Disease. The Journal of neuroscience : the official journal of the Society for Neuroscience 37, 637-647. doi: 10.1523/JNEUROSCI.2110-16.2016.

828

829 Jonsson, T., Stefansson, H., Steinberg, S., Jonsdottir, I., Jonsson, P.V., Snaedal, J., Bjornsson, S., Huttenlocher, J., Levey, A.I., Lah, J.J., et al. (2013). Variant of TREM2 associated with the risk of Alzheimer's disease. N Engl J Med 368, 107-116. doi: 10.1056/NEJMoa1211103.

832

833

834

835

836

837

838

839 Jordao, M.J.C., Sankowski, R., Brendecke, S.M., Sagar, Locatelli, G., Tai, Y.H., Tay, T.L., Schramm, E., Armbruster, S., Hagemeyer, N., et al. (2019). Single-cell profiling identifies myeloid cell subsets with distinct fates during neuroinflammation. Science 363. doi: 10.1126/science.aat7554.

Jung, C.K., Keppler, K., Steinbach, S., Blazquez-Llorca, L., and Herms, J. (2015). Fibrillar amyloid plaque formation precedes microglial activation. PloS one 10, e0119768. doi: 10.1371/journal.pone.0119768.

Kamphuis, W., Kooijman, L., Schetters, S., Orre, M., and Hol, E.M. (2016). Transcriptional profiling of CD11c-positive microglia accumulating around amyloid plaques in a mouse model for Alzheimer's disease. Biochimica et biophysica acta 1862, 1847-1860. doi: 10.1016/j.bbadis.2016.07.007.

840 Karch, C.M., and Goate, A.M. (2015). Alzheimer's disease risk genes and mechanisms of disease 841 pathogenesis. Biol Psychiatry 77, 43-51. doi: 10.1016/j.biopsych.2014.05.006. 
842 Keren-Shaul, H., Spinrad, A., Weiner, A., Matcovitch-Natan, O., Dvir-Szternfeld, R., Ulland, T.K., 843 David, E., Baruch, K., Lara-Astaiso, D., Toth, B., et al. (2017). A Unique Microglia Type Associated 844 with Restricting Development of Alzheimer's Disease. Cell 169, 1276-1290 e1217. doi: 845 10.1016/j.cell.2017.05.018.

846 Kim, J., Eltorai, A.E., Jiang, H., Liao, F., Verghese, P.B., Kim, J., Stewart, F.R., Basak, J.M., and 847 Holtzman, D.M. (2012). Anti-apoE immunotherapy inhibits amyloid accumulation in a transgenic 848 mouse model of Abeta amyloidosis. J Exp Med 209, 2149-2156. doi: 10.1084/jem.20121274.

Kleinberger, G., Yamanishi, Y., Suarez-Calvet, M., Czirr, E., Lohmann, E., Cuyvers, E., Struyfs, H., Pettkus, N., Wenninger-Weinzierl, A., Mazaheri, F., et al. (2014). TREM2 mutations implicated in neurodegeneration impair cell surface transport and phagocytosis. Sci Transl Med 6, 243ra286. doi: 10.1126/scitranslmed.3009093.

Koellhoffer, E.C., McCullough, L.D., and Ritzel, R.M. (2017). Old Maids: Aging and Its Impact on Microglia Function. Int J Mol Sci 18. doi: 10.3390/ijms18040769.

Krasemann, S., Madore, C., Cialic, R., Baufeld, C., Calcagno, N., El Fatimy, R., Beckers, L., O'Loughlin, E., Xu, Y., Fanek, Z., et al. (2017). The TREM2-APOE Pathway Drives the Transcriptional Phenotype of Dysfunctional Microglia in Neurodegenerative Diseases. Immunity 47 , 566-581 e569. doi: 10.1016/j.immuni.2017.08.008.

859 Lambert, J.C., Heath, S., Even, G., Campion, D., Sleegers, K., Hiltunen, M., Combarros, O., Zelenika, D., Bullido, M.J., Tavernier, B., et al. (2009). Genome-wide association study identifies variants at CLU and CR1 associated with Alzheimer's disease. Nat Genet 41, 1094-1099. doi: 10.1038/ng.439. Lathuiliere, A., Laversenne, V., Astolfo, A., Kopetzki, E., Jacobsen, H., Stampanoni, M., Bohrmann, B., Schneider, B.L., and Aebischer, P. (2016). A subcutaneous cellular implant for passive immunization against amyloid-beta reduces brain amyloid and tau pathologies. Brain : a journal of neurology 139, 1587-1604. doi: 10.1093/brain/aww036.

866 Hartmann, T., et al. (2012). TLR2 is a primary receptor for Alzheimer's amyloid beta peptide to trigger neuroinflammatory activation. J Immunol 188, 1098-1107. doi: 10.4049/jimmunol.1101121. Mathys, H., Adaikkan, C., Gao, F., Young, J.Z., Manet, E., Hemberg, M., De Jager, P.L., Ransohoff, R.M., Regev, A., and Tsai, L.H. (2017). Temporal Tracking of Microglia Activation in Neurodegeneration at Single-Cell Resolution. Cell reports 21, 366-380. doi: 10.1016/j.celrep.2017.09.039.

Mawuenyega, K.G., Sigurdson, W., Ovod, V., Munsell, L., Kasten, T., Morris, J.C., Yarasheski, K.E., and Bateman, R.J. (2010). Decreased clearance of CNS beta-amyloid in Alzheimer's disease. Science 330, 1774. doi: 10.1126/science.1197623.

Mazaheri, F., Snaidero, N., Kleinberger, G., Madore, C., Daria, A., Werner, G., Krasemann, S., Capell, A., Trumbach, D., Wurst, W., et al. (2017). TREM2 deficiency impairs chemotaxis and microglial responses to neuronal injury. EMBO reports. doi: 10.15252/embr.201743922.

McDonald, C.L., Hennessy, E., Rubio-Araiz, A., Keogh, B., McCormack, W., McGuirk, P., Reilly, M., and Lynch, M.A. (2016). Inhibiting TLR2 activation attenuates amyloid accumulation and glial activation in a mouse model of Alzheimer's disease. Brain Behav Immun 58, 191-200. doi: 10.1016/j.bbi.2016.07.143.

McQuade, A., and Blurton-Jones, M. (2019). Microglia in Alzheimer's Disease: Exploring How Genetics and Phenotype Influence Risk. Journal of molecular biology 431, 1805-1817. doi: 10.1016/j.jmb.2019.01.045.

Mildner, A., Huang, H., Radke, J., Stenzel, W., and Priller, J. (2017). P2Y12 receptor is expressed on human microglia under physiological conditions throughout development and is sensitive to neuroinflammatory diseases. Glia 65, 375-387. doi: 10.1002/glia.23097. 
889 Morgan, D., Diamond, D.M., Gottschall, P.E., Ugen, K.E., Dickey, C., Hardy, J., Duff, K., Jantzen, 890 P., DiCarlo, G., Wilcock, D., et al. (2000). A beta peptide vaccination prevents memory loss in an 891 animal model of Alzheimer's disease. Nature 408, 982-985. doi: 10.1038/35050116.

892 Mrdjen, D., Pavlovic, A., Hartmann, F.J., Schreiner, B., Utz, S.G., Leung, B.P., Lelios, I., Heppner, 893 F.L., Kipnis, J., Merkler, D., et al. (2018). High-Dimensional Single-Cell Mapping of Central Nervous 894 System Immune Cells Reveals Distinct Myeloid Subsets in Health, Aging, and Disease. Immunity 48, 895 380-395 e386. doi: 10.1016/j.immuni.2018.01.011.

896 Naj, A.C., Jun, G., Beecham, G.W., Wang, L.S., Vardarajan, B.N., Buros, J., Gallins, P.J., Buxbaum, 897 J.D., Jarvik, G.P., Crane, P.K., et al. (2011). Common variants at MS4A4/MS4A6E, CD2AP, CD33 898 and EPHA1 are associated with late-onset Alzheimer's disease. Nat Genet 43, 436-441. doi: $89910.1038 / \mathrm{ng} .801$.

900 Nicoll, J.A., Barton, E., Boche, D., Neal, J.W., Ferrer, I., Thompson, P., Vlachouli, C., Wilkinson, D., 901 Bayer, A., Games, D., et al. (2006). Abeta species removal after abeta42 immunization. Journal of 902 neuropathology and experimental neurology 65, 1040-1048. doi: 903 904 10.1097/01.jnen.0000240466.10758.ce.

Nicoll, J.A., Wilkinson, D., Holmes, C., Steart, P., Markham, H., and Weller, R.O. (2003). Neuropathology of human Alzheimer disease after immunization with amyloid-beta peptide: a case report. Nature medicine 9, 448-452. doi: 10.1038/nm840.

Orre, M., Kamphuis, W., Osborn, L.M., Jansen, A.H., Kooijman, L., Bossers, K., and Hol, E.M. (2014a). Isolation of glia from Alzheimer's mice reveals inflammation and dysfunction. Neurobiology of aging 35, 2746-2760. doi: 10.1016/j.neurobiolaging.2014.06.004.

910 Orre, M., Kamphuis, W., Osborn, L.M., Melief, J., Kooijman, L., Huitinga, I., Klooster, J., Bossers, 911 K., and Hol, E.M. (2014b). Acute isolation and transcriptome characterization of cortical astrocytes 912 and microglia from young and aged mice. Neurobiology of aging 35, 1-14. doi: 10.1016/j.neurobiolaging.2013.07.008.

Parhizkar, S., Arzberger, T., Brendel, M., Kleinberger, G., Deussing, M., Focke, C., Nuscher, B., Xiong, M., Ghasemigharagoz, A., Katzmarski, N., et al. (2019). Loss of TREM2 function increases amyloid seeding but reduces plaque-associated ApoE. Nature neuroscience 22, 191-204. doi: 10.1038/s41593-018-0296-9.

Perez-Riverol, Y., Csordas, A., Bai, J., Bernal-Llinares, M., Hewapathirana, S., Kundu, D.J., Inuganti, A., Griss, J., Mayer, G., Eisenacher, M., et al. (2019). The PRIDE database and related tools and resources in 2019: improving support for quantification data. Nucleic Acids Res 47, D442-D450. doi: 10.1093/nar/gky1106.

Radde, R., Bolmont, T., Kaeser, S.A., Coomaraswamy, J., Lindau, D., Stoltze, L., Calhoun, M.E., Jaggi, F., Wolburg, H., Gengler, S., et al. (2006). Abeta42-driven cerebral amyloidosis in transgenic mice reveals early and robust pathology. EMBO reports 7, 940-946. doi: 10.1038/sj.embor.7400784. Rangaraju, S., Dammer, E.B., Raza, S.A., Gao, T., Xiao, H., Betarbet, R., Duong, D.M., Webster, J.A., Hales, C.M., Lah, J.J., et al. (2018). Quantitative proteomics of acutely-isolated mouse microglia identifies novel immune Alzheimer's disease-related proteins. Molecular neurodegeneration 13, 34. doi: 10.1186/s13024-018-0266-4.

Rappsilber, J., Ishihama, Y., and Mann, M. (2003). Stop and go extraction tips for matrix-assisted laser desorption/ionization, nanoelectrospray, and LC/MS sample pretreatment in proteomics. Analytical chemistry 75, 663-670. doi:

Reddy, P.H., Manczak, M., Zhao, W., Nakamura, K., Bebbington, C., Yarranton, G., and Mao, P. (2009). Granulocyte-macrophage colony-stimulating factor antibody suppresses microglial activity: implications for anti-inflammatory effects in Alzheimer's disease and multiple sclerosis. Journal of neurochemistry 111, 1514-1528. doi: 10.1111/j.1471-4159.2009.06432.x. 
936 Sadleir, K.R., Kandalepas, P.C., Buggia-Prevot, V., Nicholson, D.A., Thinakaran, G., and Vassar, R. (2016). Presynaptic dystrophic neurites surrounding amyloid plaques are sites of microtubule disruption, BACE1 elevation, and increased Abeta generation in Alzheimer's disease. Acta neuropathologica 132, 235-256. doi: 10.1007/s00401-016-1558-9. Saido, T.C. (1998). Alzheimer's disease as proteolytic disorders: anabolism and catabolism of betaamyloid. Neurobiology of aging 19, S69-75. doi: (2014). Single App knock-in mouse models of Alzheimer's disease. Nature neuroscience 17, 661-663. doi: $10.1038 / \mathrm{nn} .3697$. W.T., Woodbury, M.E., Srivastava, G., et al. (2019). The Major Risk Factors for Alzheimer's Disease: Age, Sex, and Genes Modulate the Microglia Response to Abeta Plaques. Cell reports 27, 1293-1306 e1296. doi: 10.1016/j.celrep.2019.03.099. Wood, K., Khan, K., et al. (1999). Immunization with amyloid-beta attenuates Alzheimer-diseaselike pathology in the PDAPP mouse. Nature 400, 173-177. doi: 10.1038/22124. Achievements and Future Perspectives. Molecules 23. doi: 10.3390/molecules23051068.

Scholtzova, H., Kascsak, R.J., Bates, K.A., Boutajangout, A., Kerr, D.J., Meeker, H.C., Mehta, P.D., Spinner, D.S., and Wisniewski, T. (2009). Induction of toll-like receptor 9 signaling as a method for ameliorating Alzheimer's disease-related pathology. The Journal of neuroscience : the official journal of the Society for Neuroscience 29, 1846-1854. doi: 10.1523/JNEUROSCI.5715-08.2009.

Sevigny, J., Chiao, P., Bussiere, T., Weinreb, P.H., Williams, L., Maier, M., Dunstan, R., Salloway, S., Chen, T., Ling, Y., et al. (2016). The antibody aducanumab reduces Abeta plaques in Alzheimer's disease. Nature 537, 50-56. doi: 10.1038/nature19323.

Sharma, K., Schmitt, S., Bergner, C.G., Tyanova, S., Kannaiyan, N., Manrique-Hoyos, N., Kongi, K., Cantuti, L., Hanisch, U.K., Philips, M.A., et al. (2015). Cell type- and brain region-resolved mouse brain proteome. Nature neuroscience 18, 1819-1831. doi: 10.1038/nn.4160.

Shi, Y., and Holtzman, D.M. (2018). Interplay between innate immunity and Alzheimer disease: APOE and TREM2 in the spotlight. Nat Rev Immunol 18, 759-772. doi: 10.1038/s41577-018-00511.

Sims, R., van der Lee, S.J., Naj, A.C., Bellenguez, C., Badarinarayan, N., Jakobsdottir, J., Kunkle, B.W., Boland, A., Raybould, R., Bis, J.C., et al. (2017). Rare coding variants in PLCG2, ABI3, and TREM2 implicate microglial-mediated innate immunity in Alzheimer's disease. Nat Genet 49, 13731384. doi: 10.1038/ng.3916.

Solito, E., and Sastre, M. (2012). Microglia function in Alzheimer's disease. Front Pharmacol 3, 14. doi: 10.3389/fphar.2012.00014.

973 Thygesen, C., Ilkjaer, L., Kempf, S.J., Hemdrup, A.L., von Linstow, C.U., Babcock, A.A., Darvesh, S., Larsen, M.R., and Finsen, B. (2018). Diverse Protein Profiles in CNS Myeloid Cells and CNS Tissue From Lipopolysaccharide- and Vehicle-Injected APPSWE/PS1DeltaE9 Transgenic Mice Implicate Cathepsin $\mathrm{Z}$ in Alzheimer's Disease. Front Cell Neurosci 12, 397. doi: 10.3389/fncel.2018.00397.

978 Tusher, V.G., Tibshirani, R., and Chu, G. (2001). Significance analysis of microarrays applied to the 979 ionizing radiation response. Proceedings of the National Academy of Sciences of the United States of America 98, 5116-5121. doi: 10.1073/pnas.091062498.

981 Tyanova, S., Temu, T., Sinitcyn, P., Carlson, A., Hein, M.Y., Geiger, T., Mann, M., and Cox, J. 982 (2016). The Perseus computational platform for comprehensive analysis of (prote)omics data. Nat 983 Methods 13, 731-740. doi: 10.1038/nmeth.3901. 
984 Ulrich, J.D., Ulland, T.K., Mahan, T.E., Nystrom, S., Nilsson, K.P., Song, W.M., Zhou, Y., Reinartz, M., Choi, S., Jiang, H., et al. (2018). ApoE facilitates the microglial response to amyloid plaque pathology. J Exp Med 215, 1047-1058. doi: 10.1084/jem.20171265.

Van Acker, Z.P., Bretou, M., and Annaert, W. (2019). Endo-lysosomal dysregulations and late-onset Alzheimer's disease: impact of genetic risk factors. Molecular neurodegeneration 14, 20. doi: 10.1186/s13024-019-0323-7.

990

Wang, Y., Cella, M., Mallinson, K., Ulrich, J.D., Young, K.L., Robinette, M.L., Gilfillan, S., Krishnan, G.M., Sudhakar, S., Zinselmeyer, B.H., et al. (2015). TREM2 lipid sensing sustains the microglial response in an Alzheimer's disease model. Cell 160, 1061-1071. doi: 10.1016/j.cell.2015.01.049.

Wilcock, D.M., Rojiani, A., Rosenthal, A., Levkowitz, G., Subbarao, S., Alamed, J., Wilson, D., Wilson, N., Freeman, M.J., Gordon, M.N., et al. (2004). Passive amyloid immunotherapy clears amyloid and transiently activates microglia in a transgenic mouse model of amyloid deposition. The Journal of neuroscience : the official journal of the Society for Neuroscience 24, 6144-6151. doi: 10.1523/JNEUROSCI.1090-04.2004. impaired amyloid beta clearance in Alzheimer's disease. Alzheimer's research \& therapy 5, 33. doi: 10.1186/alzrt187.

Wisniewski, J.R., Zougman, A., Nagaraj, N., and Mann, M. (2009). Universal sample preparation method for proteome analysis. Nat Methods 6, 359-362. doi: 10.1038/nmeth.1322. Xiang, X., Werner, G., Bohrmann, B., Liesz, A., Mazaheri, F., Capell, A., Feederle, R., Knuesel, I., Kleinberger, G., and Haass, C. (2016). TREM2 deficiency reduces the efficacy of immunotherapeutic amyloid clearance. EMBO molecular medicine 8, 992-1004. doi: 10.15252/emmm.201606370. Yamasaki, A., Eimer, S., Okochi, M., Smialowska, A., Kaether, C., Baumeister, R., Haass, C., and Steiner, H. (2006). The GxGD motif of presenilin contributes to catalytic function and substrate identification of gamma-secretase. The Journal of neuroscience : the official journal of the Society for Neuroscience 26, 3821-3828. doi: 10.1523/JNEUROSCI.5354-05.2006. Yin, Z., Raj, D., Saiepour, N., Van Dam, D., Brouwer, N., Holtman, I.R., Eggen, B.J.L., Moller, T., Tamm, J.A., Abdourahman, A., et al. (2017). Immune hyperreactivity of Abeta plaque-associated microglia in Alzheimer's disease. Neurobiology of aging 55, 115-122. doi: 10.1016/j.neurobiolaging.2017.03.021. Yuan, P., Condello, C., Keene, C.D., Wang, Y., Bird, T.D., Paul, S.M., Luo, W., Colonna, M., Baddeley, D., and Grutzendler, J. (2016). TREM2 Haplodeficiency in Mice and Humans Impairs the Microglia Barrier Function Leading to Decreased Amyloid Compaction and Severe Axonal Dystrophy. Neuron 92, 252-264. doi: 10.1016/j.neuron.2016.09.016. Pulagam, K.R., Lukowiak, M., Capetillo-Zarate, E., et al. (2018). P2X4 receptor controls microglia activation and favors remyelination in autoimmune encephalitis. EMBO molecular medicine 10. doi: 10.15252/emmm.201708743. Alzheimer's disease: reassessing the role of microglia and monocytes. Cell Mol Life Sci 74, 21672201. doi: 10.1007/s00018-017-2463-7. 
1032 Figure 1. Quantitative proteomics of acutely isolated microglia. Volcano plots of APPPS1 and 1033 APP-KI versus WT microglia at 1 (A and B), $3(\mathbf{C}$ and $\mathbf{D}), 6(\mathbf{E}$ and $\mathbf{F})$ and $12(\mathbf{G}$ and $\mathbf{H})$ months of 1034 age. The minus $\log 10$ transformed p-value is plotted against the $\log 2$ transformed LFQ ratios. A permutation based FDR estimation was applied which is visualized as hyperbolic curves. Proteins with $\log 2$ LFQ ratio lower than -0.5 or higher than +0.5 with a p-value less than 0.05 which remain significantly changed after FDR correction are indicated as red circles. Non-significantly changed proteins are indicated as blue circles. Individual proteins are marked with their gene names.

Figure 2. APPPS1 microglia display earlier proteomic changes compared to APP-KI microglia.

A. Profile plots of APPPS1 and APP-KI versus WT microglia at 1, 3, 6, and 12 months of age. Lines connect the average $\log 2$ fold changes of each protein at the different time points. Regulated proteins were grouped according to three profiles: significantly increased or decreased after FDR correction $(\log 2 \mathrm{FC}>0.5$ or $<-0.5 ; \mathrm{p}<0.05$; FDR significant) at 3, 6, and 12 months, only at 3 and 6 months, or only at 12 months. Proteins that fulfill these criteria are indicated as red and blue lines for increased and decreased abundance, respectively. Selected up- or down-regulated proteins are indicated with magenta and cyan. Proteins that were regulated at 3, 6, and 12 months in APPPS1 mice as well as at 6 and 12, or only at 12 months in APP-KI mice were annotated as early MARPs. Proteins that were regulated at 6 and 12 months in APPPS1 as well as at 6 and 12, or only at 12 months in APP-KI mice were annotated as middle MARPs. Proteins that were regulated at 12 months in APPPS1 and APP-KI mice were annotated as advanced MARPs. Heatmaps show the $\log 2$ fold changes of the top 74 up- or down-regulated proteins for early (B), middle (C) and advanced (D) MARPs and are compared to the $\log 2$ fold changes of related transcripts of DAM and homeostatic microglia (Keren-Shaul et al., 2017), indicated with K-S. Crosses indicate missing values.

1055

Figure 3. Gene ontology enrichment cluster analysis for biological process (BP) of MARPs. Bar graphs show the clustering of early MARPs (A), middle MARPs (B) and advanced MARPs (C) for BP. Up- and down-regulated proteins were analyzed separately using the web-based software tool DAVID 6.8 with all consistently quantified proteins (5500) as an individual background. Significantly enriched clusters (Enrichment Score > 1.301) for up-and down-regulated proteins are indicated in blue and red, respectively. 
1062 Figure 4. Microglial CLEC7a is prominently up-regulated in 3 month old APPPS1 mice.

1063 Immunohistochemical analysis of CLEC7a (red) revealed an increased abundance of this early MARP

1064 in IBA1 positive (green) APPPS1 microglia surrounding A $\beta$ plaques (magenta) that is less prominent

1065 in APP-KI microglia. CLEC7a was barely detected in WT microglia. Hoechst was used for nuclear 1066 staining (blue). Boxed regions in upper panels (scale bar: $50 \mu \mathrm{m}$ ) are shown with a higher 1067 magnification in lower panels (scale bar: $10 \mu \mathrm{m}$ ).

1068

1069 Figure 5. Microglial CLEC7a is increased in both AD mouse models at 12 months of age. 1070 Immunohistochemical analysis showed an up-regulation of CLEC7a (red) in IBA1 positive (green) 1071 APPPS1 and APP-KI microglia surrounding A $\beta$ plaques (magenta), compared to WT where CLEC7a 1072 was barely detected. Hoechst was used for nuclear staining (blue). Boxed regions in upper panels 1073 (scale bar: $50 \mu \mathrm{m}$ ) are shown with a higher magnification in lower panels (scale bar: $10 \mu \mathrm{m}$ ).

Figure 6. Microglial TMEM119 is down-regulated in both AD mouse models at 12 months of age. Immunohistochemical analysis of TMEM119 (red) shows a broad coverage signal of this

1077 homeostatic marker in IBA1 positive (green) WT microglia. In the APPPS1 and APP-KI mice, 1078 TMEM119 signal is reduced in IBA1 positive microglia surrounding A $\beta$ plaques (magenta). Of note, 1079 increased TMEM119 signal was often found in the core of amyloid plaques in APPPS1 and APP-KI 1080 mice. Hoechst was used for nuclear staining (blue). Boxed regions in upper panels (scale bar: $50 \mu \mathrm{m}$ ) 1081 are shown with a higher magnification in lower panels (scale bar: $10 \mu \mathrm{m}$ ) and illustrate reduced levels of TMEM119 in plaque associated microglia. plaques. A. Immunohistochemical analysis showing total $A \beta$ (green), fibrillar $A \beta$ (ThR, red) and microglia (IBA1, magenta) in both mouse models at 3, 6 and 12 months of age. Hoechst was used for nuclear staining (blue). Scale bar: $100 \mu \mathrm{m} \mathrm{B}$. Western blot analysis of insoluble A $\beta$ at 3, 6 and 12 months of age confirms increased levels of fibrillar A $\beta$ in APPPS1 compared to APP-KI mice.

Figure 8. Fibrillar A $\beta$ triggers higher microglial recruitment in 3 month old APPPS1 mice and 
1093 plaque halo (magenta) in 3 month old APPPS 1 and APP-KI mice. Hoechst (HOE) was used for nuclear 1094 staining (blue). Yellow arrows indicate intracellular fibrillar A $\beta$ within APPPS1 microglia. Scale bar: $109510 \mu \mathrm{m}$. B. Quantification of IBA1 positive cells recruited to amyloid plaques in 3 month old APPPS1 1096 and APP-KI mice. Microglial numbers are normalized to the plaque area. C. Quantification of plaque 1097 size in 3 month old APPPS1 and APP-KI mice. D. Imunohistochemical analysis of IBA1 (green) and 1098 CD68 (red) positive microglial cells recruited to A $\beta$ plaques (magenta) in 3 month old APPPS1 and 1099 APP-KI mice. Hoechst was used for nuclear staining (blue). Scale bar: $20 \mu \mathrm{m}$. E. Quantification of 1100 CD68 coverage in 3 month old APPPS1 and APP-KI mice. CD68 coverage is normalized to the plaque 1101 area. F. Quantification of CD68 coverage per microglia in 3 month old APPPS1 and APP-KI mice. 1102 CD68 coverage is normalized to the number of IBA1 positive cells recruited to amyloid plaque. G. 1103 Immunohistochemical analysis of dystrophic neurites detected using an antibody against APP (green) 1104 in 3 month old APPPS1 and APP-KI mice. ThR was used to detect fibrillar A $\beta$ plaque core (red) and 1105 the whole $A \beta$ plaque was visualized using an antibody against $A \beta$ (magenta). Hoechst was used for 1106 nuclear staining (blue). Scale bar: $20 \mu \mathrm{m}$. H. Quantification of area covered by dystrophic neurites in 11073 month old APPPS1 and APP-KI mice. In B, C, E, F and H, represented values are expressed as the 1108 mean of $\mathrm{n}=3$ mice per genotype $\pm \mathrm{SD}(* \mathrm{P}<0.05 ; * * \mathrm{P}<0.01$, unpaired two-tailed Student's T-test; 1109 n.s: not significant). I. Mean Fluorescence Intensity (MFI) of E.coli-pHrodo signal within the CD11b 1110 positive cells in 3 and 6 month old APPPS1, APP-KI and WT mice. CytoD was used to inhibit phagocytosis and serves as a negative control. a.u.: arbitrary units. J. Percentage of CD11b and E.colipHrodo double positive cells from the total CD11b positive population. In $\mathbf{I}$ and $\mathbf{J}$, values for the 3 month old group are expressed as the mean of $n=3$ mice per genotype \pm SD from three independent experiments and for the 6 month old group as the mean of $n=2$ mice per genotype \pm SD from two independent experiments $(* * * \mathrm{P}<0.001$, Two-way ANOVA, Dunnett's multiple comparison test; n.s: not significant). 


\section{Supplementary Figure Legends}

1123 Suppl. Figure 1. Quality control of microglial isolation using MACS. FACS analysis of the 1124 CD11b-enriched (A) and CD11b-depleted fraction (B). Propidium Iodide (PI) was used to analyze 1125 cell viability (PI negative fraction).

Suppl. Figure 2. Improvement of the data acquisition method for quantitative proteomics of microglia. A. Workflow of the proteomic analysis. Microglia were acutely isolated using the CD11b MACS system. Protein lysates were subjected to tryptic digestion followed by quantitative LCMS/MS analysis. APPPS1 microglia samples were first measured using DDA to generate a spectral library required for DIA analysis. Afterwards, both APPPS1 and APPKI microglia were measured using DIA and data was subjected to further bioinformatics analysis. B. Distribution of quantified proteins with DDA and DIA. The number of quantified proteins is plotted against the $\log 10$ transformed iBAQ (intensity based absolute quantification) values with a bin size of 0.25 . The iBAQ values are an estimate of the relative molar abundance of a protein within the sample. The number of consistently quantified proteins per bin for DDA and DIA are indicated in blue and red, respectively. Proteins that were only quantified with DDA or DIA are colored in light blue and orange, respectively. The single values are connected with dashed lines for better visibility. Please note that DIA provides additional quantifications for low abundant proteins. Hereby, DIA extends the dynamic range for protein quantification by almost one order of magnitude. C. Number of relatively quantified proteins between APPPS1 and WT microglia for 1, 3, 6, and 12 months with DDA (blue) and DIA (red). Only proteins that were consistently quantified in all APPPS1 and WT samples per age group were counted. Please note that DIA provides between 24 and $35 \%$ additional quantifications per age group. D. The comparison of relatively quantified proteins of APPPS1 and APP-KI versus WT at 12 months shows a large overlap of $93.5 \%$ indicating a very consistent quantification.

1147 Suppl. Figure 3. A $\beta$ pathology in 3, 6 and 12 month old APPPS1 and APP-KI mice. 1148 Immunohistochemical analysis of A $\beta$ load (NAB228, green) in APPPS1 and APP-KI mice. Hoechst was used for nuclear staining (blue). Scale bar: $400 \mu \mathrm{m}$. 
11546 and 12, or only at 12 months in APP-KI mice were annotated as early MARPs. Proteins that were 1155 regulated at 6 and 12 months in APPPS 1 as well as at 6 and 12, or only at 12 months in APP-KI mice 1156 were annotated as middle MARPs. Proteins that were regulated at 12 months in APPPS1 and APP-KI 1157 mice were annotated as advanced MARPs. B. Correlation plot of $\log 2$ protein fold changes detected 1158 at 12 months for APPPS1 and APP-KI versus WT. The plot shows a significant correlation of 1159 proteomic changes at 12 months. Early, middle, and advanced MARPs are indicated in red, orange, 1160 and black circles with yellow filling, respectively. Selected proteins are annotated with their gene 1161 names. C. Comparison of our proteomic study with the single cell transcriptomics study (Keren-Shaul 1162 et al., 2017) reveals a modest overlap. A Venn diagram illustrates the comparison of quantified 1163 proteins in APPPS1 and APP-KI versus WT at 12 months and DAM and homeostatic microglial 1164 transcripts. Overall, 3348 common proteins and related transcripts were quantified. D. Biochemical 1165 validation of proteomic data was performed using Western blot analysis of microglial lysates from 12 1166 month old mice. This analysis revealed an increased abundance of up-regulated MARPs APOE, 1167 TREM2, CD68 and FABP5 as well as a decreased abundance of the down-regulated MARP CSF1R 1168 in APPPS1 and APP-KI compared to WT microglia. Arrows indicate antibody-detected specific bands 1169 and asterisk indicates unspecific bands.

Suppl. Figure 5. Gene ontology enrichment cluster analysis for cellular component (CC) and molecular function (MF) of MARPs. The bar graphs show the clustering of early MARPs (A, D), middle MARPs $(\mathbf{B}, \mathbf{E})$ and advanced MARPs $(\mathbf{C}, \mathbf{F})$ for CC and MF. Up- and down-regulated proteins were analyzed separately using the web-based software tool DAVID 6.8 using all consistently quantified proteins (5500) as an individual background. Significantly enriched clusters (Enrichment Score > 1.301) for up- and down-regulated proteins are indicated in blue and red, respectively.

Suppl. Figure 6. Microglial TREM2 is prominently up-regulated in 3 month old APPPS1 mice. Immunohistochemical analysis of TREM2 (red) revealed an increased abundance in IBA1 positive (green) APPPS1 microglia surrounding A $\beta$ plaques (magenta) that is less prominent in APP-KI microglia. Hoechst was used for nuclear staining (blue). Boxed regions in upper panels (scale bar: 50 $\mu \mathrm{m})$ are shown with a higher magnification in lower panels (scale bar: $10 \mu \mathrm{m}$ ).

1184 Suppl. Figure 7. Microglial APOE is prominently up-regulated in 3 month old APPPS1 mice. 1185 Immunohistochemical analysis of APOE (red) revealed an up-regulation in IBA1 positive (green) 
1186 APPPS1 microglia surrounding A $\beta$ plaques (magenta) that is less prominent in APP-KI microglia. 1187 APOE could not be detected in WT microglia. Hoechst was used for nuclear staining (blue). Of note, 1188 astrocytic APOE immunoreactivity was also detected, particularly in the WT, reflecting its 1189 physiological expression. Yellow arrows indicate APOE positive microglia. Boxed regions in upper 1190 panels (scale bar: $50 \mu \mathrm{m}$ ) are shown with a higher magnification in lower panels (scale bar: $10 \mu \mathrm{m}$ ).

1192 Suppl. Figure 8. Phagocytosis is impaired earlier in APPPS1 compared to APP-KI microglia. A.

1193 Histograms represent the fuorescence intensity of uptaken E.coli-pHrodo green particles within the 1194 CD11b positive population for every genotype and time point ( 3 and 6 months). Dashed lines indicate 1195 the mean fluorescence intensity (MFI) calculated with the geometric mean for each condition. B. 1196 FACS analysis representing the percentage of CD11b and E.coli-pHrodo positive cells out of the 1197 whole CD11b positive population for every genotype. 


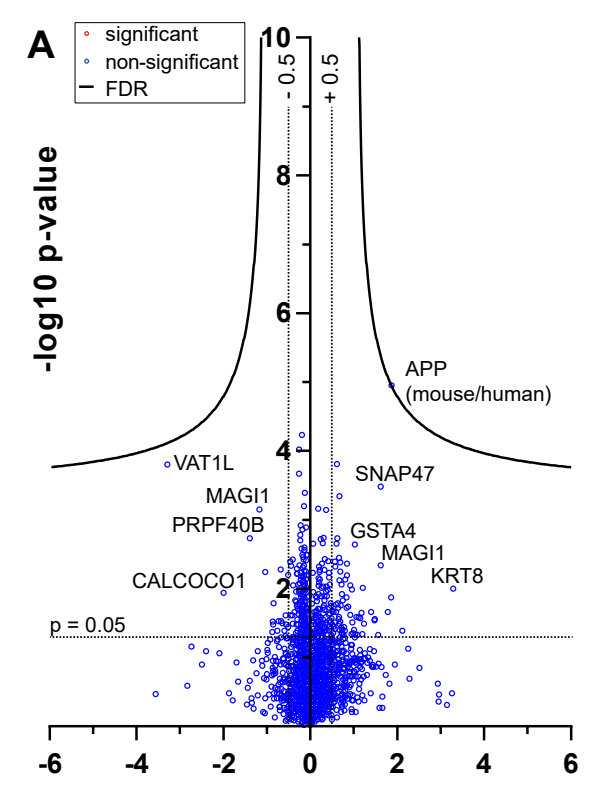

log2 LFQ ratio (APPPS1/WT) $1 \mathrm{M}$

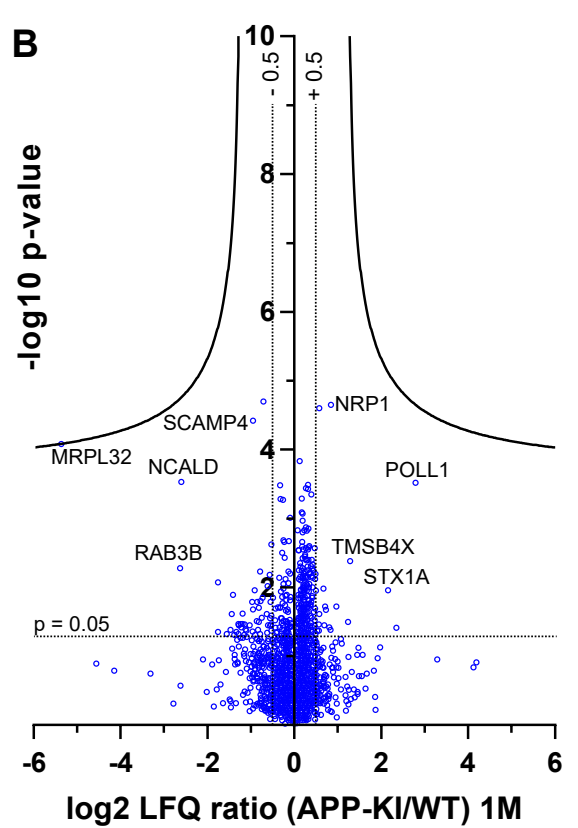

C

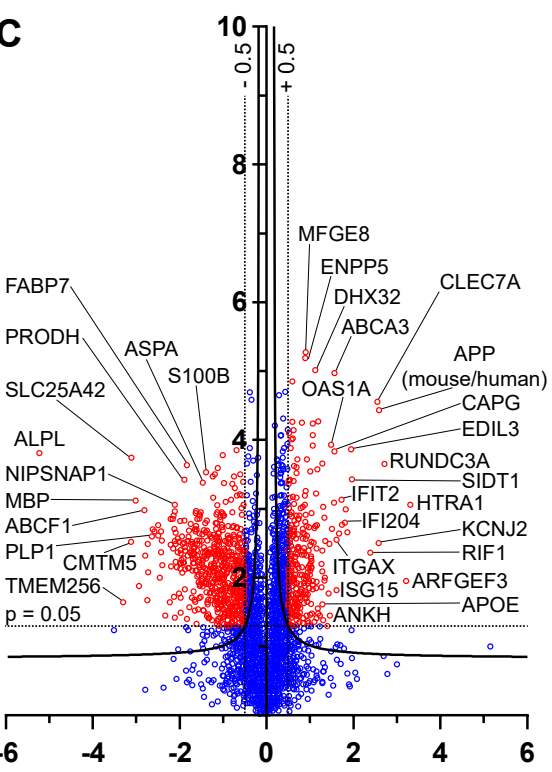

log2 LFQ ratio (APPPS1/WT) 3M

D

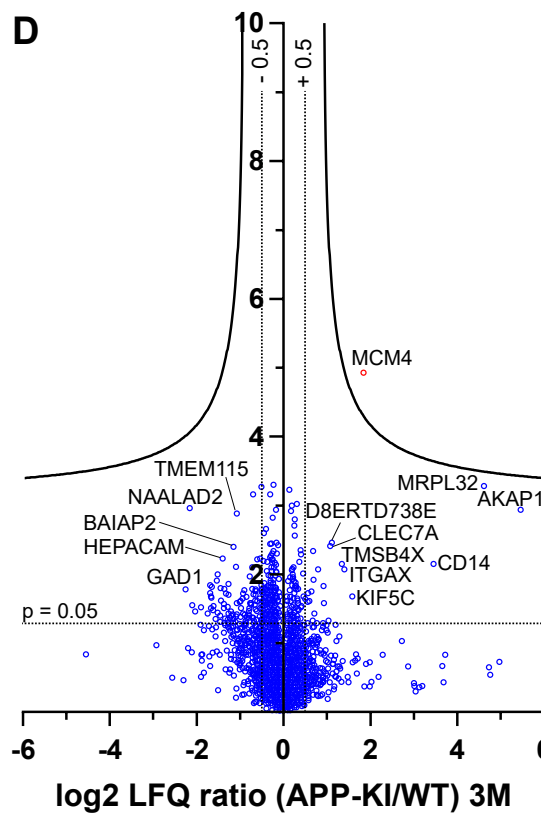

E

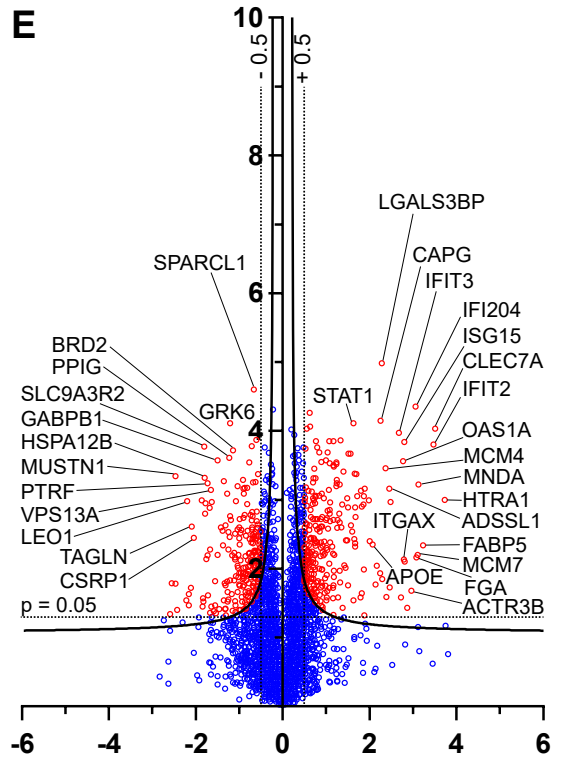

log2 LFQ ratio (APPPS1/WT) 6M

F

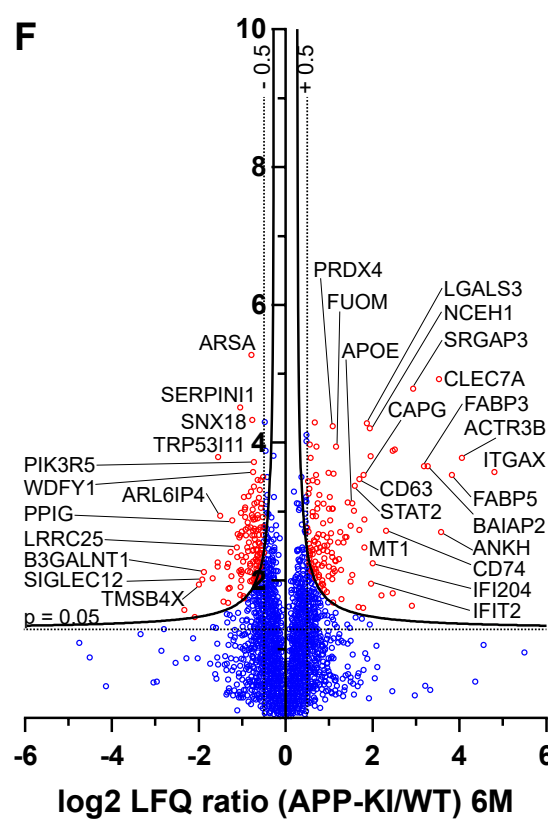

G

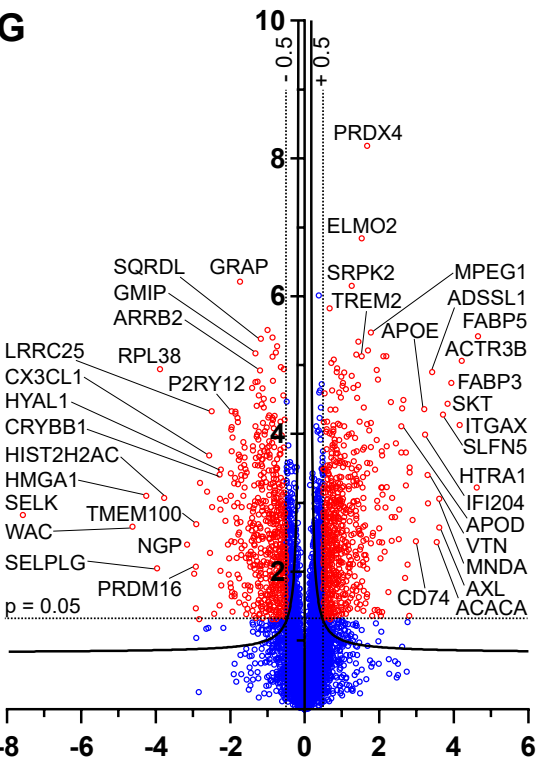

log2 LFQ ratio (APPPS1/WT) 12M

H

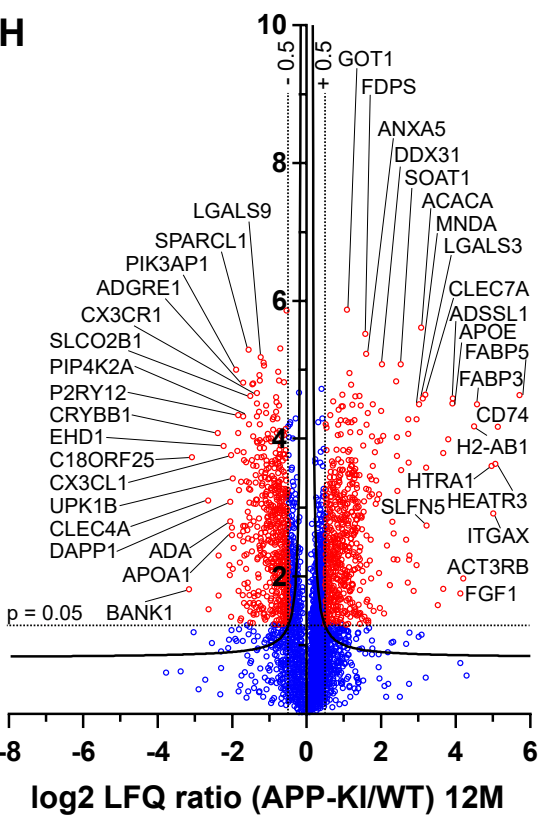

Fig 1 
bioRxiv preprint doi: https://doi.org/10.1101/861146; this version posted December 2, 2019. The copyright holder for this preprint (which was not certified by peer review) is the author/funder. All rights reserved. No reuse allowed without permission.

A
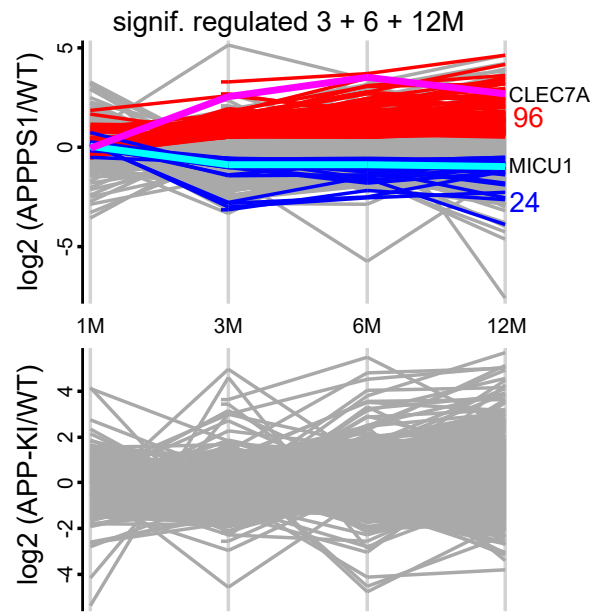

B

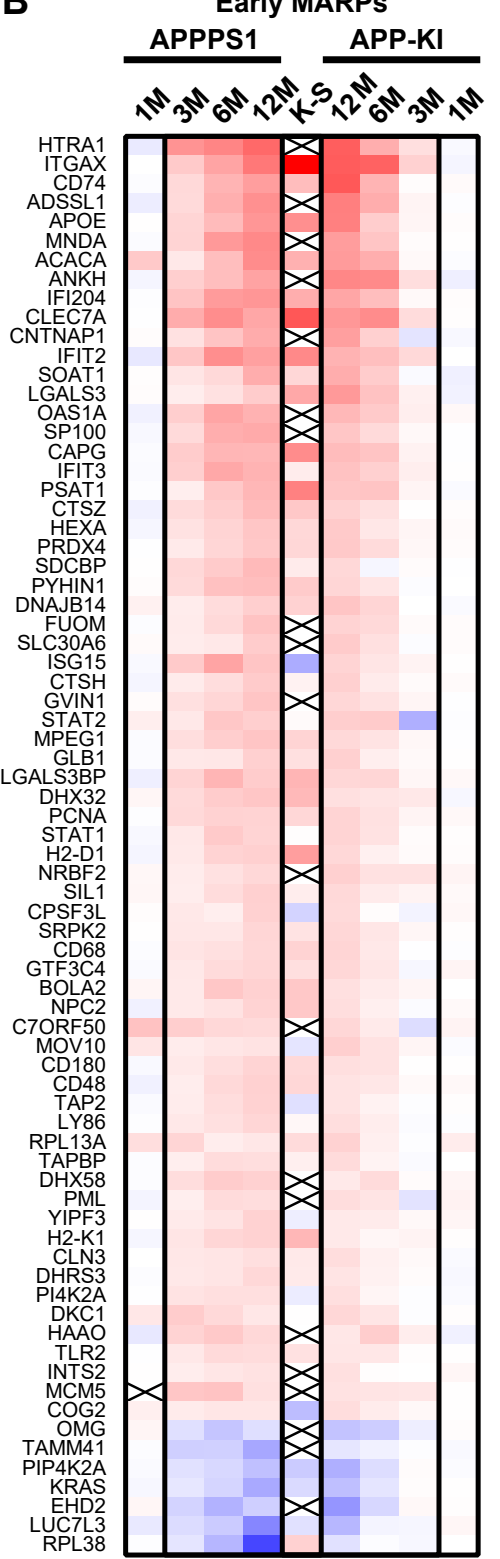

signif. regulated only $6+12 \mathrm{M}$
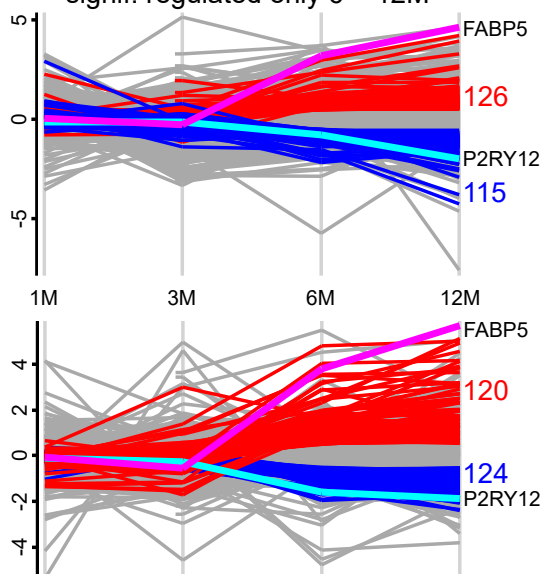

C

Middle MARPs
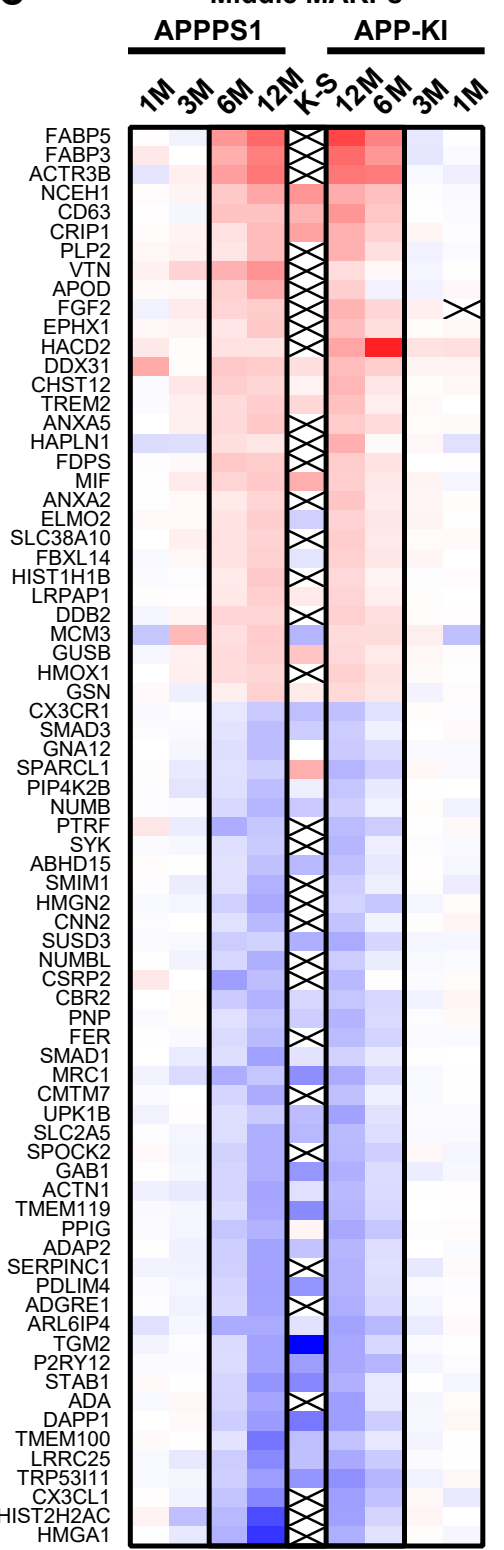

D signif. regulated only $12 \mathrm{M}$

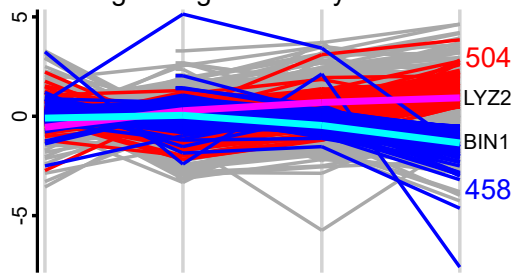

$3 \mathrm{M}$

$6 \mathrm{M}$

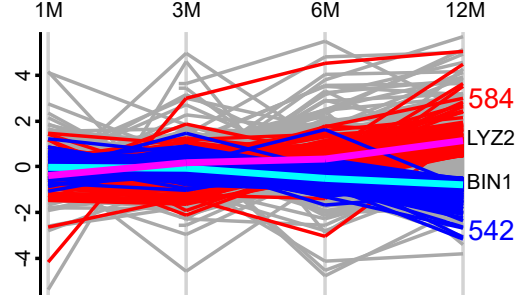

Advanced MARPs

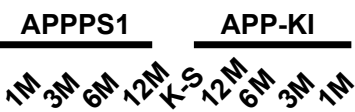

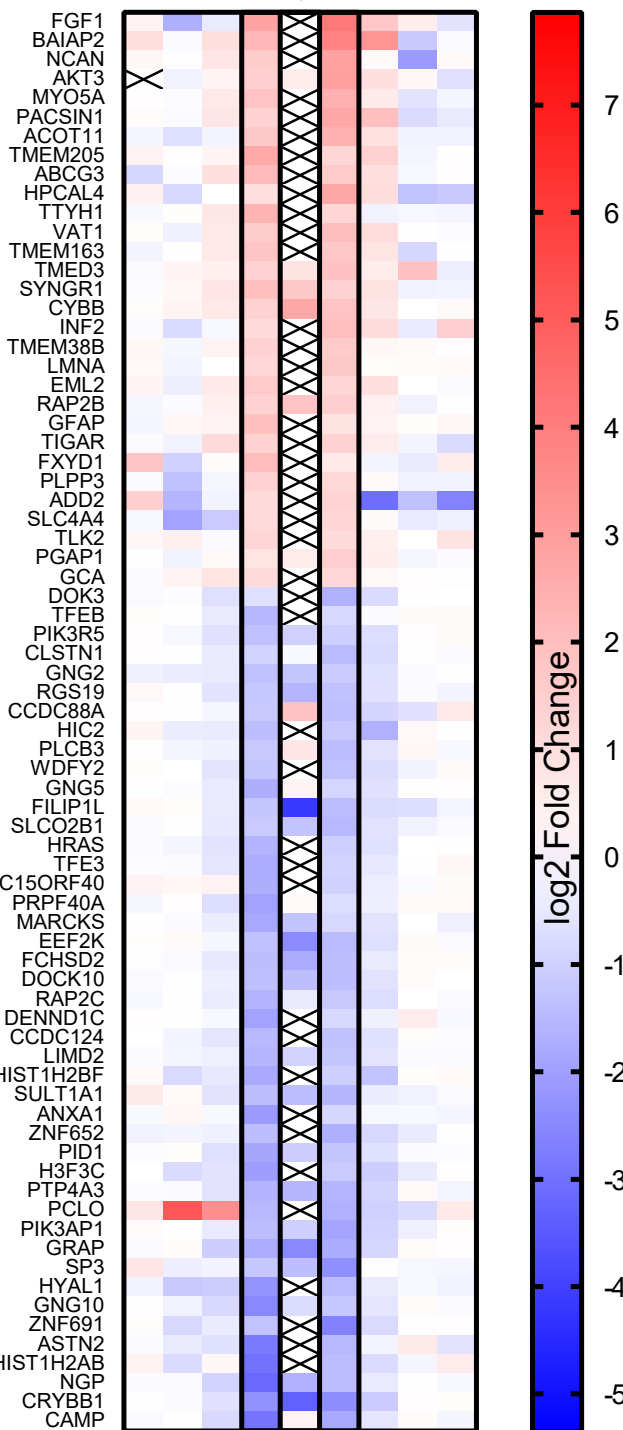

Fig 2 


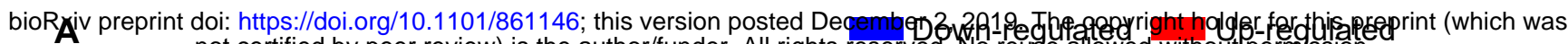
not certified by peer review) is the author/funder. All rights reserved. No reuse allowed withoutpermission.

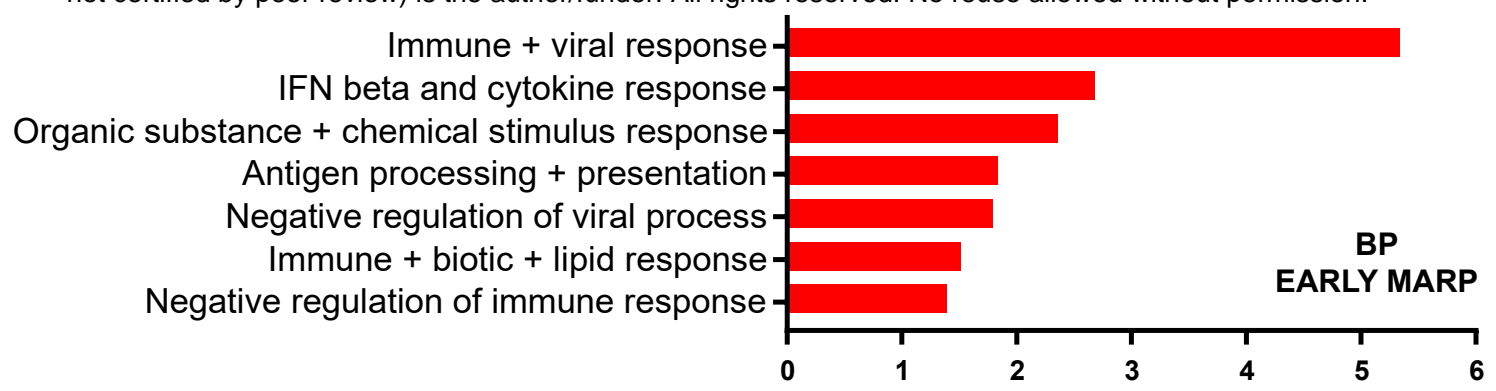

B

Cell differentiation + development + proliferation Hexose + carbohyd.+ pyridine nucleotide metabolism Anatomical structure morphogenesis + angiogenesis -

Wound healing + blood coagulation -

Organic substance + chemical stimulus response

Tissue regeneration + wound healing Cell proliferation

Chemotaxis + immune cell migration -

Organ regeneration + liver and gland development Response to bacterium + lipid

Cell adhesion + activation

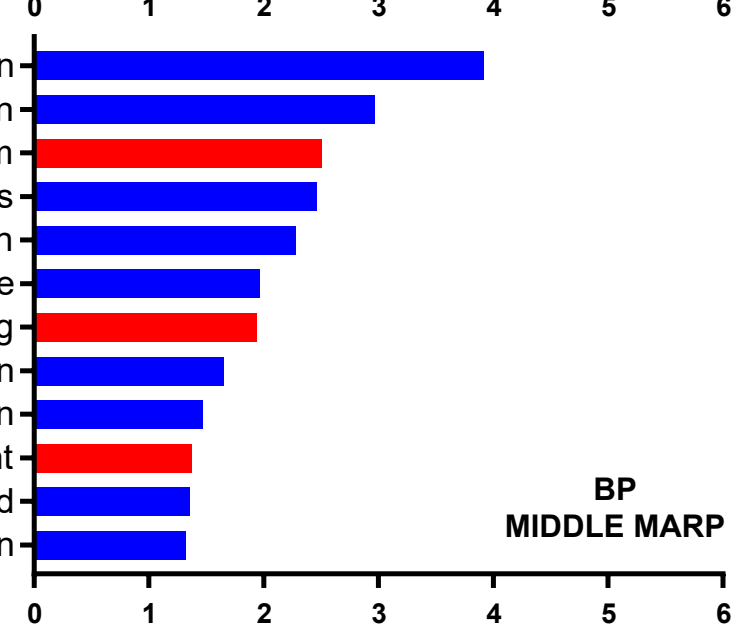

C

Phosphorylation + intracellular signal transduction -
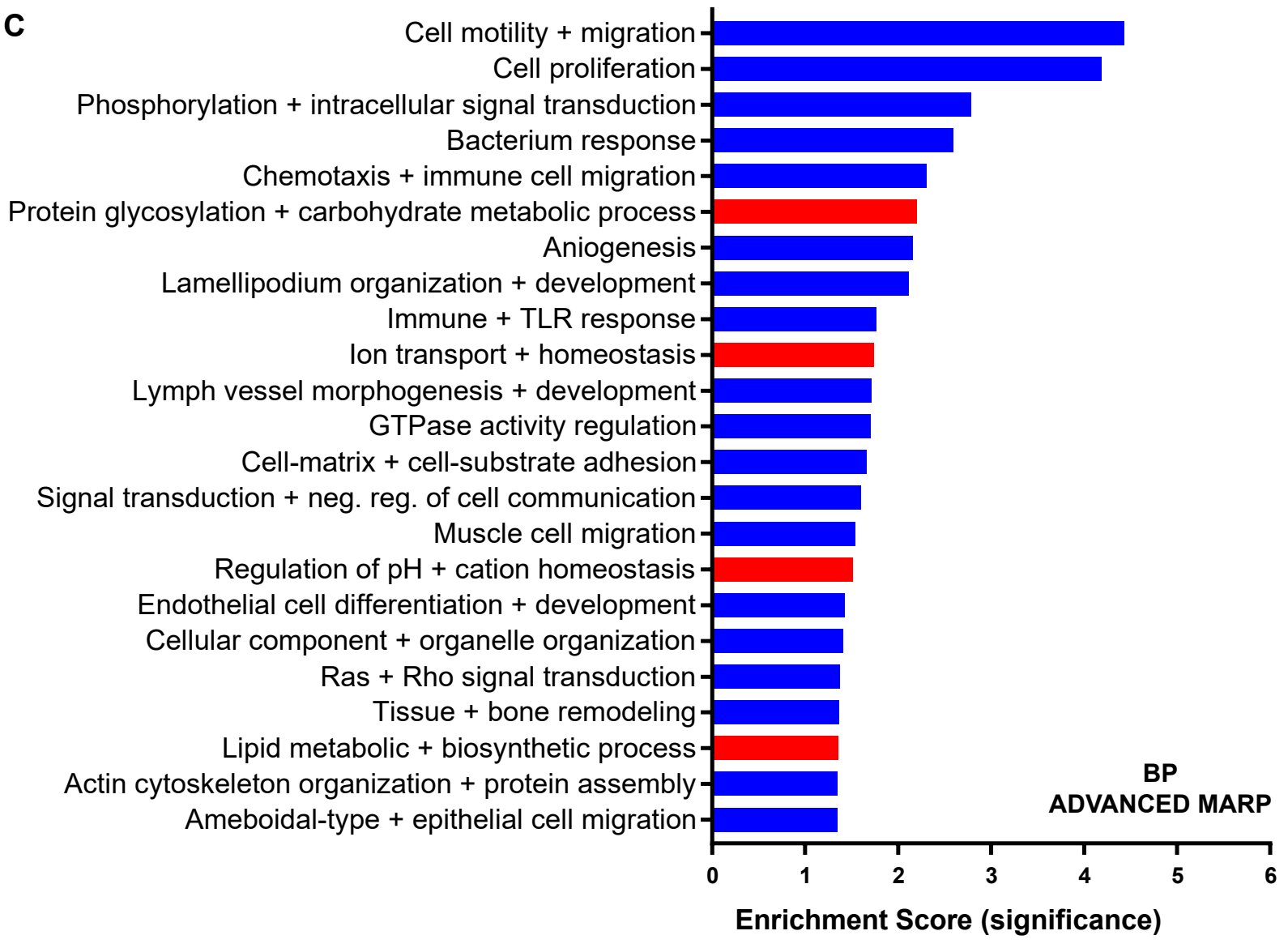

Fig 3 
bioRxiv preprint doi: https://doi.org/10.1101/861146; this version posted December 2, 2019. The copyright holder for this preprint (which was not certified by peer review) is the author/funder. All rights reserved. No reuse allowed without permission.

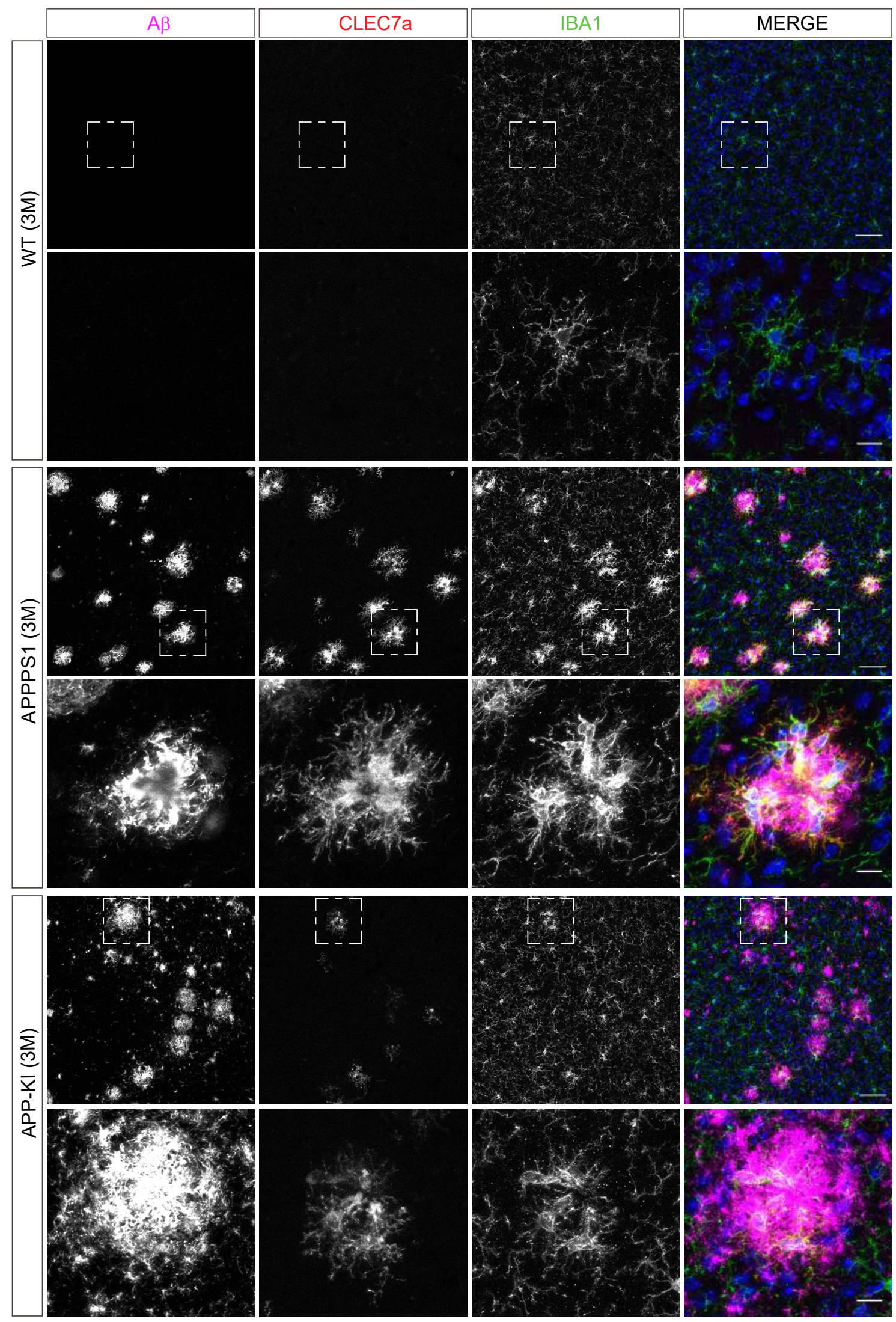

Fig 4 
bioRxiv preprint doi: https://doi.org/10.1101/861146; this version posted December 2, 2019. The copyright holder for this preprint (which was not certified by peer review) is the author/funder. All rights reserved. No reuse allowed without permission.

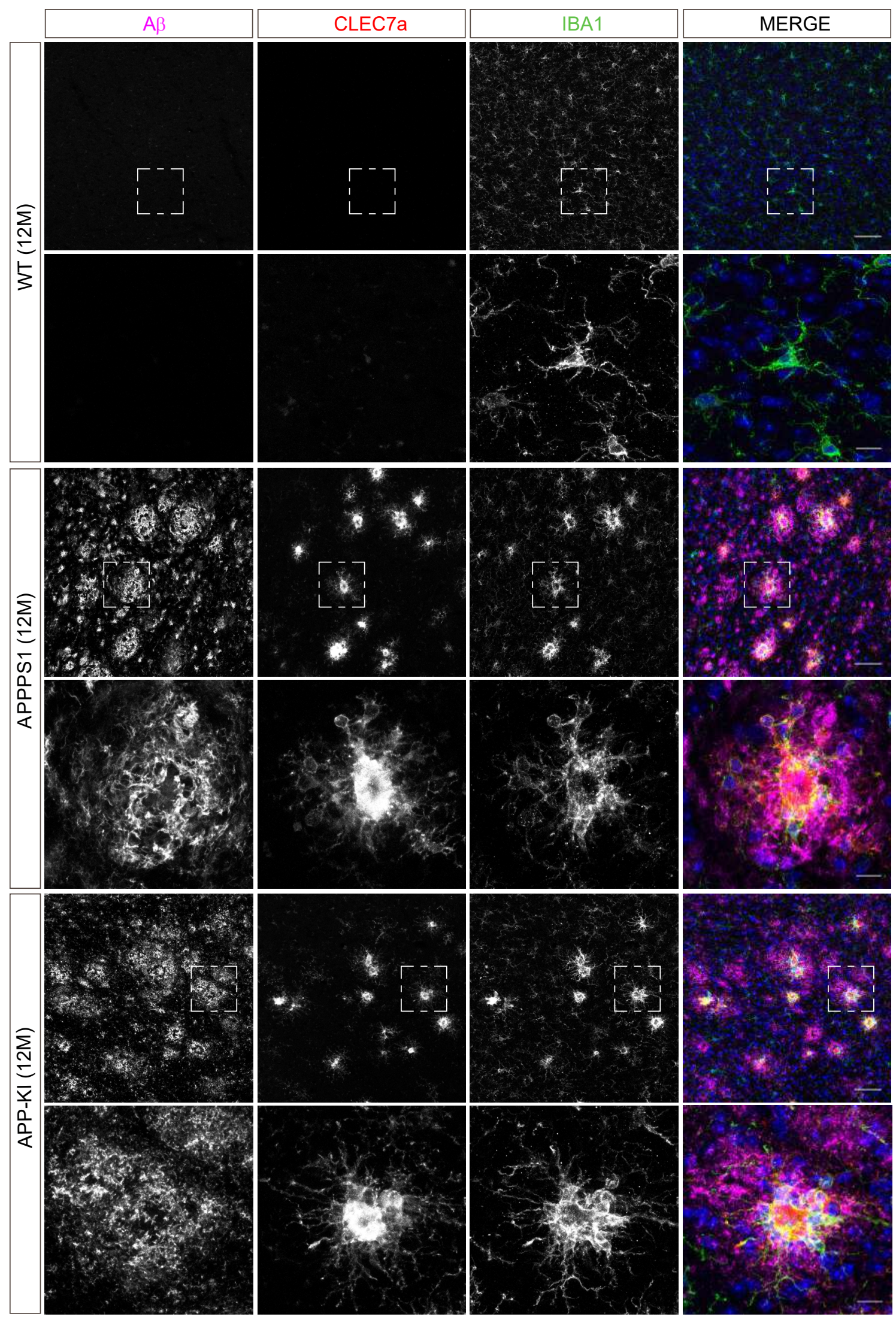

Fig 5 
bioRxiv preprint doi: https://doi.org/10.1101/861146; this version posted December 2, 2019. The copyright holder for this preprint (which was not certified by peer review) is the author/funder. All rights reserved. No reuse allowed without permission.

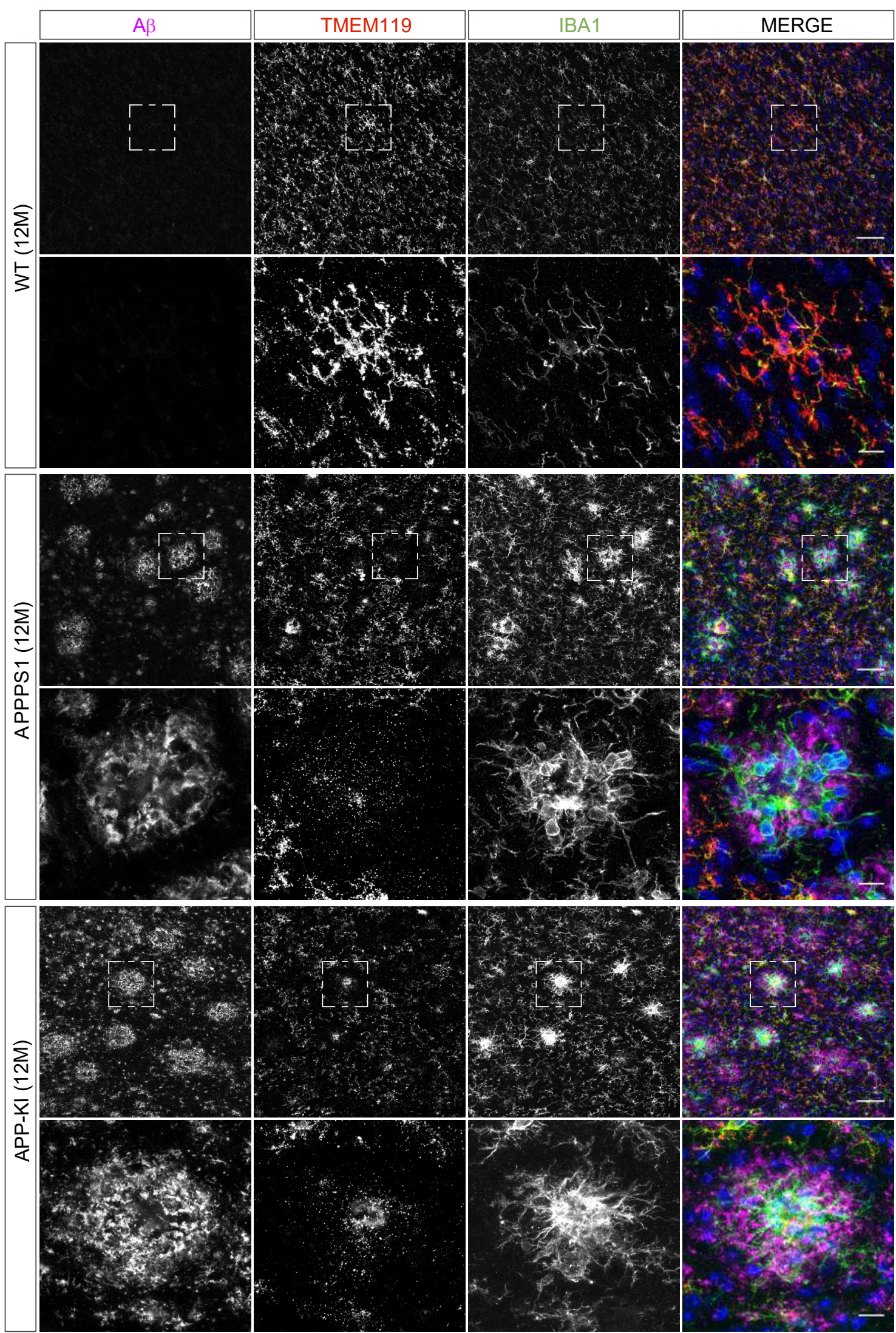


bioRxiv preprint doi: https://doi.org/10.1101/861146; this version posted December 2, 2019. The copyright holder for this preprint (which was not certified by peer review) is the author/funder. All rights reserved. No reuse allowed without permission.

A

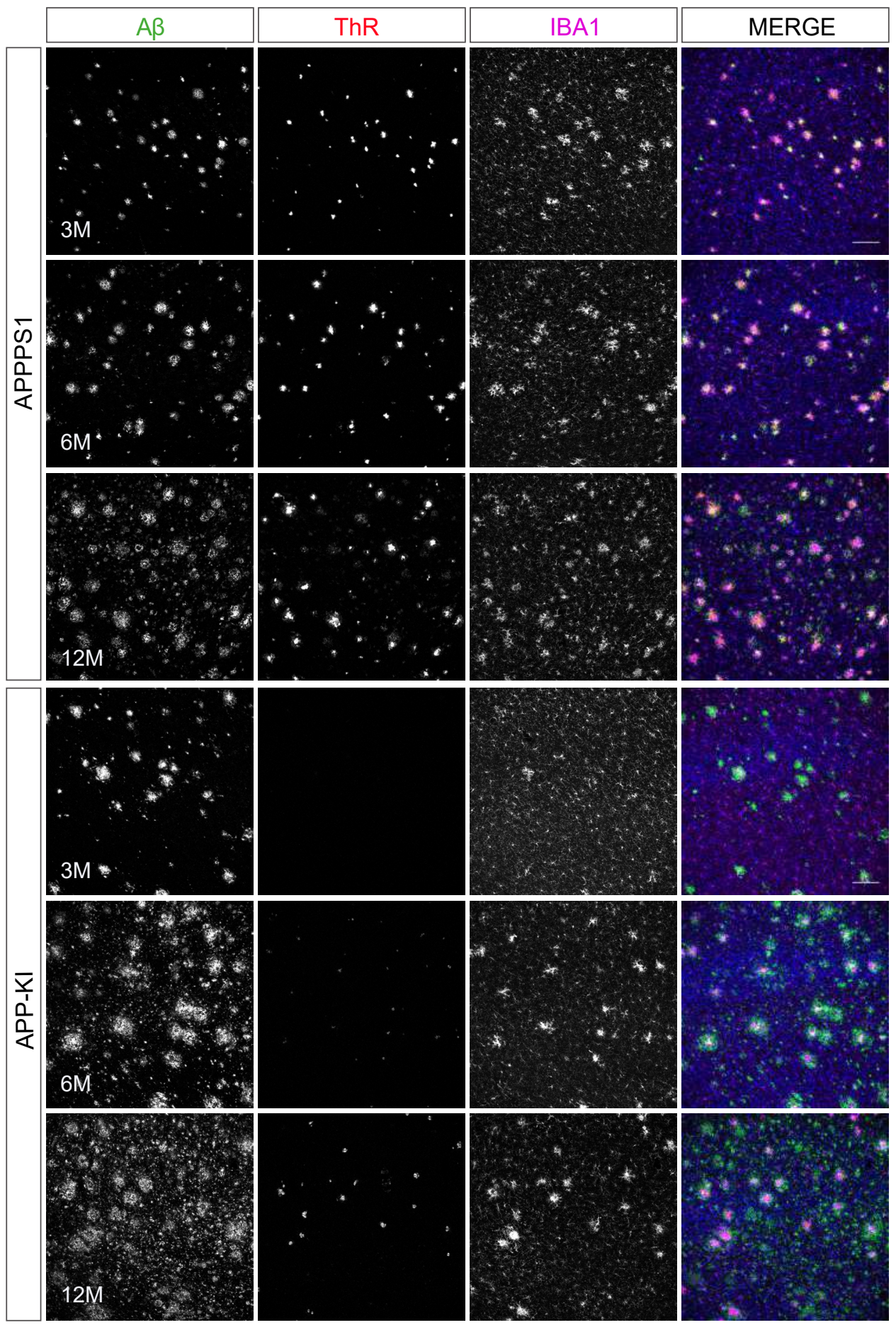

B

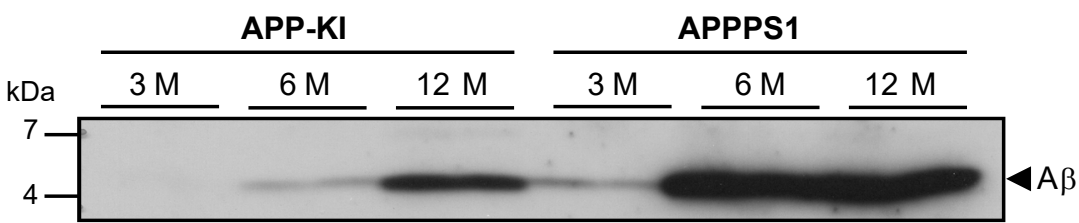


bioRxiv preprint doi: https://doi.org/10.1101/861146; this version posted December 2, 2019. The copyright holder for this preprint (which was not certified by peer review) is the author/funder. All rights reserved. No reuse allowed without permission.

A

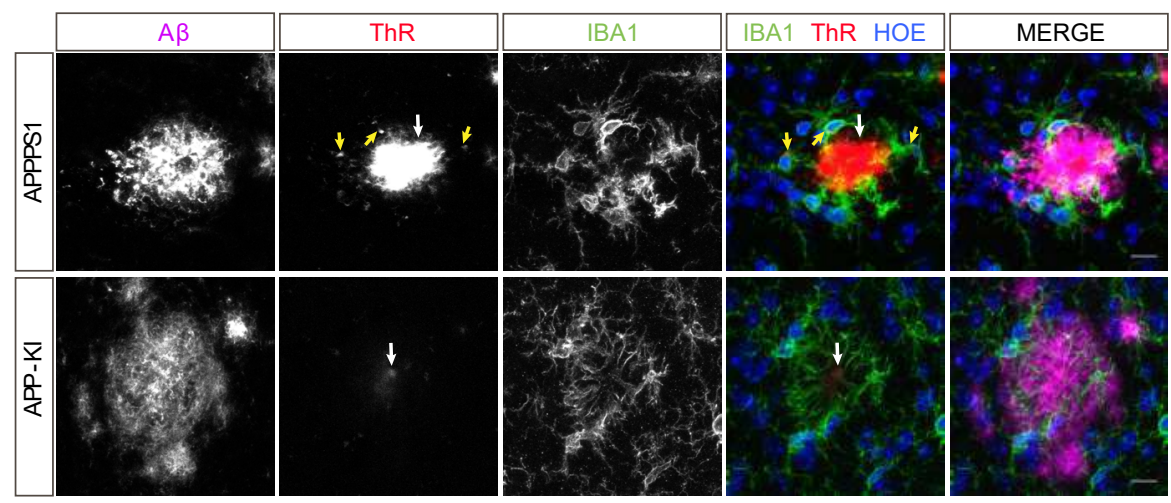

D

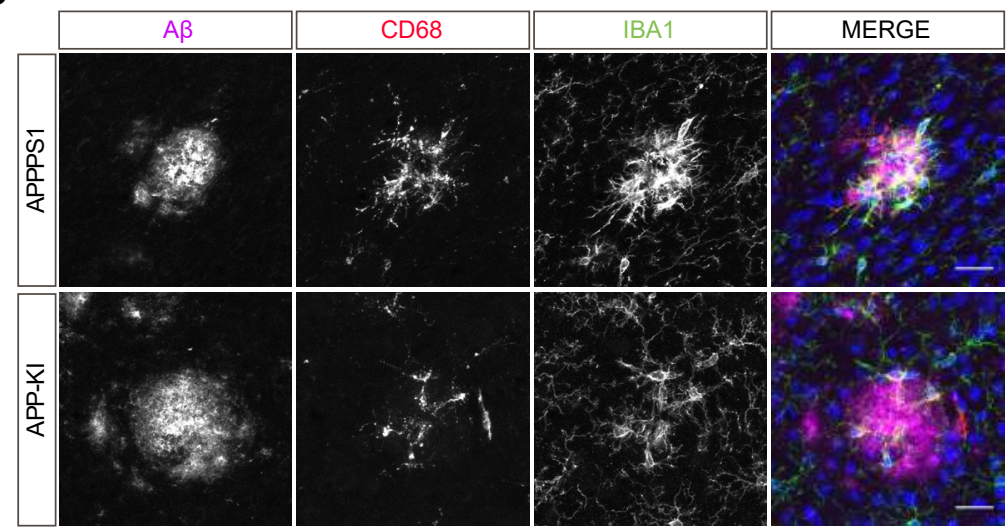

G

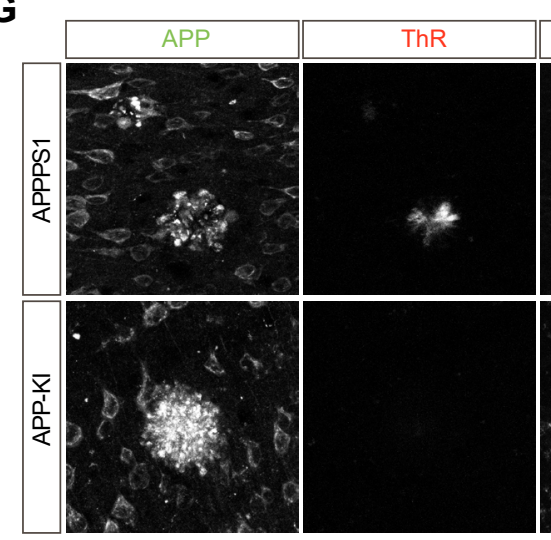

I
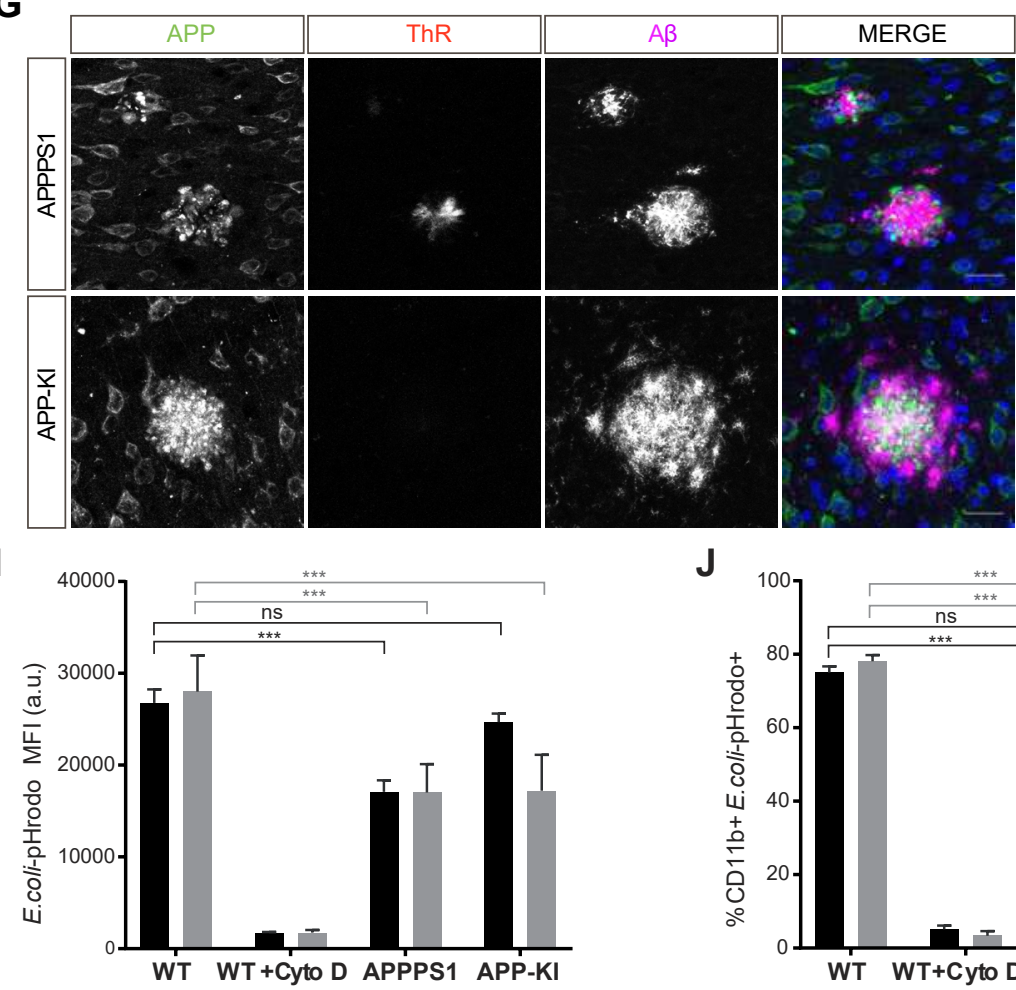

B

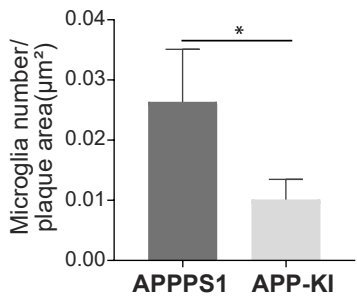

C
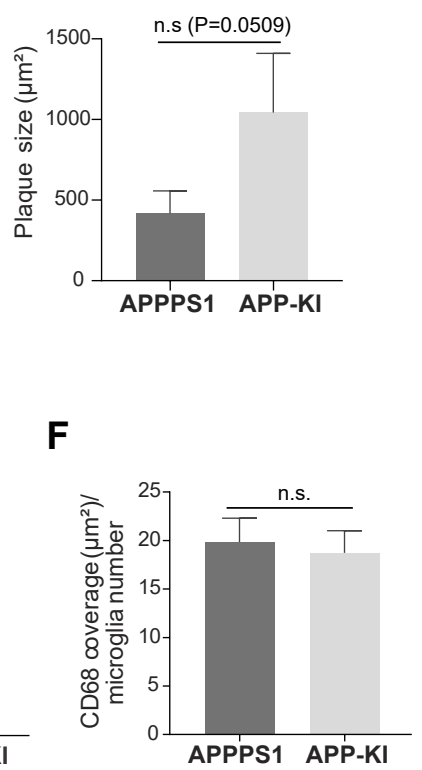

F
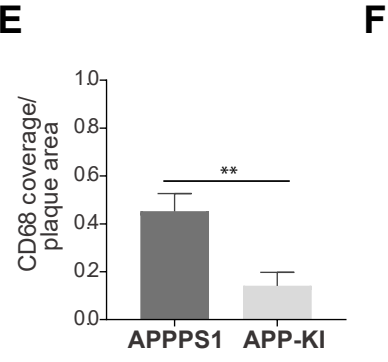

H

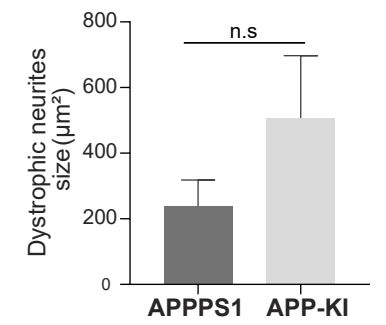

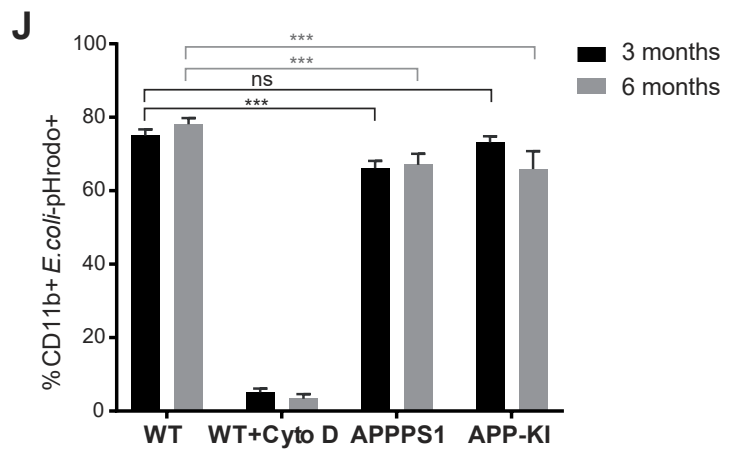

Fig 8 
bioRxiv preprint doi: https://doi.org/10.1101/861146; this version posted December 2, 2019. The copyright holder for this preprint (which was not certified by peer review) is the author/funder. All rights reserved. No reuse allowed without permission.

A
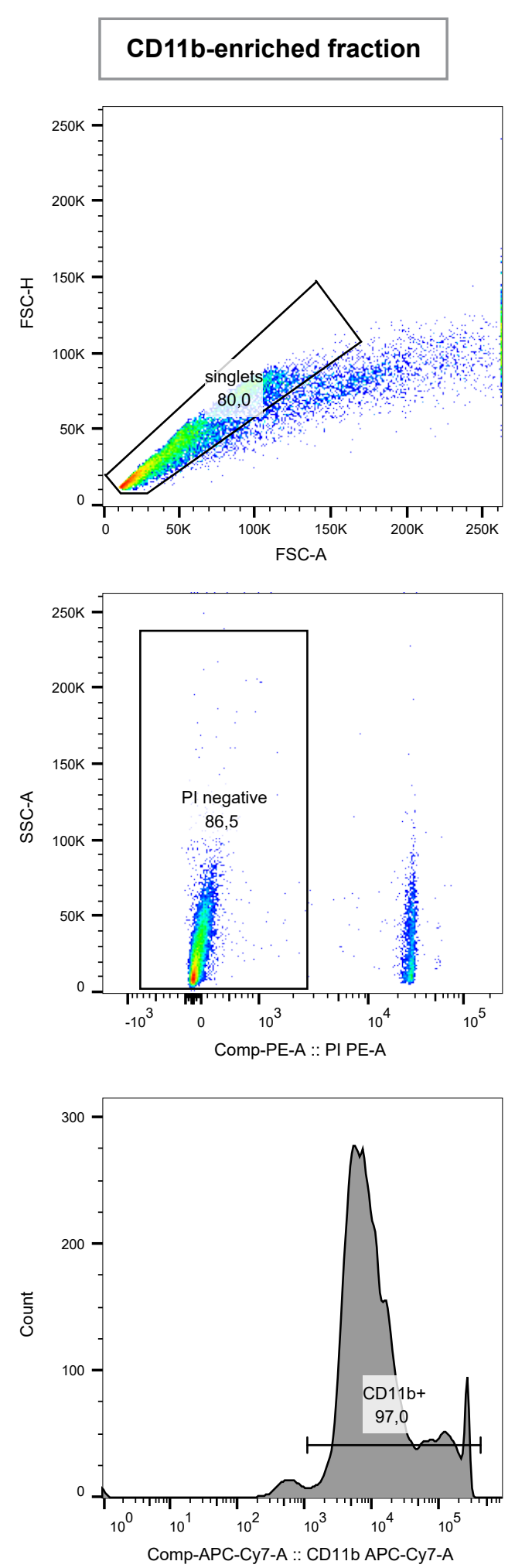

B
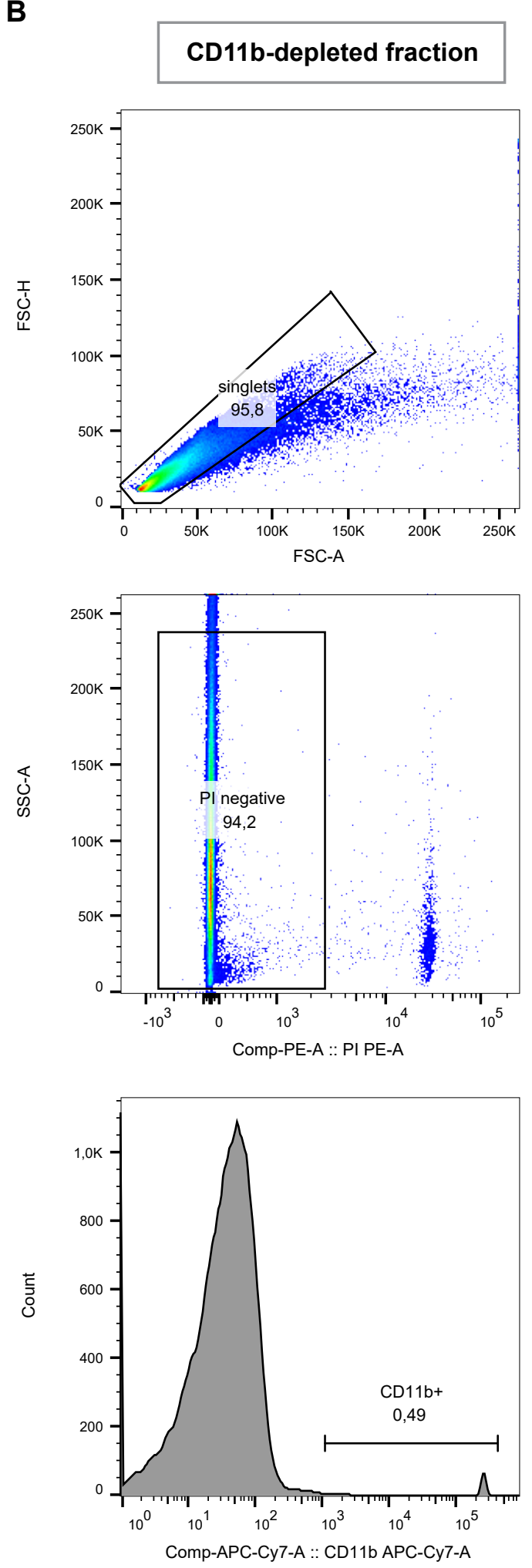
A bioRxiv preprint doi: https://doi.org/10.1101/861146; this version posted December 2, 2019. The copyright holder for this preprint (which was APPPS1/
WT

B

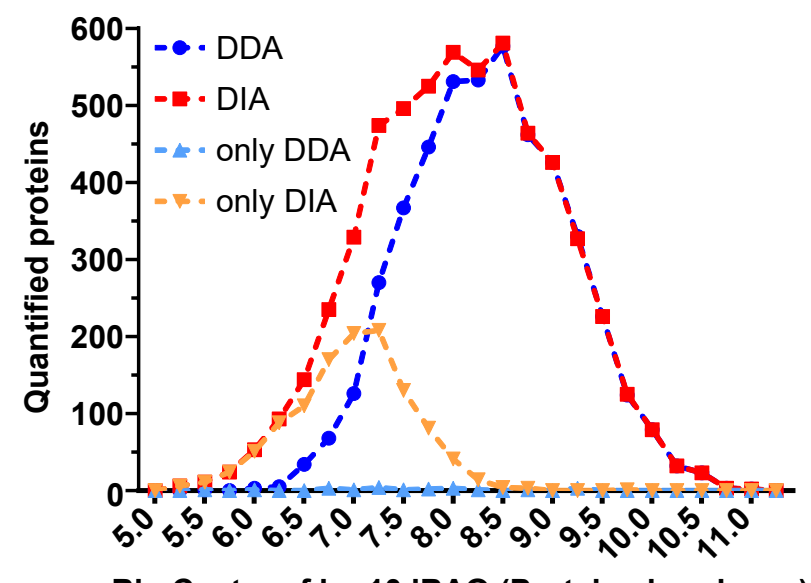

Bin Center of log10 iBAQ (Protein abundance)
C

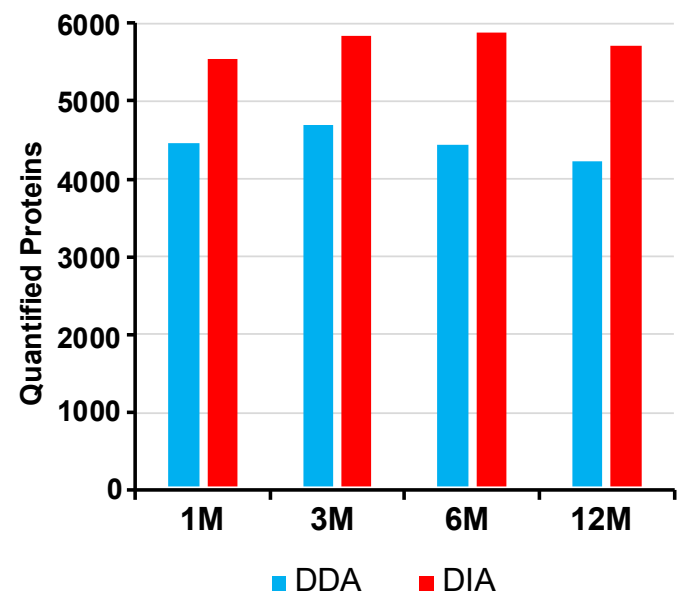

D

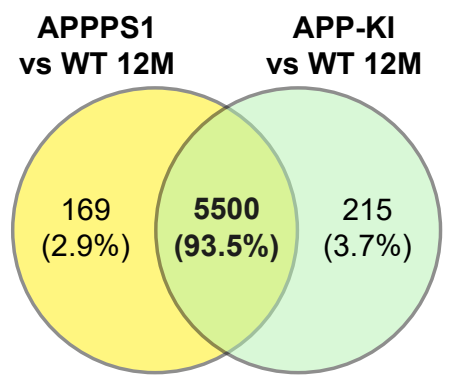


bioRxiv preprint doi: https://doi.org/10.1101/861146; this version posted December 2, 2019. The copyright holder for this preprint (which was not certified by peer review) is the author/funder. All rights reserved. No reuse allowed without permission.

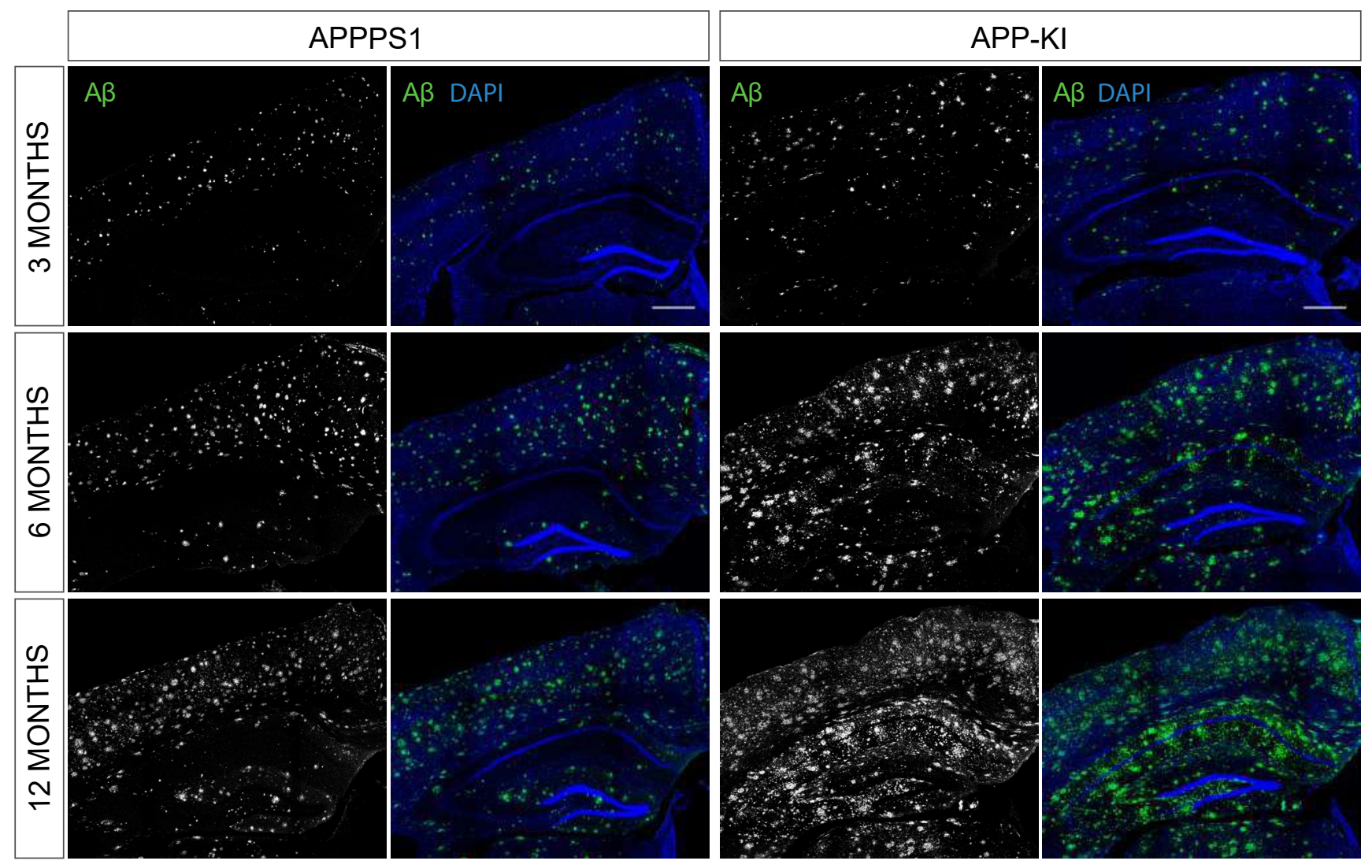


A bioRxiv preprint doi: https://doi.org/10.1101/861146; thB version posted December 2, 2019. The copyright holder for this preprint (which was APPPS1
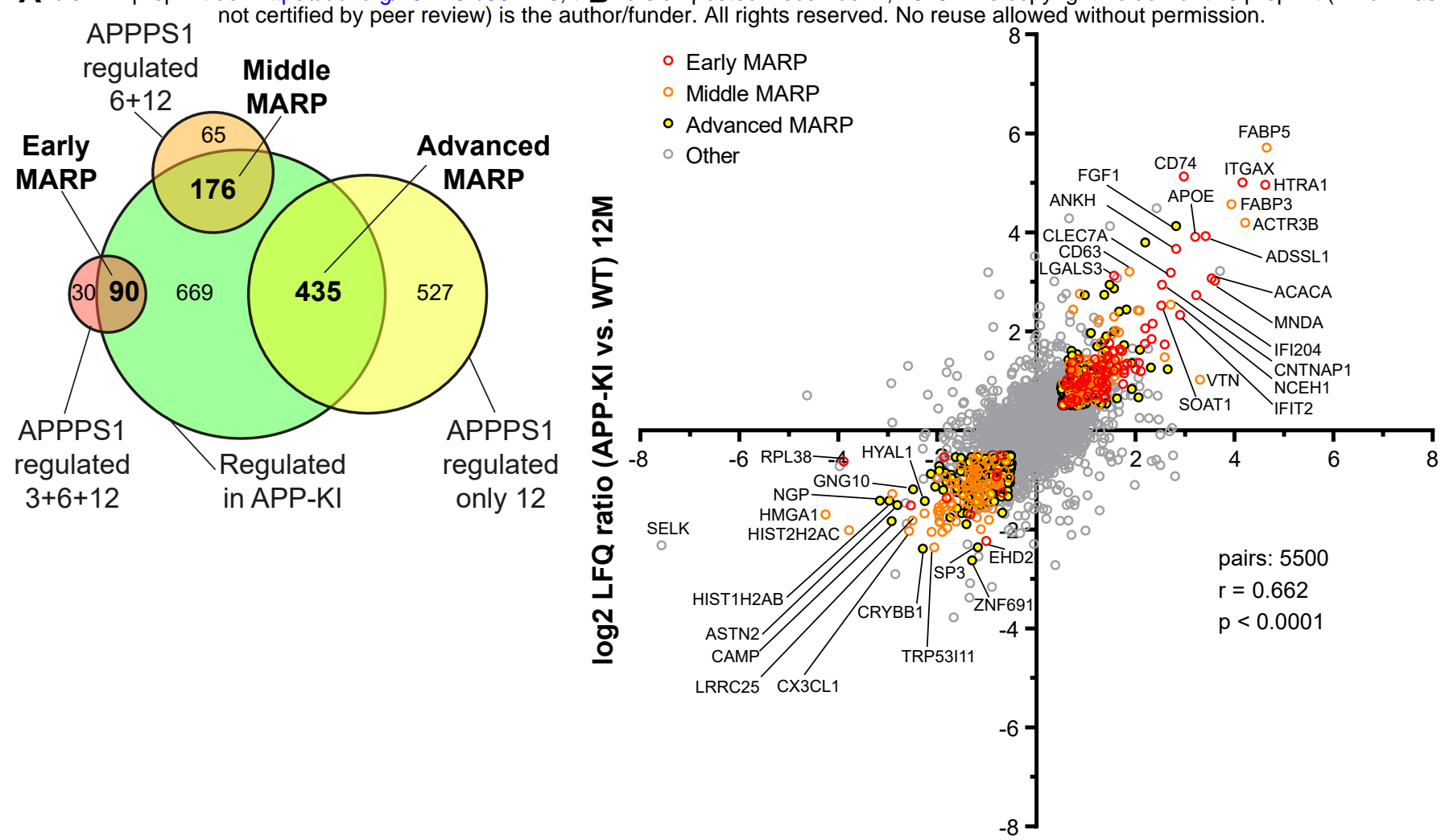

log2 LFQ ratio (APPPS1 vs. WT) 12M

\section{C}

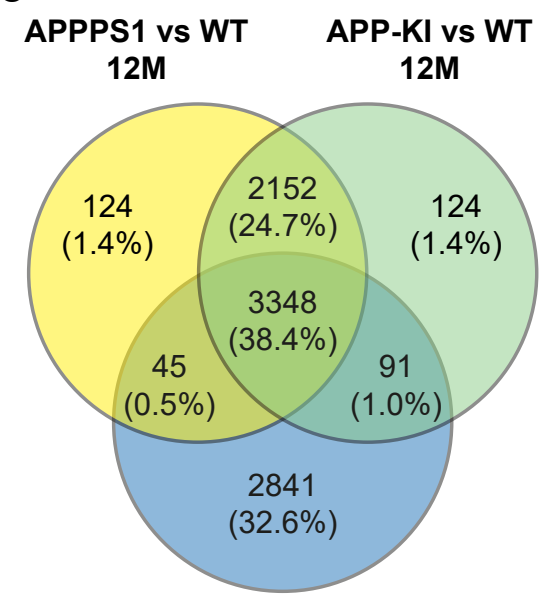

Keren-Shaul

\section{D}

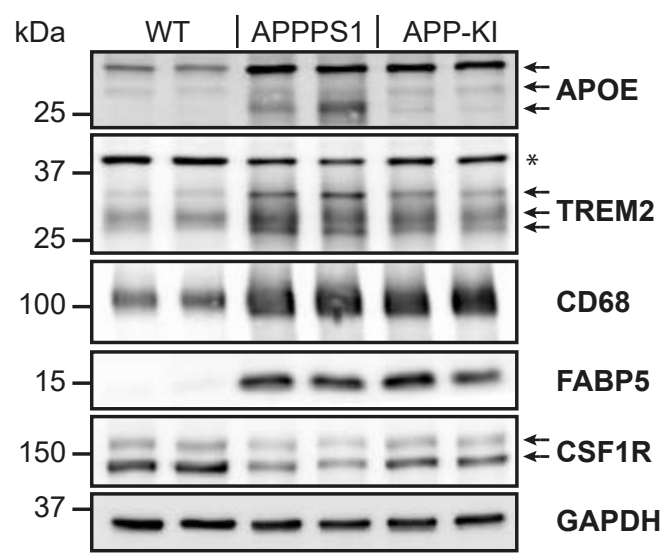


bioR Aiv preprint doi: https://doi.org/10.1101/861146; this version posted December 2 2019. The gopyright holder for this preprint (which was

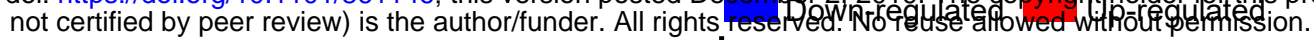

Cell surface + MHC complex Lytic vacuole + lysosome + endosome

Golgi apparatus Endoplasmic reticulum Membrane raft + cytoplasmic membrane-bound vesicle

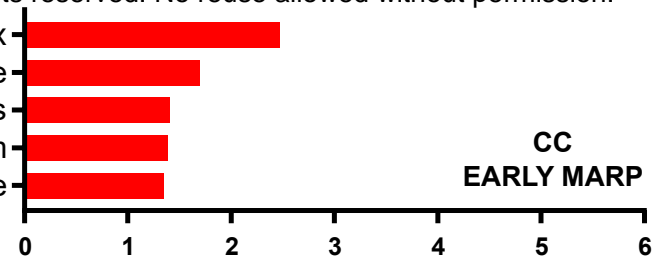

B

C

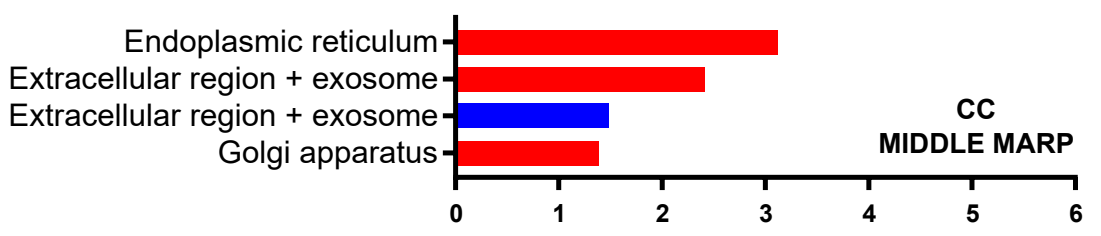

Extrinsic comp. of plasma mem.+ G-protein complex

Extracellular region + exosome

Endoplasmic reticulum

Cell-cell + cell-substrate junction

Golgi apparatus

Cell leading edge membrane + ruffle membrane

Bicellular tight + occluding + apicaljunction

Vacuole + endosome

Extracellular region + exosome Integral component of organelle/Golgi membrane Lytic vacuole + lysosome Lytic vacuole + lysosome + endosome

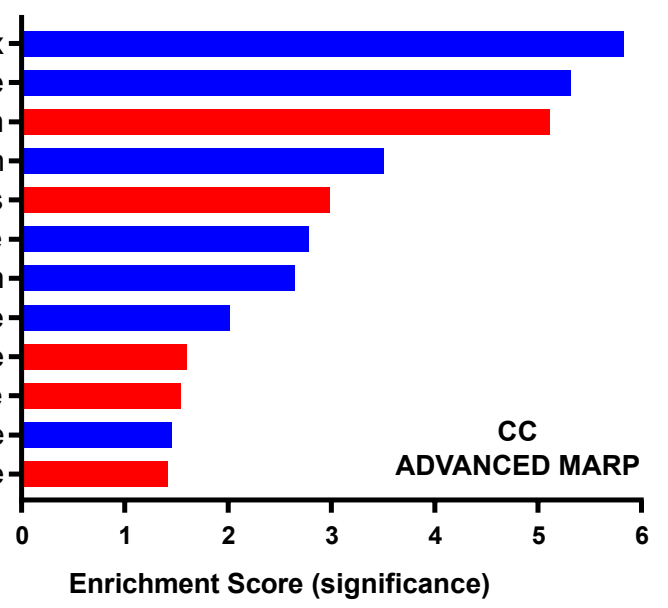

D

Peptide antigen + receptor binding Receptor + signal transducer activity

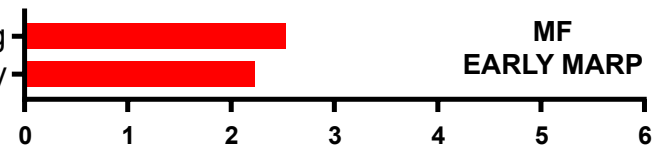

E

Receptor + signal transducer activity Glycosaminoglycan + heparin binding lon binding

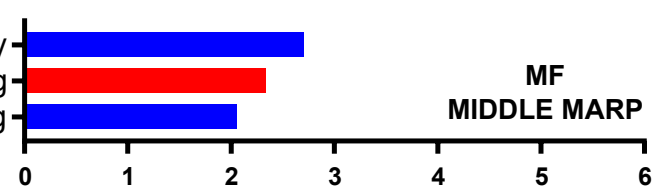

Receptor + signal transducer activity

Glycosyltransferase activity + carbohydrate binding

Molecular function + enzyme + GTPase regulator

Lipid + phospholipid + phosphatidylinositol binding

Active transmembrane transporter + ATPase activity

Aldehyde dehydrogenase + oxidoreductase activity

Protein kinase regulator activity

Passive transmem. transporter + ion channel activity

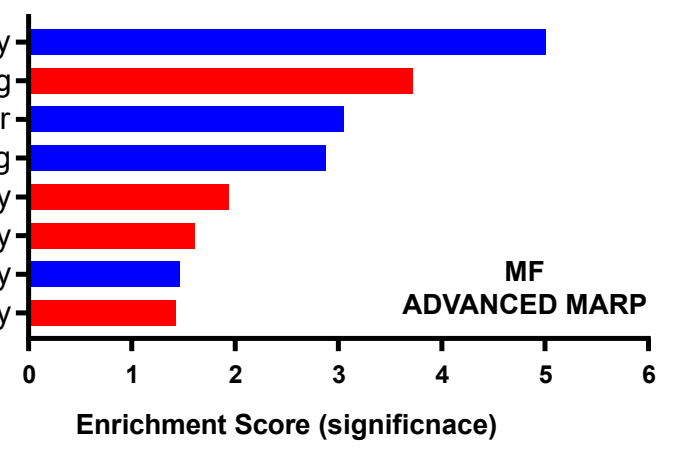


bioRxiv preprint doi: https://doi.org/10.1101/861146; this version posted December 2, 2019. The copyright holder for this preprint (which was not certified by peer review) is the author/funder. All rights reserved. No reuse allowed without permission.

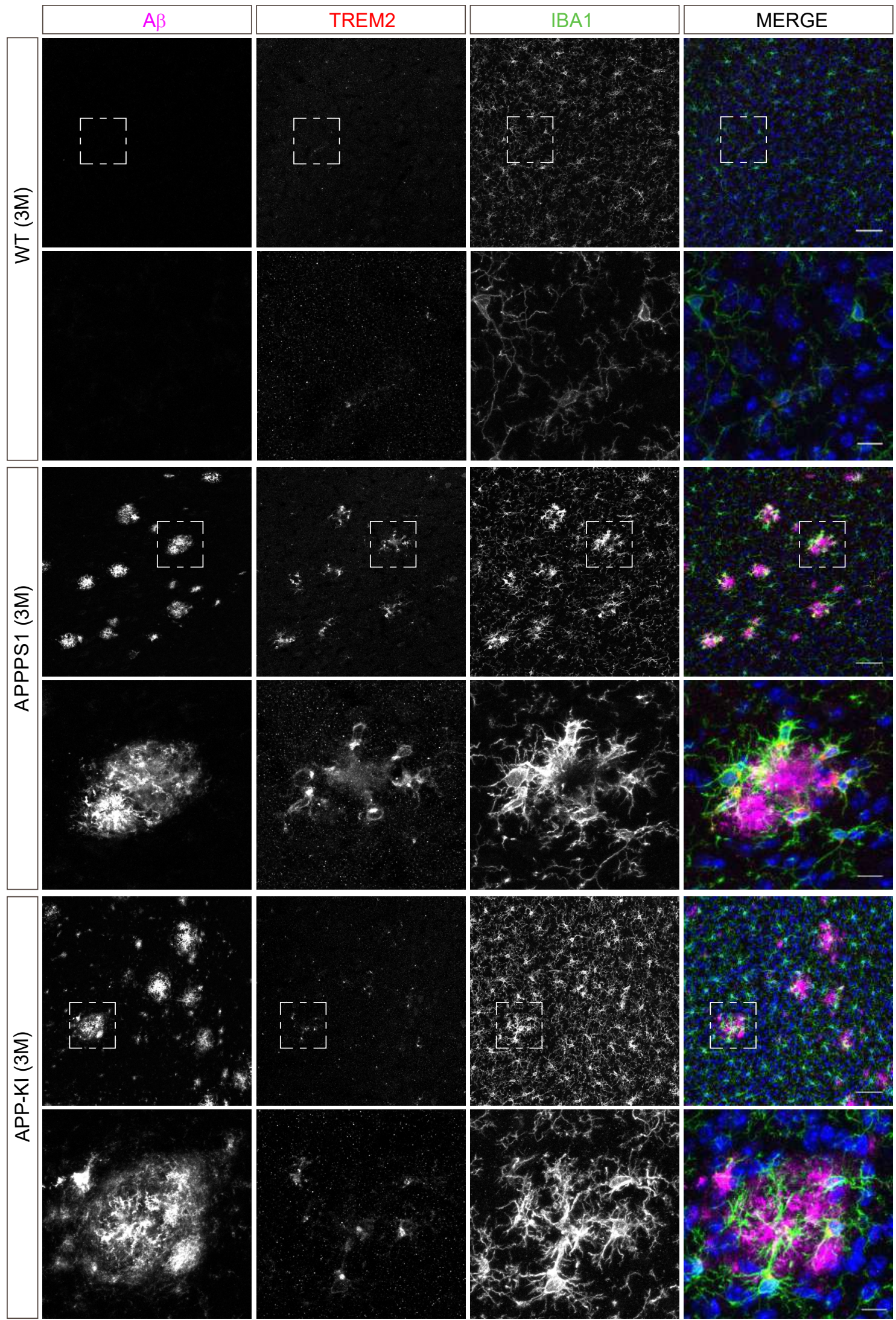

Suppl. Fig 6 
bioRxiv preprint doi: https://doi.org/10.1101/861146; this version posted December 2, 2019. The copyright holder for this preprint (which was not certified by peer review) is the author/funder. All rights reserved. No reuse allowed without permission.

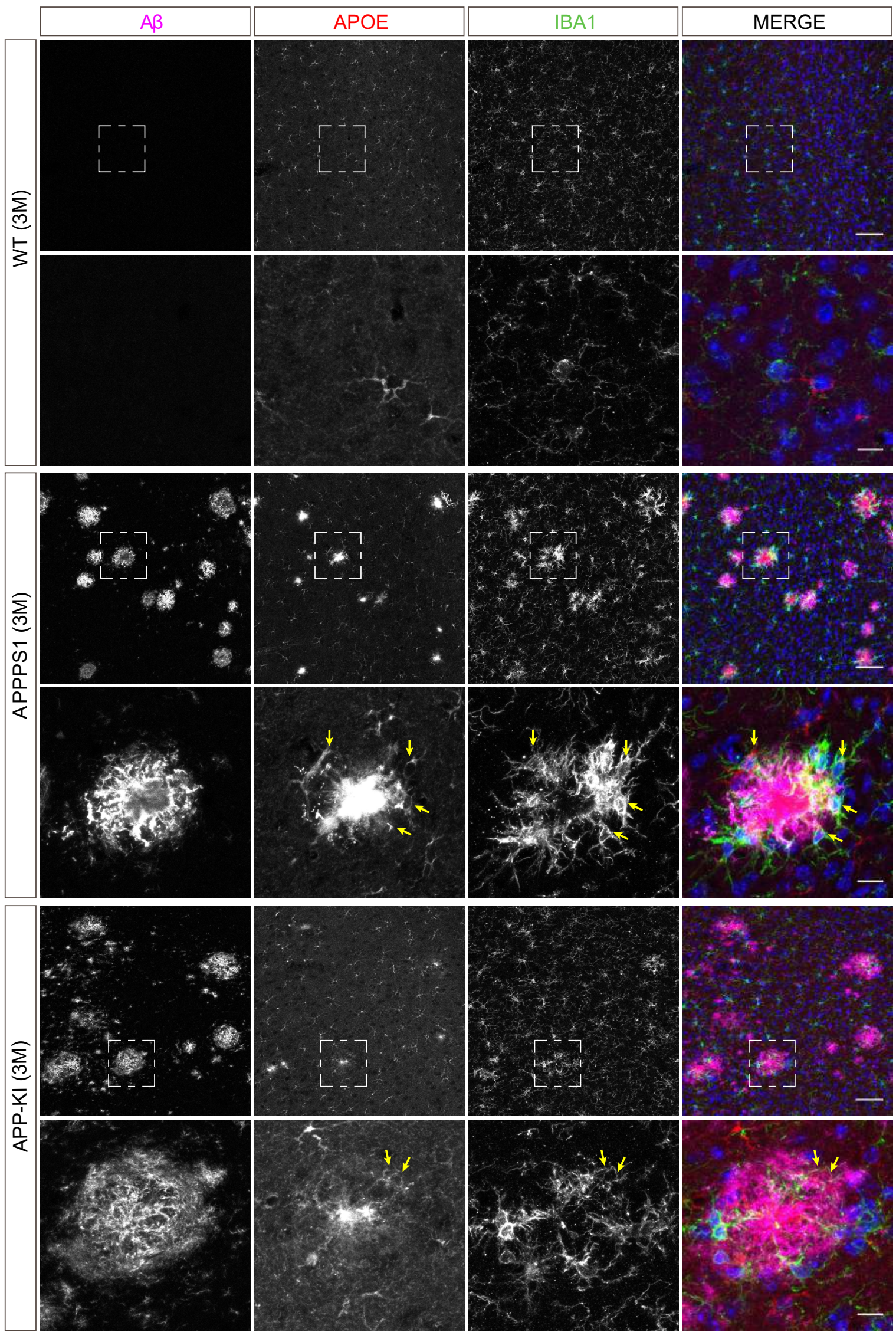

Suppl. Fig 7 
bioRxiv preprint doi: https://doi.org/10.1101/861146; this version posted December 2, 2019. The copyright holder for this preprint (which was

A E.coli-pHrodo-Mean fluorescent intensity - 3 months

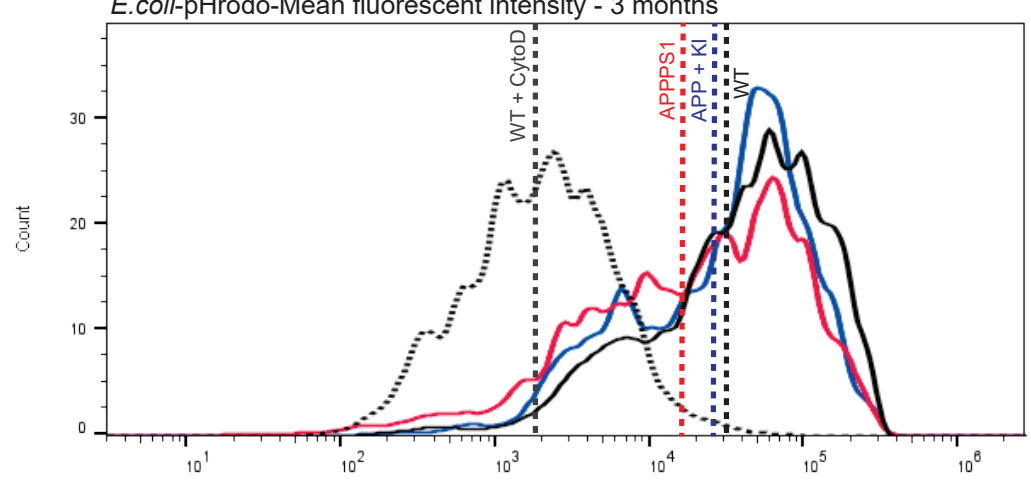

Comp-FITC-A;: GFP FITC-A. MFI (geom. mean)

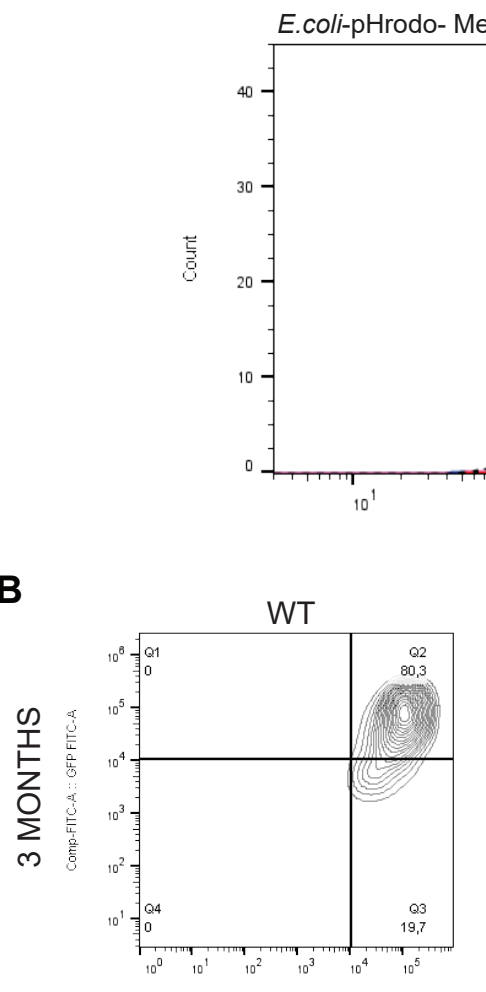

Comp-APC-CY7-A. CD11b APC-CY7.A.

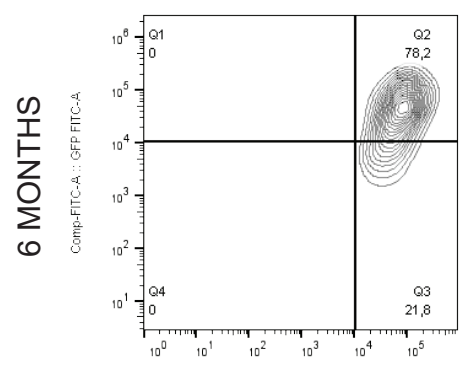

B

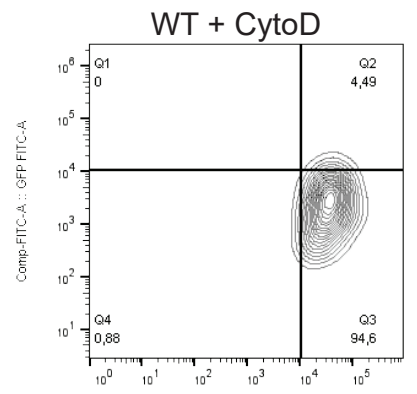

Comp-APC-CY7-A: CD11b APCCCY7.A.

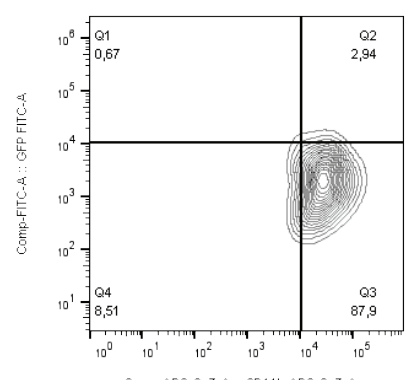

Sample (3M)

WT

WT + CytoD

APPPS1

$\mathrm{APP}+\mathrm{KI}$
MFI (geom. mean)

30298

1925

16365

24561

\section{Sample (6M) MFI (geom. mean)}

WT

28836

WT + CytoD 1626

APPPS1 16930

$\mathrm{APP}+\mathrm{KI}$
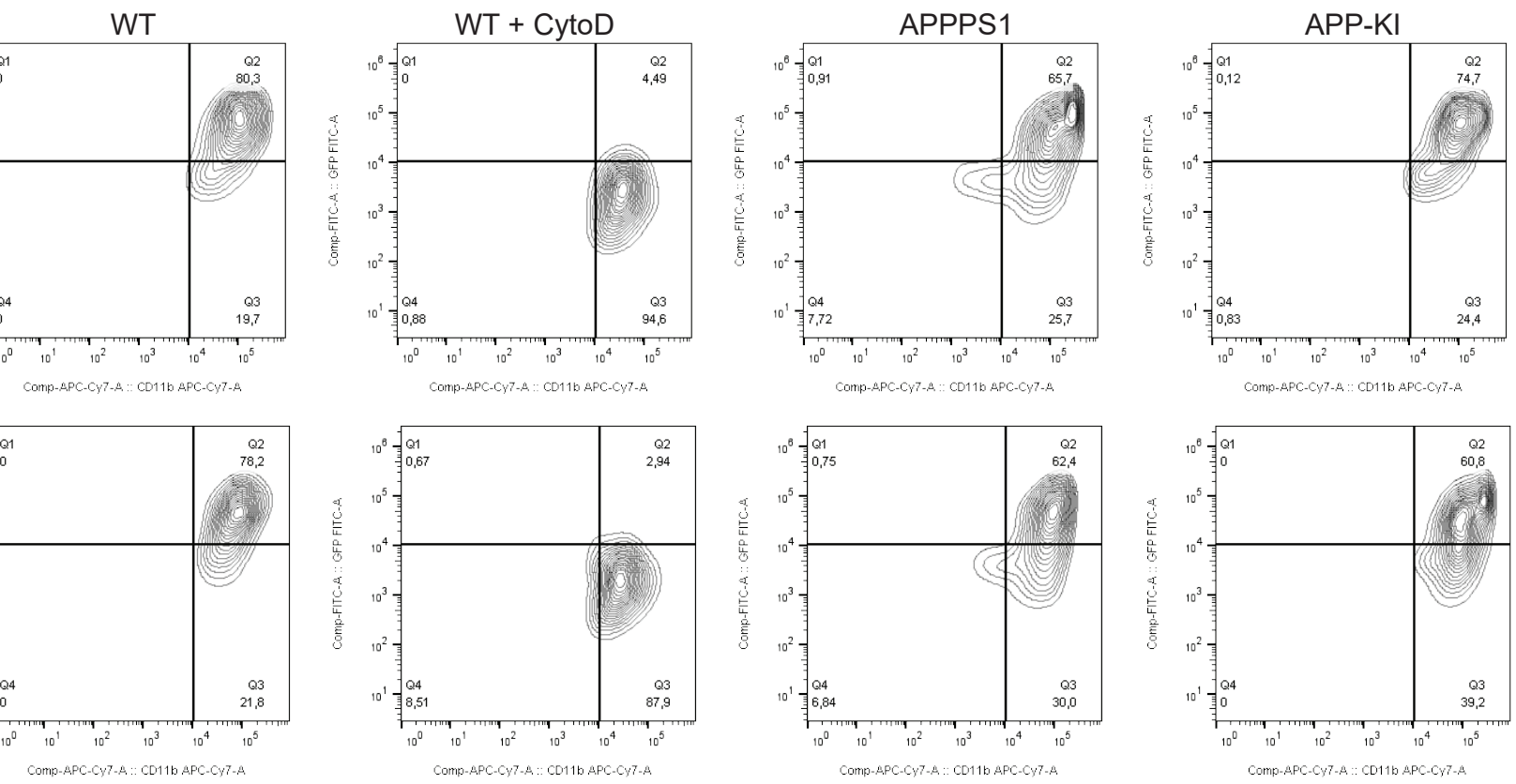

Comp-APCC.CY7.A : CD 11 b APC-CY7.A

Comp-APC-CY7-A: CO11b APC-CY7-A.
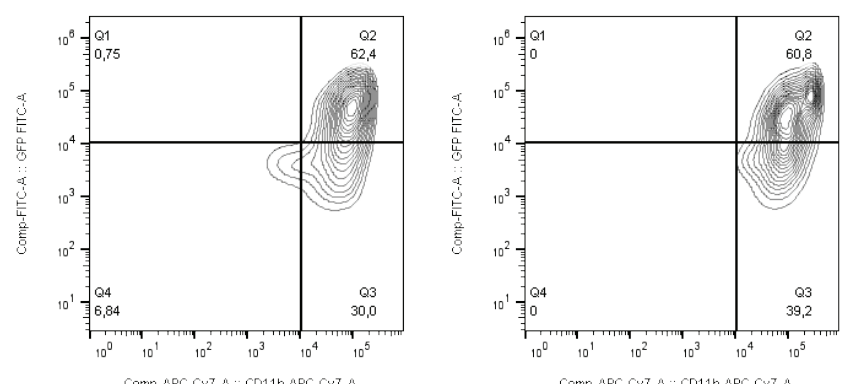


\section{Supplementary Tables}

Suppl. Table 1: Optimized mass to charge $(\mathrm{m} / \mathrm{z})$ window distribution for Sequential Window Acquisition of all theoretical Mass Spectra (SWATH-MS) based on DIA.

\begin{tabular}{|c|c|c|c|c|}
\hline Window & m/z start & $m / z$ end & Center & Isolation width $[\mathrm{m} / \mathrm{z}]$ \\
\hline 1 & 300 & 360 & 330 & 60 \\
\hline 2 & 359 & 399 & 379 & 40 \\
\hline 3 & 398 & 428 & 413 & 30 \\
\hline 4 & 427 & 452 & 439.5 & 25 \\
\hline 5 & 451 & 475 & 463 & 24 \\
\hline 6 & 474 & 497 & 485.5 & 23 \\
\hline 7 & 496 & 518 & 507 & 22 \\
\hline 8 & 517 & 539 & 528 & 22 \\
\hline 9 & 538 & 560 & 549 & 22 \\
\hline 10 & 559 & 581 & 570 & 22 \\
\hline 11 & 580 & 602 & 591 & 22 \\
\hline 12 & 601 & 623 & 612 & 22 \\
\hline 13 & 622 & 646 & 634 & 24 \\
\hline 14 & 645 & 669 & 657 & 24 \\
\hline 15 & 668 & 694 & 681 & 26 \\
\hline 16 & 693 & 719 & 706 & 26 \\
\hline 17 & 718 & 746 & 732 & 28 \\
\hline 18 & 745 & 777 & 761 & 32 \\
\hline 19 & 776 & 808 & 792 & 32 \\
\hline 20 & 807 & 839 & 823 & 32 \\
\hline 21 & 838 & 870 & 854 & 32 \\
\hline 22 & 869 & 904 & 886.5 & 35 \\
\hline 23 & 903 & 943 & 923 & 40 \\
\hline 24 & 942 & 1,122 & 1,032 & 180 \\
\hline 25 & 1,121 & 1,401 & 1,261 & 280 \\
\hline
\end{tabular}


Suppl. Table 2: Comparison of proteomic results of APPPS1 microglia from DDA and DIA including the average peptide IDs, protein IDs, protein quantifications calculated for all samples, numbers of relatively quantified proteins from 1, 3, 6, and 12 months as well as their averages.

\begin{tabular}{|l|r|r|r|}
\hline & \multicolumn{1}{|l|}{ DDA } & \multicolumn{1}{l|}{ DIA } & \multicolumn{1}{c|}{$\begin{array}{c}\text { DIA vs } \\
\text { DDA }\end{array}$} \\
\hline Overall Average Peptide IDs & 53912 & 74281 & $137.8 \%$ \\
\hline Overall Average Protein IDs & 5502 & 5953 & $108.2 \%$ \\
\hline Overall Average Protein Quantifications & 5053 & 5952 & $117.8 \%$ \\
\hline Relative quantifications (3 vs 3) APPPS1 vs WT 1M & 4425 & 5491 & $124.1 \%$ \\
\hline Relative quantifications (3 vs 3) APPPS1 vs WT 3M & 4646 & 5789 & $124.6 \%$ \\
\hline Relative quantifications (3 vs 3) APPPS1 vs WT 6M & 4391 & 5848 & $133.2 \%$ \\
\hline Relative quantifications (3 vs 3) APPPS1 vs WT 12M & 4185 & 5669 & $135.5 \%$ \\
\hline Average of relative quantifications & 4412 & 5699 & $129.3 \%$ \\
\hline
\end{tabular}

Suppl. Table 3: Quantitative proteomic data analysis of APPPS1 (A) and APP-KI (B) versus WT microglia at $1,3,6$, and 12 months using DIA. The table shows the number of consistently quantified proteins as well as proteins with a significant up- or down-regulation with and without FDR correction. A log2 fold change $>0.5$ or $<-0.5$ and a p-value of less than 0.05 were applied as regulation thresholds. The amount of up-and downregulated proteins with FDR correction is shown as percentage from the total number of quantified proteins.

\begin{tabular}{|c|c|c|c|c|}
\hline & $\begin{array}{c}\text { APPPS1 } \\
\text { vs } \\
\text { WT } \\
\text { 1M }\end{array}$ & $\begin{array}{c}\text { APPPS1 } \\
\text { vS } \\
\text { WT } \\
\text { 3M }\end{array}$ & $\begin{array}{c}\text { APPPS1 } \\
\text { vs } \\
\text { WT } \\
\text { 6M }\end{array}$ & $\begin{array}{c}\text { APPPS1 } \\
\text { vs } \\
\text { WT } \\
\text { 12M }\end{array}$ \\
\hline Quantifications (3 vs 3) & 5491 & 5789 & 5848 & 5669 \\
\hline Regulated & 98 & 1010 & 679 & 1409 \\
\hline Up-regulated & 76 & 332 & 365 & 776 \\
\hline Down-regulated & 22 & 678 & 314 & 633 \\
\hline Up-regulated FDR corrected & 0 & 332 & 309 & 776 \\
\hline Down-regulated FDR corrected & 0 & 678 & 261 & 633 \\
\hline Up-regulated FDR corrected (\%) & $0.0 \%$ & $5.7 \%$ & $5.3 \%$ & $13.7 \%$ \\
\hline Down-regulated FDR corrected (\%) & $0.0 \%$ & $11.7 \%$ & $4.5 \%$ & $11.2 \%$ \\
\hline
\end{tabular}

\begin{tabular}{|c|c|c|c|c|}
\hline & $\begin{array}{c}\text { APP-KI } \\
\text { vs } \\
\text { WT } \\
\text { 1M }\end{array}$ & $\begin{array}{c}\text { APP-KI } \\
\text { vs } \\
\text { WT } \\
\text { 3M }\end{array}$ & $\begin{array}{c}\text { APP-KI } \\
\text { vs } \\
\text { WT } \\
\text { 6M }\end{array}$ & $\begin{array}{c}\text { APP-KI } \\
\text { vs } \\
\text { WT } \\
\text { 12M }\end{array}$ \\
\hline Quantifications (3 vs 3) & 5713 & 5711 & 5653 & 5715 \\
\hline Regulated & 41 & 700 & 559 & 1337 \\
\hline Up-regulated & 19 & 22 & 245 & 704 \\
\hline Down-regulated & 54 & 109 & 267 & 666 \\
\hline Up-regulated FDR corrected & 0 & 1 & 140 & 704 \\
\hline Down-regulated FDR corrected & 0 & 0 & 151 & 666 \\
\hline Up-regulated FDR corrected (\%) & $0.0 \%$ & $0.0 \%$ & $2.5 \%$ & $12.3 \%$ \\
\hline Down-regulated FDR corrected (\%) & $0.0 \%$ & $0.0 \%$ & $2.7 \%$ & $11.7 \%$ \\
\hline
\end{tabular}


Suppl. Table 4: Identified early, middle, and advanced MARPs. Protein groups are represented by the major UniProt accession.

\begin{tabular}{|c|c|c|c|c|c|}
\hline \multirow[b]{2}{*}{$\begin{array}{l}\text { Gene } \\
\text { Name }\end{array}$} & \multirow[b]{2}{*}{\begin{tabular}{|l} 
UniProt \\
Accession \\
\end{tabular}} & \multirow[b]{2}{*}{ Protein Name } & \multicolumn{3}{|c|}{ MARPs (up: +1; down: -1) } \\
\hline & & & $\begin{array}{c}\text { Early } \\
\text { MARP }\end{array}$ & $\begin{array}{l}\text { Middle } \\
\text { MARP }\end{array}$ & $\begin{array}{c}\text { Advanced } \\
\text { MARP }\end{array}$ \\
\hline Aacs & Q9D2R0 & Acetoacetyl-CoA synthetase & 0 & 1 & 0 \\
\hline Aagab & Q8R2R3 & Alpha- and gamma-adaptin-binding protein p34 & 0 & 0 & -1 \\
\hline Aak1 & Q3UHJ0 & AP2-associated protein kinase 1 & 0 & 0 & 1 \\
\hline Aarsd1 & Q3THG9 & Alanyl-tRNA editing protein Aarsd1 & 0 & 0 & 1 \\
\hline Abca9 & Q8K449 & ATP-binding cassette sub-family A member 9 & 0 & -1 & 0 \\
\hline Abcb1b & P06795 & Multidrug resistance protein $1 \mathrm{~B}$ & 0 & 1 & 0 \\
\hline Abcd2 & Q61285 & ATP-binding cassette sub-family D member 2 & 0 & 1 & 0 \\
\hline Abcg3 & Q99P81 & ATP-binding cassette sub-family G member 3 & 0 & 0 & 1 \\
\hline Abhd15 & Q5F2F2 & Protein ABHD15 & 0 & -1 & 0 \\
\hline Abil & Q8CBW3 & Abl interactor 1 & 0 & 0 & -1 \\
\hline Abi3 & Q8BYZ1 & ABI gene family member 3 & 0 & 0 & -1 \\
\hline Acaca & Q5SWU9 & Acetyl-CoA carboxylase 1 & 1 & 0 & 0 \\
\hline Acbd3 & Q8BMP6 & Golgi resident protein GCP60 & 0 & 0 & 1 \\
\hline Acot11 & Q8VHQ9 & Acyl-coenzyme A thioesterase 11 & 0 & 0 & 1 \\
\hline Acox3 & Q9EPL9 & Peroxisomal acyl-coenzyme A oxidase 3 & 0 & 1 & 0 \\
\hline Acsbg1 & Q99PU5 & Long-chain-fatty-acid--CoA ligase ACSBG1 & 0 & 0 & 1 \\
\hline Acss2 & Q9QXG4 & Acetyl-coenzyme A synthetase, cytoplasmic & 0 & 0 & 1 \\
\hline Actn1 & Q7TPR4 & Alpha-actinin-1 & 0 & -1 & 0 \\
\hline Actn4 & P57780 & Alpha-actinin-4 & 0 & 0 & -1 \\
\hline Actr3b & Q641P0 & Actin-related protein $3 \mathrm{~B}$ & 0 & 1 & 0 \\
\hline Ada & P03958 & Adenosine deaminase & 0 & -1 & 0 \\
\hline Adam 15 & O88839 & Disintegrin and metalloproteinase domain-containing protein 15 & 0 & 0 & -1 \\
\hline Adam 22 & Q9R1V6 & Disintegrin and metalloproteinase domain-containing protein 22 & 0 & 0 & 1 \\
\hline Adap2 & Q8R2V5 & Arf-GAP with dual PH domain-containing protein 2 & 0 & -1 & 0 \\
\hline Add2 & Q9QYB8 & Beta-adducin & 0 & 0 & 1 \\
\hline Adgre1 & Q61549 & Adhesion $\mathrm{G}$ protein-coupled receptor E1 & 0 & -1 & 0 \\
\hline Adk & P55264 & Adenosine kinase & 0 & 0 & 1 \\
\hline Adss & P46664 & Adenylosuccinate synthetase isozyme 2 & 0 & 1 & 0 \\
\hline Adssl1 & P28650 & Adenylosuccinate synthetase isozyme 1 & 1 & 0 & 0 \\
\hline
\end{tabular}




\begin{tabular}{|c|c|c|c|c|c|}
\hline \multirow[b]{2}{*}{$\begin{array}{l}\text { Gene } \\
\text { Name } \\
\end{array}$} & \multirow[b]{2}{*}{$\begin{array}{l}\text { UniProt } \\
\text { Accession }\end{array}$} & \multirow[b]{2}{*}{ Protein Name } & \multicolumn{3}{|c|}{ MARPs (up: +1; down: -1) } \\
\hline & & & $\begin{array}{c}\text { Early } \\
\text { MARP }\end{array}$ & $\begin{array}{l}\text { Middle } \\
\text { MARP }\end{array}$ & $\begin{array}{c}\text { Advanced } \\
\text { MARP }\end{array}$ \\
\hline Ahcy & P50247 & Adenosylhomocysteinase & 0 & 0 & 1 \\
\hline Aif1 & O70200 & Allograft inflammatory factor 1 & 0 & 0 & -1 \\
\hline Akap5 & D3YVF0 & A-kinase anchor protein 5 & 0 & 0 & 1 \\
\hline Akt3 & Q9WUA6 & RAC-gamma serine/threonine-protein kinase & 0 & 0 & 1 \\
\hline Alb & $\mathrm{P} 07724$ & Serum albumin & 0 & -1 & 0 \\
\hline Aldh1b1 & Q9CZS1 & Aldehyde dehydrogenase $\mathrm{X}$, mitochondrial & 0 & 0 & 1 \\
\hline Aldh111 & Q8R0Y6 & Cytosolic 10-formyltetrahydrofolate dehydrogenase & 0 & 0 & 1 \\
\hline Aldh112 & Q8K009 & Mitochondrial 10-formyltetrahydrofolate dehydrogenase & 0 & 0 & 1 \\
\hline Aldh2 & $\mathrm{P} 47738$ & Aldehyde dehydrogenase, mitochondrial & 0 & 0 & 1 \\
\hline Aldoa & P05064 & Fructose-bisphosphate aldolase A & 0 & 1 & 0 \\
\hline $\mathrm{Alg} 10 \mathrm{~b}$ & Q3UGP8 & Putative Dol-P-Glc:Glc(2)Man(9)GlcNAc(2)-PP-Dol alpha-1,2-glucosyltransferase & 0 & 0 & 1 \\
\hline Ankh & Q9JHZ2 & Progressive ankylosis protein & 1 & 0 & 0 \\
\hline Anks1a & P59672 & Ankyrin repeat and SAM domain-containing protein $1 \mathrm{~A}$ & 0 & 0 & -1 \\
\hline Anxa1 & P10107 & Annexin A1 & 0 & 0 & -1 \\
\hline Anxa2 & P07356 & Annexin A2 & 0 & 1 & 0 \\
\hline Anxa5 & P48036 & Annexin A5 & 0 & 1 & 0 \\
\hline Ap1s1 & P61967 & AP-1 complex subunit sigma-1A & 0 & 0 & 1 \\
\hline Ap4b1 & Q9WV76 & AP-4 complex subunit beta-1 & 0 & 1 & 0 \\
\hline Apod & P51910 & Apolipoprotein D & 0 & 1 & 0 \\
\hline Apoe & P08226 & Apolipoprotein E & 1 & 0 & 0 \\
\hline Arhgap12 & Q8C0D4 & Rho GTPase-activating protein 12 & 0 & -1 & 0 \\
\hline Arhgap22 & Q8BL80 & Rho GTPase-activating protein 22 & 0 & 0 & -1 \\
\hline Arhgap30 & Q640N3 & Rho GTPase-activating protein 30 & 0 & 0 & -1 \\
\hline Arhgap31 & A6X8Z5 & Rho GTPase-activating protein 31 & 0 & 0 & -1 \\
\hline Arhgdib & Q61599 & Rho GDP-dissociation inhibitor 2 & 0 & 0 & -1 \\
\hline Arl6ip4 & Q9JM93 & ADP-ribosylation factor-like protein 6-interacting protein 4 & 0 & -1 & 0 \\
\hline Arrb2 & Q91YI4 & Beta-arrestin-2 & 0 & -1 & 0 \\
\hline Arsa & P50428 & Arylsulfatase A & 0 & 0 & -1 \\
\hline Arsg & Q3TYD4 & Arylsulfatase $\mathrm{G}$ & 0 & 0 & -1 \\
\hline Asah1 & Q9WV54 & Acid ceramidase & 0 & -1 & 0 \\
\hline
\end{tabular}




\begin{tabular}{|c|c|c|c|c|c|}
\hline \multirow[b]{2}{*}{$\begin{array}{l}\text { Gene } \\
\text { Name } \\
\end{array}$} & \multirow[b]{2}{*}{$\begin{array}{l}\text { UniProt } \\
\text { Accession }\end{array}$} & \multirow[b]{2}{*}{ Protein Name } & \multicolumn{3}{|c|}{ MARPs (up: +1; down: -1) } \\
\hline & & & $\begin{array}{c}\text { Early } \\
\text { MARP }\end{array}$ & $\begin{array}{l}\text { Middle } \\
\text { MARP }\end{array}$ & $\begin{array}{c}\text { Advanced } \\
\text { MARP }\end{array}$ \\
\hline Asph & Q8BSY0 & Aspartyl/asparaginyl beta-hydroxylase & 0 & 0 & 1 \\
\hline Astn2 & Q80Z10 & Astrotactin-2 & 0 & 0 & -1 \\
\hline $\operatorname{Atg} 2 \mathrm{a}$ & Q6P4T0 & Autophagy-related protein 2 homolog A & 0 & 0 & 1 \\
\hline $\operatorname{Atg} 7$ & Q9D906 & Ubiquitin-like modifier-activating enzyme ATG7 & 0 & 0 & 1 \\
\hline Atp1b2 & P14231 & Sodium/potassium-transporting ATPase subunit beta- 2 & 0 & 0 & 1 \\
\hline Atp1b3 & P97370 & Sodium/potassium-transporting ATPase subunit beta-3 & 0 & 0 & 1 \\
\hline Atp6v0a1 & Q9Z1G4 & V-type proton ATPase $116 \mathrm{kDa}$ subunit a isoform 1 & 0 & 0 & 1 \\
\hline Atp6v1a & P50516 & V-type proton ATPase catalytic subunit A & 0 & 0 & 1 \\
\hline Atp6v1b2 & P62814 & V-type proton ATPase subunit B, brain isoform & 0 & 0 & 1 \\
\hline Atp6v1c1 & Q9Z1G3 & V-type proton ATPase subunit C 1 & 0 & 0 & 1 \\
\hline Atp6v1d & P57746 & V-type proton ATPase subunit D & 0 & 0 & 1 \\
\hline Atp6v1e1 & P50518 & V-type proton ATPase subunit E 1 & 0 & 0 & 1 \\
\hline Atp6v1h & Q8BVE3 & V-type proton ATPase subunit $\mathrm{H}$ & 0 & 0 & 1 \\
\hline Atp8a2 & P98200 & Phospholipid-transporting ATPase IB & 0 & 0 & -1 \\
\hline Atxn10 & P28658 & Ataxin-10 & 0 & 0 & 1 \\
\hline B3galnt1 & Q920V1 & UDP-GalNAc:beta-1,3-N-acetylgalactosaminyltransferase 1 & 0 & 0 & -1 \\
\hline B4galt5 & Q9JMK0 & Beta-1,4-galactosyltransferase 5 & 0 & 0 & 1 \\
\hline Baiap2 & Q8BKX1 & Brain-specific angiogenesis inhibitor 1 -associated protein 2 & 0 & 0 & 1 \\
\hline Baz1b & Q9Z277 & Tyrosine-protein kinase BAZ1B & 0 & 0 & -1 \\
\hline Bid & P70444 & BH3-interacting domain death agonist & 0 & 0 & -1 \\
\hline Bin1 & O08539 & Myc box-dependent-interacting protein 1 & 0 & 0 & -1 \\
\hline Bin2 & D3Z6Q9 & Bridging integrator 2 & 0 & -1 & 0 \\
\hline Blvrb & Q923D2 & Flavin reductase (NADPH) & 0 & 0 & -1 \\
\hline Bola2 & Q8BGS2 & BolA-like protein 2 & 1 & 0 & 0 \\
\hline Borcs5 & Q9D920 & BLOC-1-related complex subunit 5 & 0 & 0 & -1 \\
\hline Borcs6 & Q9D6W8 & BLOC-1-related complex subunit 6 & 0 & 0 & -1 \\
\hline Bri3bp & Q8BXV2 & BRI3-binding protein & 0 & 0 & 1 \\
\hline Brix 1 & Q9DCA5 & Ribosome biogenesis protein BRX1 homolog & 0 & 1 & 0 \\
\hline Brk1 & Q91VR8 & Protein BRICK1 & 0 & 0 & -1 \\
\hline C5ar1 & P30993 & C5a anaphylatoxin chemotactic receptor 1 & 0 & 0 & -1 \\
\hline
\end{tabular}




\begin{tabular}{|c|c|c|c|c|c|}
\hline & & & MAI & lp: $+1 ; d$ & $n:-1)$ \\
\hline $\begin{array}{l}\text { Gene } \\
\text { Name }\end{array}$ & $\begin{array}{l}\text { UniProt } \\
\text { Accession }\end{array}$ & Protein Name & $\begin{array}{c}\text { Early } \\
\text { MARP }\end{array}$ & $\begin{array}{l}\text { Middle } \\
\text { MARP }\end{array}$ & $\begin{array}{c}\text { Advanced } \\
\text { MARP }\end{array}$ \\
\hline Calr & $\mathrm{P} 14211$ & Calreticulin & 0 & 0 & 1 \\
\hline Camp & P51437 & Cathelicidin antimicrobial peptide & 0 & 0 & -1 \\
\hline Capg & $\mathrm{P} 24452$ & Macrophage-capping protein & 1 & 0 & 0 \\
\hline Capn1 & $\mathrm{O} 35350$ & Calpain-1 catalytic subunit & 0 & 1 & 0 \\
\hline Casd1 & Q7TN73 & CAS1 domain-containing protein 1 & 0 & 0 & 1 \\
\hline Cask & O70589 & Peripheral plasma membrane protein CASK & 0 & 0 & -1 \\
\hline Cbr2 & $\mathrm{P} 08074$ & Carbonyl reductase [NADPH] 2 & 0 & -1 & 0 \\
\hline $\mathrm{Cc} 2 \mathrm{~d} 1 \mathrm{~b}$ & Q8BRN9 & Coiled-coil and $\mathrm{C} 2$ domain-containing protein $1 \mathrm{~B}$ & 0 & -1 & 0 \\
\hline Ccdc124 & Q9D8X2 & Coiled-coil domain-containing protein 124 & 0 & 0 & -1 \\
\hline Ccdc30 & Q8BVF4 & Coiled-coil domain-containing protein 30 & 0 & 0 & -1 \\
\hline $\operatorname{Ccdc50}$ & Q810U5 & Coiled-coil domain-containing protein 50 & 0 & 0 & -1 \\
\hline Ccdc88a & Q5SNZ0 & Girdin & 0 & 0 & -1 \\
\hline $\mathrm{Ccm} 2$ & Q8K2Y9 & Cerebral cavernous malformations protein 2 homolog & 0 & 0 & -1 \\
\hline Ccnd1 & P25322 & G1/S-specific cyclin-D1 & 0 & 0 & -1 \\
\hline Ccnk & O88874 & Cyclin-K & 0 & 0 & 1 \\
\hline $\mathrm{Cd} 180$ & Q62192 & CD180 antigen & 1 & 0 & 0 \\
\hline $\mathrm{Cd} 48$ & P18181 & CD48 antigen & 1 & 0 & 0 \\
\hline Cd63 & P41731 & CD63 antigen & 0 & 1 & 0 \\
\hline Cd68 & P31996 & Macrosialin & 1 & 0 & 0 \\
\hline $\mathrm{Cd} 74$ & P04441 & H-2 class II histocompatibility antigen gamma chain & 1 & 0 & 0 \\
\hline Cdc42bpb & Q7TT50 & Serine/threonine-protein kinase MRCK beta & 0 & -1 & 0 \\
\hline Cdk6 & Q64261 & Cyclin-dependent kinase 6 & 1 & 0 & 0 \\
\hline Cdk7 & Q03147 & Cyclin-dependent kinase 7 & 0 & 1 & 0 \\
\hline Cep170 & Q6A065 & Centrosomal protein of $170 \mathrm{kDa}$ & 0 & 0 & -1 \\
\hline Cfl1 & $\mathrm{P} 18760$ & Cofilin-1 & 0 & 0 & -1 \\
\hline Chmp3 & Q9CQ10 & Charged multivesicular body protein 3 & 0 & 0 & -1 \\
\hline Chmp6 & P0C0A3 & Charged multivesicular body protein 6 & 0 & 0 & -1 \\
\hline Chst12 & Q99LL3 & Carbohydrate sulfotransferase 12 & 0 & 1 & 0 \\
\hline $\mathrm{Ckb}$ & Q04447 & Creatine kinase B-type & 0 & 0 & -1 \\
\hline Clec5a & Q9R007 & C-type lectin domain family 5 member A & 0 & 0 & -1 \\
\hline
\end{tabular}




\begin{tabular}{|c|c|c|c|c|c|}
\hline & & & MAI & lp: $+1 ; d$ & $\mathrm{n}:-1)$ \\
\hline $\begin{array}{l}\text { Gene } \\
\text { Name }\end{array}$ & \begin{tabular}{|l} 
UniProt \\
Accession
\end{tabular} & Protein Name & $\begin{array}{c}\text { Early } \\
\text { MARP }\end{array}$ & $\begin{array}{l}\text { Middle } \\
\text { MARP }\end{array}$ & $\begin{array}{c}\text { Advanced } \\
\text { MARP }\end{array}$ \\
\hline Clec7a & Q6QLQ4 & C-type lectin domain family 7 member A & 1 & 0 & 0 \\
\hline $\mathrm{Cln} 3$ & Q61124 & Battenin & 1 & 0 & 0 \\
\hline Clstn1 & Q9EPL2 & Calsyntenin-1 & 0 & 0 & -1 \\
\hline Cmklr1 & P97468 & Chemokine-like receptor 1 & 0 & 0 & -1 \\
\hline $\mathrm{Cmtm} 7$ & Q9ESD6 & CKLF-like MARVEL transmembrane domain-containing protein 7 & 0 & -1 & 0 \\
\hline Cnih4 & Q9CX13 & Protein cornichon homolog 4 & 0 & 0 & 1 \\
\hline Cnn2 & Q08093 & Calponin-2 & 0 & -1 & 0 \\
\hline Cnpy2 & Q9QXT0 & Protein canopy homolog 2 & 0 & 0 & 1 \\
\hline Cntnap1 & O54991 & Contactin-associated protein 1 & 1 & 0 & 0 \\
\hline $\operatorname{Cog} 2$ & Q921L5 & Conserved oligomeric Golgi complex subunit 2 & 1 & 0 & 0 \\
\hline $\operatorname{Cog} 5$ & Q8C0L8 & Conserved oligomeric Golgi complex subunit 5 & 1 & 0 & 0 \\
\hline $\operatorname{Cog} 7$ & Q3UM29 & Conserved oligomeric Golgi complex subunit 7 & 0 & 1 & 0 \\
\hline $\operatorname{Cog} 8$ & Q9JJA2 & Conserved oligomeric Golgi complex subunit 8 & 0 & 0 & 1 \\
\hline Colgalt1 & Q8K297 & Procollagen galactosyltransferase 1 & 1 & 0 & 0 \\
\hline Commd1 & Q8K4M5 & COMM domain-containing protein 1 & 0 & 0 & -1 \\
\hline Commd10 & Q8JZY2 & COMM domain-containing protein 10 & 0 & 0 & -1 \\
\hline Commd5 & Q8R395 & COMM domain-containing protein 5 & 0 & 0 & -1 \\
\hline Commd8 & Q9CZG3 & COMM domain-containing protein 8 & 0 & 0 & -1 \\
\hline Coro1b & Q9WUM3 & Coronin-1B & 0 & 0 & -1 \\
\hline $\mathrm{Cpq}$ & Q9WVJ3 & Carboxypeptidase Q & 0 & -1 & 0 \\
\hline Cpsf31 & Q9CWS4 & Integrator complex subunit 11 & 1 & 0 & 0 \\
\hline Crip1 & P63254 & Cysteine-rich protein 1 & 0 & 1 & 0 \\
\hline Crlf3 & Q9Z2L7 & Cytokine receptor-like factor 3 & 0 & 0 & -1 \\
\hline Crybb1 & Q9WVJ5 & Beta-crystallin B1 & 0 & 0 & -1 \\
\hline Csad & Q9DBE0 & Cysteine sulfinic acid decarboxylase & 0 & 0 & -1 \\
\hline Csf1r & P09581 & Macrophage colony-stimulating factor 1 receptor & 0 & 0 & -1 \\
\hline Csrp2 & P97314 & Cysteine and glycine-rich protein 2 & 0 & -1 & 0 \\
\hline Cst3 & $\mathrm{P} 21460$ & Cystatin-C & 0 & 0 & -1 \\
\hline Cstb & Q62426 & Cystatin-B & 0 & 1 & 0 \\
\hline Cstf3 & Q99LI7 & Cleavage stimulation factor subunit 3 & 0 & 0 & 1 \\
\hline
\end{tabular}




\begin{tabular}{|c|c|c|c|c|c|}
\hline & & & MAI & lp: $+1 ; d$ & $\mathrm{n}:-1)$ \\
\hline $\begin{array}{l}\text { Gene } \\
\text { Name }\end{array}$ & $\begin{array}{l}\text { UniProt } \\
\text { Accession }\end{array}$ & Protein Name & $\begin{array}{c}\text { Early } \\
\text { MARP }\end{array}$ & $\begin{array}{l}\text { Middle } \\
\text { MARP }\end{array}$ & $\begin{array}{c}\text { Advanced } \\
\text { MARP }\end{array}$ \\
\hline Ctbs & Q8R242 & Di-N-acetylchitobiase & 0 & -1 & 0 \\
\hline Ctnnb1 & Q02248 & Catenin beta-1 & 0 & 0 & 1 \\
\hline Ctsa & P16675 & Lysosomal protective protein & 0 & 0 & 1 \\
\hline Ctsd & $\mathrm{P} 18242$ & Cathepsin D & 1 & 0 & 0 \\
\hline Ctsh & P49935 & Pro-cathepsin H & 1 & 0 & 0 \\
\hline Ctsz & Q9WUU7 & Cathepsin Z & 1 & 0 & 0 \\
\hline Cttnbp2nl & Q99LJ0 & CTTNBP2 N-terminal-like protein & 0 & 0 & -1 \\
\hline Cutc & Q9D8X1 & Copper homeostasis protein cutC homolog & 0 & 0 & 1 \\
\hline Cux1 & P53564 & Homeobox protein cut-like 1 & 0 & 0 & 1 \\
\hline $\mathrm{Cx} 3 \mathrm{cl} 1$ & O35188 & Fractalkine & 0 & -1 & 0 \\
\hline $\mathrm{Cx} 3 \mathrm{cr} 1$ & Q9Z0D9 & CX3C chemokine receptor 1 & 0 & -1 & 0 \\
\hline Cybb & Q61093 & Cytochrome b-245 heavy chain & 0 & 0 & 1 \\
\hline Cyfip1 & Q7TMB8 & Cytoplasmic FMR1-interacting protein 1 & 0 & 0 & -1 \\
\hline Cyhr1 & Q9QXA1 & Cysteine and histidine-rich protein 1 & 0 & 1 & 0 \\
\hline Cyp20a1 & Q8BKE6 & Cytochrome P450 20A1 & 0 & 0 & 1 \\
\hline Cyth4 & Q80YW0 & Cytohesin-4 & 0 & 0 & -1 \\
\hline Dalrd3 & Q6PJN8 & DALR anticodon-binding domain-containing protein 3 & 0 & 0 & -1 \\
\hline Dapp1 & Q9QXT1 & Dual adapter for phosphotyrosine and 3-phosphotyrosine and 3-phosphoinositide & 0 & -1 & 0 \\
\hline Dcxr & Q91X52 & L-xylulose reductase & 0 & 0 & -1 \\
\hline $\mathrm{Ddb} 2$ & Q99J79 & DNA damage-binding protein 2 & 0 & 1 & 0 \\
\hline Ddx31 & Q6NZQ2 & Probable ATP-dependent RNA helicase DDX31 & 0 & 1 & 0 \\
\hline Ddx5 & Q61656 & Probable ATP-dependent RNA helicase DDX5 & 0 & 0 & -1 \\
\hline Dennd1c & Q8CFK6 & DENN domain-containing protein $1 \mathrm{C}$ & 0 & 0 & -1 \\
\hline Dffa & O54786 & DNA fragmentation factor subunit alpha & 0 & 0 & -1 \\
\hline Dhcr7 & O88455 & 7-dehydrocholesterol reductase & 0 & 1 & 0 \\
\hline Dhrs3 & O88876 & Short-chain dehydrogenase/reductase 3 & 1 & 0 & 0 \\
\hline Dhx32 & Q8BZS9 & Putative pre-mRNA-splicing factor ATP-dependent RNA helicase DHX32 & 1 & 0 & 0 \\
\hline Dhx58 & Q99J87 & Probable ATP-dependent RNA helicase DHX58 & 1 & 0 & 0 \\
\hline Dip2b & Q3UH60 & Disco-interacting protein 2 homolog B & 0 & 0 & -1 \\
\hline Dkc1 & Q9ESX5 & H/ACA ribonucleoprotein complex subunit 4 & 1 & 0 & 0 \\
\hline
\end{tabular}




\begin{tabular}{|c|c|c|c|c|c|}
\hline \multirow[b]{2}{*}{$\begin{array}{l}\text { Gene } \\
\text { Name } \\
\end{array}$} & \multirow[b]{2}{*}{ UniProtAccession } & \multirow[b]{2}{*}{ Protein Name } & \multicolumn{3}{|c|}{ MARPs (up: +1; down: -1) } \\
\hline & & & EarlyMARP & $\begin{array}{c}\text { MiddleMA } \\
\text { RP }\end{array}$ & $\begin{array}{c}\text { Advanced } \\
\text { MARP }\end{array}$ \\
\hline Dnaja2 & Q9QYJ0 & DnaJ homolog subfamily A member 2 & 0 & 0 & -1 \\
\hline Dnajb14 & Q149L6 & DnaJ homolog subfamily B member 14 & 1 & 0 & 0 \\
\hline Dock10 & Q8BZN6 & Dedicator of cytokinesis protein 10 & 0 & 0 & -1 \\
\hline Dock4 & P59764 & Dedicator of cytokinesis protein 4 & 0 & 0 & -1 \\
\hline Dok1 & P97465 & Docking protein 1 & 0 & 0 & -1 \\
\hline Dok3 & Q9QZK7 & Docking protein 3 & 0 & 0 & -1 \\
\hline Dpagt1 & P42867 & UDP-N-acetylglucosamine--dolichyl-phosphate N-acetylglucosaminephosphotransferase & 0 & 0 & 1 \\
\hline Dpy1914 & A2AJQ3 & Probable C-mannosyltransferase DPY19L4 & 0 & 0 & 1 \\
\hline Dusp3 & Q9D7X3 & Dual specificity protein phosphatase 3 & 0 & 0 & 1 \\
\hline Dynlt3 & P56387 & Dynein light chain Tctex-type 3 & 0 & 0 & 1 \\
\hline Echs1 & Q8BH95 & Enoyl-CoA hydratase, mitochondrial & 0 & 0 & 1 \\
\hline Eef2k & O08796 & Eukaryotic elongation factor 2 kinase & 0 & 0 & -1 \\
\hline Ehd2 & Q8BH64 & EH domain-containing protein 2 & -1 & 0 & 0 \\
\hline Eif4b & Q8BGD9 & Eukaryotic translation initiation factor 4B & 0 & 0 & -1 \\
\hline Elmo2 & Q8BHL5 & Engulfment and cell motility protein 2 & 0 & 1 & 0 \\
\hline Elovl1 & Q9JLJ5 & Elongation of very long chain fatty acids protein 1 & 0 & 0 & 1 \\
\hline $\mathrm{Eml2}$ & Q7TNG5 & Echinoderm microtubule-associated protein-like 2 & 0 & 0 & 1 \\
\hline Eno1 & P17182 & Alpha-enolase & 0 & 0 & 1 \\
\hline Enpp1 & P06802 & Ectonucleotide pyrophosphatase/phosphodiesterase family member 1 & 0 & 1 & 0 \\
\hline Enpp4 & Q8BTJ4 & Bis(5'-adenosyl)-triphosphatase enpp4 & 0 & -1 & 0 \\
\hline Entpd1 & P55772 & Ectonucleoside triphosphate diphosphohydrolase 1 & 0 & 0 & -1 \\
\hline Epb4112 & O70318 & Band 4.1-like protein 2 & 0 & 0 & -1 \\
\hline Epdr1 & Q99M71 & Mammalian ependymin-related protein 1 & 0 & 0 & -1 \\
\hline Epha2 & Q03145 & Ephrin type-A receptor 2 & 0 & 0 & -1 \\
\hline Ephx1 & Q9D379 & Epoxide hydrolase 1 & 0 & 1 & 0 \\
\hline Epn1 & Q80VP1 & Epsin-1 & 0 & 0 & -1 \\
\hline Ergic2 & Q9CR89 & Endoplasmic reticulum-Golgi intermediate compartment protein 2 & 0 & 0 & 1 \\
\hline Erlec1 & Q8VEH8 & Endoplasmic reticulum lectin 1 & 0 & 0 & 1 \\
\hline Erola & Q8R180 & ERO1-like protein alpha & 0 & 0 & 1 \\
\hline Erp29 & P57759 & Endoplasmic reticulum resident protein 29 & 0 & 1 & 0 \\
\hline
\end{tabular}




\begin{tabular}{|c|c|c|c|c|c|}
\hline \multirow[b]{2}{*}{$\begin{array}{l}\text { Gene } \\
\text { Name }\end{array}$} & \multirow[b]{2}{*}{$\begin{array}{l}\text { UniProt } \\
\text { Accession }\end{array}$} & \multirow[b]{2}{*}{ Protein Name } & \multicolumn{3}{|c|}{ MARPs (up: +1; down: -1) } \\
\hline & & & $\begin{array}{c}\text { Early } \\
\text { MARP }\end{array}$ & $\begin{array}{l}\text { Middle } \\
\text { MARP }\end{array}$ & $\begin{array}{c}\text { Advanced } \\
\text { MARP }\end{array}$ \\
\hline Erp44 & Q9D1Q6 & Endoplasmic reticulum resident protein 44 & 0 & 0 & 1 \\
\hline Evi5 & P97366 & Ecotropic viral integration site 5 protein & 0 & 0 & -1 \\
\hline Exoc1 & Q8R3S6 & Exocyst complex component 1 & 0 & 0 & -1 \\
\hline F11r & O88792 & Junctional adhesion molecule A & 0 & 0 & -1 \\
\hline F13a1 & Q8BH61 & Coagulation factor XIII A chain & 0 & -1 & 0 \\
\hline Fabp3 & $\mathrm{P} 11404$ & Fatty acid-binding protein, heart & 0 & 1 & 0 \\
\hline Fabp5 & Q05816 & Fatty acid-binding protein, epidermal & 0 & 1 & 0 \\
\hline Fam160b1 & Q8CDM8 & Protein FAM160B1 & 0 & 0 & 1 \\
\hline Fam213b & Q9DB60 & Prostamide/prostaglandin $\mathrm{F}$ synthase & 0 & 0 & -1 \\
\hline Fam3c & Q91VU0 & Protein FAM3C & 0 & 0 & 1 \\
\hline Fam45a & Q9D8N2 & Protein FAM45A & 0 & 0 & -1 \\
\hline Fam49b & Q921M7 & Protein FAM49B & 0 & 0 & -1 \\
\hline Fasn & P19096 & Fatty acid synthase & 0 & 0 & 1 \\
\hline Fbxl14 & Q8BID8 & F-box/LRR-repeat protein 14 & 0 & 1 & 0 \\
\hline Fchsd2 & Q3USJ8 & F-BAR and double SH3 domains protein 2 & 0 & 0 & -1 \\
\hline Fdps & Q920E5 & Farnesyl pyrophosphate synthase & 0 & 1 & 0 \\
\hline Fer & P70451 & Tyrosine-protein kinase Fer & 0 & -1 & 0 \\
\hline Fez2 & Q6TYB5 & Fasciculation and elongation protein zeta- 2 & 0 & 0 & -1 \\
\hline Fgd2 & Q8BY35 & FYVE, RhoGEF and PH domain-containing protein 2 & 0 & 0 & -1 \\
\hline Fgf1 & P61148 & Fibroblast growth factor 1 & 0 & 0 & 1 \\
\hline Fgf2 & P15655 & Fibroblast growth factor 2 & 0 & 1 & 0 \\
\hline Fhit & O89106 & $\operatorname{Bis}\left(5^{\prime}\right.$-adenosyl)-triphosphatase & 0 & -1 & 0 \\
\hline Filip11 & Q6P6L0 & Filamin A-interacting protein 1-like & 0 & 0 & -1 \\
\hline Fkbp2 & $\mathrm{P} 45878$ & Peptidyl-prolyl cis-trans isomerase FKBP2 & 0 & 1 & 0 \\
\hline Fmnl1 & Q9JL26 & Formin-like protein 1 & 0 & 0 & -1 \\
\hline Fmnl2 & A2APV2 & Formin-like protein 2 & 0 & -1 & 0 \\
\hline Fmnl3 & Q6ZPF4 & Formin-like protein 3 & 0 & -1 & 0 \\
\hline Fnbp1 & Q80TY0 & Formin-binding protein 1 & 0 & 0 & -1 \\
\hline Frmd4a & Q8BIE6 & FERM domain-containing protein 4A & 0 & 0 & -1 \\
\hline Fry & E9Q8I9 & Protein furry homolog & 0 & 0 & 1 \\
\hline
\end{tabular}




\begin{tabular}{|c|c|c|c|c|c|}
\hline \multirow[b]{2}{*}{$\begin{array}{l}\text { Gene } \\
\text { Name }\end{array}$} & \multirow[b]{2}{*}{$\begin{array}{l}\text { UniProt } \\
\text { Accession }\end{array}$} & \multirow[b]{2}{*}{ Protein Name } & \multicolumn{3}{|c|}{ MARPs (up: +1; down: -1) } \\
\hline & & & $\begin{array}{c}\text { Early } \\
\text { MARP }\end{array}$ & $\begin{array}{l}\text { Middle } \\
\text { MARP }\end{array}$ & $\begin{array}{c}\text { Advanced } \\
\text { MARP }\end{array}$ \\
\hline Fscn1 & Q61553 & Fascin & 0 & -1 & 0 \\
\hline Fth1 & P09528 & Ferritin heavy chain & 0 & 0 & 1 \\
\hline Fuom & Q8R2K1 & Fucose mutarotase & 1 & 0 & 0 \\
\hline Fxyd1 & Q9Z239 & Phospholemman & 0 & 0 & 1 \\
\hline Fyn & P39688 & Tyrosine-protein kinase Fyn & 0 & 0 & 1 \\
\hline Gab1 & Q9QYY0 & GRB2-associated-binding protein 1 & 0 & -1 & 0 \\
\hline Gab2 & Q9Z1S8 & GRB2-associated-binding protein 2 & 0 & 0 & -1 \\
\hline Galnt1 & O08912 & Polypeptide N-acetylgalactosaminyltransferase 1 & 0 & 0 & 1 \\
\hline Galnt2 & Q6PB93 & Polypeptide N-acetylgalactosaminyltransferase 2 & 0 & 0 & 1 \\
\hline Gatm & Q9D964 & Glycine amidinotransferase, mitochondrial & 0 & 0 & -1 \\
\hline Gca & Q8VC88 & Grancalcin & 0 & 0 & 1 \\
\hline Gcat & O88986 & 2-amino-3-ketobutyrate coenzyme A ligase, mitochondrial & 0 & 0 & 1 \\
\hline Gcc2 & Q8CHG3 & GRIP and coiled-coil domain-containing protein 2 & 0 & 0 & 1 \\
\hline Gde1 & Q9JL56 & Glycerophosphodiester phosphodiesterase 1 & 0 & 0 & 1 \\
\hline Get4 & Q9D1H7 & Golgi to ER traffic protein 4 homolog & 0 & 0 & 1 \\
\hline Gfap & P03995 & Glial fibrillary acidic protein & 0 & 0 & 1 \\
\hline Gfpt1 & P47856 & Glutamine--fructose-6-phosphate aminotransferase [isomerizing] 1 & 0 & 1 & 0 \\
\hline Gja1 & $\mathrm{P} 23242$ & Gap junction alpha-1 protein & 0 & 0 & 1 \\
\hline Glb1 & $\mathrm{P} 23780$ & Beta-galactosidase & 1 & 0 & 0 \\
\hline Glg1 & Q61543 & Golgi apparatus protein 1 & 0 & 0 & 1 \\
\hline Glmn & Q8BZM1 & Glomulin & 0 & 0 & 1 \\
\hline Gmip & Q6PGG2 & GEM-interacting protein & 0 & 0 & -1 \\
\hline Gna12 & $\mathrm{P} 27600$ & Guanine nucleotide-binding protein subunit alpha-12 & 0 & -1 & 0 \\
\hline Gna15 & P30678 & Guanine nucleotide-binding protein subunit alpha- 15 & 0 & 0 & -1 \\
\hline Gnai1 & B2RSH2 & Guanine nucleotide-binding protein G(i) subunit alpha-1 & 0 & 0 & -1 \\
\hline Gnai2 & $\mathrm{P} 08752$ & Guanine nucleotide-binding protein G(i) subunit alpha-2 & 0 & 0 & -1 \\
\hline Gnb1 & P62874 & Guanine nucleotide-binding protein $\mathrm{G}(\mathrm{I}) / \mathrm{G}(\mathrm{S}) / \mathrm{G}(\mathrm{T})$ subunit beta-1 & 0 & 0 & -1 \\
\hline Gnb2 & P62880 & Guanine nucleotide-binding protein $\mathrm{G}(\mathrm{I}) / \mathrm{G}(\mathrm{S}) / \mathrm{G}(\mathrm{T})$ subunit beta-2 & 0 & 0 & -1 \\
\hline Gng10 & Q9CXP8 & Guanine nucleotide-binding protein $\mathrm{G}(\mathrm{I}) / \mathrm{G}(\mathrm{S}) / \mathrm{G}(\mathrm{O})$ subunit gamma-10 & 0 & 0 & -1 \\
\hline Gng2 & P63213 & Guanine nucleotide-binding protein $\mathrm{G}(\mathrm{I}) / \mathrm{G}(\mathrm{S}) / \mathrm{G}(\mathrm{O})$ subunit gamma-2 & 0 & 0 & -1 \\
\hline
\end{tabular}




\begin{tabular}{|c|c|c|c|c|c|}
\hline & & & MAI & lp: $+1 ; d$ & $\mathrm{n}:-1)$ \\
\hline $\begin{array}{l}\text { Gene } \\
\text { Name }\end{array}$ & $\begin{array}{l}\text { UniProt } \\
\text { Accession }\end{array}$ & Protein Name & $\begin{array}{c}\text { Early } \\
\text { MARP }\end{array}$ & $\begin{array}{l}\text { Middle } \\
\text { MARP }\end{array}$ & $\begin{array}{c}\text { Advanced } \\
\text { MARP }\end{array}$ \\
\hline Gng5 & Q80SZ7 & Guanine nucleotide-binding protein $\mathrm{G}(\mathrm{I}) / \mathrm{G}(\mathrm{S}) / \mathrm{G}(\mathrm{O})$ subunit gamma-5 & 0 & 0 & -1 \\
\hline Gngt2 & Q61017 & Guanine nucleotide-binding protein $\mathrm{G}(\mathrm{I}) / \mathrm{G}(\mathrm{S}) / \mathrm{G}(\mathrm{O})$ subunit gamma-T2 & 0 & 0 & -1 \\
\hline Gns & Q8BFR4 & N-acetylglucosamine-6-sulfatase & 0 & 0 & 1 \\
\hline Golga3 & P55937 & Golgin subfamily A member 3 & 0 & 0 & 1 \\
\hline Golga4 & Q91VW5 & Golgin subfamily A member 4 & 0 & 1 & 0 \\
\hline Golga5 & Q9QYE6 & Golgin subfamily A member 5 & 0 & 0 & 1 \\
\hline Golt1b & Q9CR60 & Vesicle transport protein GOT1B & 0 & 0 & 1 \\
\hline Got1 & P05201 & Aspartate aminotransferase, cytoplasmic & 0 & 0 & 1 \\
\hline Gpd1 & P13707 & Glycerol-3-phosphate dehydrogenase [NAD $(+)]$, cytoplasmic & -1 & 0 & 0 \\
\hline Gpi & P06745 & Glucose-6-phosphate isomerase & 0 & 0 & 1 \\
\hline Gpld1 & $\mathrm{O} 70362$ & Phosphatidylinositol-glycan-specific phospholipase D & 0 & -1 & 0 \\
\hline Gpm6a & P35802 & Neuronal membrane glycoprotein M6-a & 0 & 0 & 1 \\
\hline Gpr84 & Q8CIM5 & G-protein coupled receptor 84 & 1 & 0 & 0 \\
\hline Grap & Q9CX99 & GRB2-related adapter protein & 0 & 0 & -1 \\
\hline Gsdmdc1 & Q9D8T2 & Gasdermin-D & 0 & 0 & -1 \\
\hline Gsn & $\mathrm{P} 13020$ & Gelsolin & 0 & 1 & 0 \\
\hline $\mathrm{Gtf} 3 \mathrm{c} 4$ & Q8BMQ2 & General transcription factor 3C polypeptide 4 & 1 & 0 & 0 \\
\hline Gusb & $\mathrm{P} 12265$ & Beta-glucuronidase & 0 & 1 & 0 \\
\hline Gvin1 & Q80SU7 & Interferon-induced very large GTPase 1 & 1 & 0 & 0 \\
\hline Gyg1 & Q9R062 & Glycogenin-1 & 0 & 0 & 1 \\
\hline Gys 1 & Q9Z1E4 & Glycogen [starch] synthase, muscle & 0 & 0 & 1 \\
\hline $\mathrm{H} 2 \mathrm{afz}$ & P0C0S6 & Histone H2A.Z;Histone H2A.V & 0 & -1 & 0 \\
\hline H2-D1 & P01899 & H-2 class I histocompatibility antigen, D-B alpha chain & 1 & 0 & 0 \\
\hline $\mathrm{H} 2-\mathrm{K} 1$ & P01901 & H-2 class I histocompatibility antigen, K-B alpha chain & 1 & 0 & 0 \\
\hline $\mathrm{H} 2-\mathrm{T} 23$ & P06339 & H-2 class I histocompatibility antigen, D-37 alpha chain & 0 & 1 & 0 \\
\hline $\mathrm{H} 3 \mathrm{f} 3 \mathrm{c}$ & $\mathrm{P} 02301$ & Histone H3.3C;Histone H3.3 & 0 & 0 & -1 \\
\hline Haao & Q78JT3 & 3-hydroxyanthranilate 3,4-dioxygenase & 1 & 0 & 0 \\
\hline Hacd2 & Q9D3B1 & Very-long-chain (3R)-3-hydroxyacyl-CoA dehydratase 2 & 0 & 1 & 0 \\
\hline Hapln1 & Q9QUP5 & Hyaluronan and proteoglycan link protein 1 & 0 & 1 & 0 \\
\hline Hck & P08103 & Tyrosine-protein kinase HCK & 0 & 0 & -1 \\
\hline
\end{tabular}




\begin{tabular}{|c|c|c|c|c|c|}
\hline \multirow[b]{2}{*}{$\begin{array}{l}\text { Gene } \\
\text { Name } \\
\end{array}$} & \multirow[b]{2}{*}{$\begin{array}{l}\text { UniProt } \\
\text { Accession }\end{array}$} & \multirow[b]{2}{*}{ Protein Name } & \multicolumn{3}{|c|}{ MARPs (up: +1; down: -1) } \\
\hline & & & $\begin{array}{c}\text { Early } \\
\text { MARP }\end{array}$ & $\begin{array}{l}\text { Middle } \\
\text { MARP }\end{array}$ & $\begin{array}{c}\text { Advanced } \\
\text { MARP }\end{array}$ \\
\hline Hepacam & Q640R3 & Hepatocyte cell adhesion molecule & 0 & 0 & 1 \\
\hline Hexa & P29416 & Beta-hexosaminidase subunit alpha & 1 & 0 & 0 \\
\hline Hexb & P20060 & Beta-hexosaminidase subunit beta & 0 & 0 & 1 \\
\hline $\mathrm{Hic} 2$ & Q9JLZ6 & Hypermethylated in cancer 2 protein & 0 & 0 & -1 \\
\hline Hist1h1a & $\mathrm{P} 43275$ & Histone H1.1 & 0 & 1 & 0 \\
\hline Hist1h1b & P43276 & Histone H1.5 & 0 & 1 & 0 \\
\hline Hist1h2ab & $\mathrm{P} 22752$ & Histone H2A type 1 & 0 & 0 & -1 \\
\hline Hist1h2bf & P10853 & Histone $\mathrm{H} 2 \mathrm{~B}$ type $1-\mathrm{F} / \mathrm{J} / \mathrm{L}$ & 0 & 0 & -1 \\
\hline Hist $2 \mathrm{~h} 2 \mathrm{ac}$ & Q64523 & Histone H2A type 2-C & 0 & -1 & 0 \\
\hline Hmga1 & $\mathrm{P} 17095$ & High mobility group protein HMG-I/HMG-Y & 0 & -1 & 0 \\
\hline Hmgn2 & P09602 & Non-histone chromosomal protein HMG-17 & 0 & -1 & 0 \\
\hline Hmha1 & Q3TBD2 & Minor histocompatibility protein HA-1 & 0 & 0 & -1 \\
\hline Hmox 1 & P14901 & Heme oxygenase 1 & 0 & 1 & 0 \\
\hline Hpca & P84075 & Neuron-specific calcium-binding protein hippocalcin & 0 & 0 & 1 \\
\hline Hpcal1 & P62748 & Hippocalcin-like protein 1 & 0 & 0 & 1 \\
\hline Hpcal4 & Q8BGZ1 & Hippocalcin-like protein 4 & 0 & 0 & 1 \\
\hline Hpf1 & Q8CFE2 & Histone PARylation factor 1 & 0 & 0 & 1 \\
\hline Hpgd & Q8VCC1 & 15-hydroxyprostaglandin dehydrogenase $[\mathrm{NAD}(+)]$ & 0 & 0 & -1 \\
\hline Hpgds & Q9JHF7 & Hematopoietic prostaglandin D synthase & 0 & 0 & -1 \\
\hline Hras & Q61411 & GTPase HRas & 0 & 0 & -1 \\
\hline Hsd17b12 & O70503 & Very-long-chain 3-oxoacyl-CoA reductase & 0 & 1 & 0 \\
\hline Hspa5 & P20029 & $78 \mathrm{kDa}$ glucose-regulated protein & 0 & 0 & 1 \\
\hline Htra1 & Q9R118 & Serine protease HTRA1 & 1 & 0 & 0 \\
\hline Hyal1 & Q91ZJ9 & Hyaluronidase-1 & 0 & 0 & -1 \\
\hline Idh2 & P54071 & Isocitrate dehydrogenase [NADP], mitochondrial & 0 & -1 & 0 \\
\hline Ier3ip1 & Q9CR20 & Immediate early response 3 -interacting protein 1 & 0 & 0 & 1 \\
\hline Ifi204 & P0DOV2 & Interferon-activable protein 204 & 1 & 0 & 0 \\
\hline Ifit2 & Q64112 & Interferon-induced protein with tetratricopeptide repeats 2 & 1 & 0 & 0 \\
\hline Ifit3 & Q64345 & Interferon-induced protein with tetratricopeptide repeats 3 & 1 & 0 & 0 \\
\hline Ifitm3 & Q9CQW9 & Interferon-induced transmembrane protein 3 & 0 & 1 & 0 \\
\hline
\end{tabular}




\begin{tabular}{|c|c|c|c|c|c|}
\hline & & & MAI & lp: $+1 ; d$ & $\mathrm{n}:-1)$ \\
\hline $\begin{array}{l}\text { Gene } \\
\text { Name }\end{array}$ & $\begin{array}{l}\text { UniProt } \\
\text { Accession }\end{array}$ & Protein Name & $\begin{array}{c}\text { Early } \\
\text { MARP }\end{array}$ & $\begin{array}{l}\text { Middle } \\
\text { MARP }\end{array}$ & $\begin{array}{c}\text { Advanced } \\
\text { MARP }\end{array}$ \\
\hline Igfbp7 & Q61581 & Insulin-like growth factor-binding protein 7 & 0 & -1 & 0 \\
\hline Il16 & O54824 & Pro-interleukin-16 & 0 & 0 & -1 \\
\hline Il6st & Q00560 & Interleukin-6 receptor subunit beta & 0 & 0 & -1 \\
\hline Ilf2 & Q9CXY6 & Interleukin enhancer-binding factor 2 & 0 & 0 & 1 \\
\hline Inf2 & Q0GNC1 & Inverted formin-2 & 0 & 0 & 1 \\
\hline Inpp4b & Q6P1Y8 & Type II inositol 3,4-bisphosphate 4-phosphatase & 0 & 0 & -1 \\
\hline Ints 1 & Q6P4S8 & Integrator complex subunit 1 & 0 & 0 & 1 \\
\hline Ints2 & Q80UK8 & Integrator complex subunit 2 & 1 & 0 & 0 \\
\hline Ints3 & Q7TPD0 & Integrator complex subunit 3 & 0 & 0 & 1 \\
\hline Ints5 & Q8CHT3 & Integrator complex subunit 5 & 0 & 0 & 1 \\
\hline Ints7 & Q7TQK1 & Integrator complex subunit 7 & 0 & 0 & 1 \\
\hline Ipo4 & Q8VI75 & Importin-4 & 0 & 1 & 0 \\
\hline Irak1 & Q62406 & Interleukin-1 receptor-associated kinase 1 & 0 & 0 & -1 \\
\hline Isg15 & Q64339 & Ubiquitin-like protein ISG15 & 1 & 0 & 0 \\
\hline Ist1 & Q9CX00 & IST1 homolog & 0 & 1 & 0 \\
\hline Itga9 & B8JK39 & Integrin alpha-9 & 0 & -1 & 0 \\
\hline Itgav & P43406 & Integrin alpha-V & 0 & 0 & -1 \\
\hline Itgax & Q9QXH4 & Integrin alpha-X & 1 & 0 & 0 \\
\hline Itgb6 & Q9Z0T9 & Integrin beta- 6 & 0 & 0 & -1 \\
\hline Itpr2 & Q97329 & Inositol 1,4,5-trisphosphate receptor type 2 & 0 & -1 & 0 \\
\hline Itpr3 & P70227 & Inositol 1,4,5-trisphosphate receptor type 3 & 0 & -1 & 0 \\
\hline Ivns1abp & Q920Q8 & Influenza virus NS1A-binding protein homolog & 0 & 0 & -1 \\
\hline Jak1 & P52332 & Tyrosine-protein kinase JAK1 & 0 & 0 & -1 \\
\hline Kif1a & $\mathrm{P} 33173$ & Kinesin-like protein KIF1A & 0 & 0 & 1 \\
\hline Kras & P32883 & GTPase KRas & -1 & 0 & 0 \\
\hline Krtcap2 & Q5RL79 & Keratinocyte-associated protein 2 & 0 & 0 & 1 \\
\hline Ldhb & P16125 & L-lactate dehydrogenase B chain & 0 & 0 & -1 \\
\hline Lgals3 & $\mathrm{P} 16110$ & Galectin-3 & 1 & 0 & 0 \\
\hline Lgals3bp & Q07797 & Galectin-3-binding protein & 1 & 0 & 0 \\
\hline Lgals9 & O08573 & Galectin-9 & 0 & 0 & -1 \\
\hline
\end{tabular}




\begin{tabular}{|c|c|c|c|c|c|}
\hline & & & MAI & lp: $+1 ; d$ & $n:-1)$ \\
\hline $\begin{array}{l}\text { Gene } \\
\text { Name }\end{array}$ & $\begin{array}{l}\text { UniProt } \\
\text { Accession }\end{array}$ & Protein Name & $\begin{array}{c}\text { Early } \\
\text { MARP }\end{array}$ & $\begin{array}{l}\text { Middle } \\
\text { MARP }\end{array}$ & $\begin{array}{c}\text { Advanced } \\
\text { MARP }\end{array}$ \\
\hline Limd2 & Q8BGB5 & LIM domain-containing protein 2 & 0 & 0 & -1 \\
\hline Llgl1 & Q80Y17 & Lethal(2) giant larvae protein homolog 1 & -1 & 0 & 0 \\
\hline Lman1 & Q9D0F3 & Protein ERGIC-53 & 0 & 1 & 0 \\
\hline Lman2 & Q9DBH5 & Vesicular integral-membrane protein VIP36 & 0 & 0 & 1 \\
\hline Lmna & $\mathrm{P} 48678$ & Prelamin-A/C & 0 & 0 & 1 \\
\hline Lmnb2 & P21619 & Lamin-B2 & 0 & 0 & 1 \\
\hline Lpcat2 & Q8BYI6 & Lysophosphatidylcholine acyltransferase 2 & 0 & 0 & -1 \\
\hline Lrp1 & Q912X7 & Prolow-density lipoprotein receptor-related protein 1 & 0 & 0 & -1 \\
\hline Lrpap1 & P55302 & Alpha-2-macroglobulin receptor-associated protein & 0 & 1 & 0 \\
\hline Lrrc20 & Q8CI70 & Leucine-rich repeat-containing protein 20 & 0 & 0 & 1 \\
\hline Lrrc25 & Q8K1T1 & Leucine-rich repeat-containing protein 25 & 0 & -1 & 0 \\
\hline Lrrc8d & Q8BGR2 & Volume-regulated anion channel subunit LRRC8D & 0 & 0 & 1 \\
\hline Ltc4s & Q60860 & Leukotriene C4 synthase & 0 & 0 & -1 \\
\hline Luc713 & Q5SUF2 & Luc7-like protein 3 & -1 & 0 & 0 \\
\hline Ly86 & O88188 & Lymphocyte antigen 86 & 1 & 0 & 0 \\
\hline Lyn & P25911 & Tyrosine-protein kinase Lyn & 0 & 0 & -1 \\
\hline Lyplal1 & Q3UFF7 & Lysophospholipase-like protein 1 & 0 & 0 & 1 \\
\hline Lyz2 & P08905 & Lysozyme C-2 & 0 & 0 & 1 \\
\hline Magt1 & Q9CQY5 & Magnesium transporter protein 1 & 0 & 0 & 1 \\
\hline Manf & Q9CXI5 & Mesencephalic astrocyte-derived neurotrophic factor & 0 & 0 & 1 \\
\hline Map1s & Q8C052 & Microtubule-associated protein $1 \mathrm{~S}$ & 0 & 0 & -1 \\
\hline Map3k3 & Q61084 & Mitogen-activated protein kinase kinase kinase 3 & 0 & 0 & -1 \\
\hline Map4 & $\mathrm{P} 27546$ & Microtubule-associated protein 4 & 0 & 0 & -1 \\
\hline Map4k4 & P97820 & Mitogen-activated protein kinase kinase kinase kinase 4 & 0 & -1 & 0 \\
\hline Map7d1 & $\mathrm{A} 2 \mathrm{AJI0}$ & MAP7 domain-containing protein 1 & 0 & -1 & 0 \\
\hline Mapre1 & Q61166 & Microtubule-associated protein RP/EB family member 1 & 0 & 0 & -1 \\
\hline Marcks & $\mathrm{P} 26645$ & Myristoylated alanine-rich C-kinase substrate & 0 & 0 & -1 \\
\hline Marcksl1 & P28667 & MARCKS-related protein & 0 & 0 & -1 \\
\hline $\mathrm{Mcm} 2$ & P97310 & DNA replication licensing factor MCM2 & 0 & 1 & 0 \\
\hline $\mathrm{Mcm} 3$ & $\mathrm{P} 25206$ & DNA replication licensing factor MCM3 & 0 & 1 & 0 \\
\hline
\end{tabular}




\begin{tabular}{|c|c|c|c|c|c|}
\hline \multirow[b]{2}{*}{$\begin{array}{l}\text { Gene } \\
\text { Name }\end{array}$} & \multirow[b]{2}{*}{$\begin{array}{l}\text { UniProt } \\
\text { Accession }\end{array}$} & \multirow[b]{2}{*}{ Protein Name } & \multicolumn{3}{|c|}{ MARPs (up: +1; down: -1) } \\
\hline & & & $\begin{array}{c}\text { Early } \\
\text { MARP }\end{array}$ & $\begin{array}{l}\text { Middle } \\
\text { MARP }\end{array}$ & $\begin{array}{c}\text { Advanced } \\
\text { MARP }\end{array}$ \\
\hline Mcm5 & $\mathrm{P} 49718$ & DNA replication licensing factor MCM5 & 1 & 0 & 0 \\
\hline Med15 & Q924H2 & Mediator of RNA polymerase II transcription subunit 15 & 0 & 0 & 1 \\
\hline Mgat2 & Q921V5 & Alpha-1,6-mannosyl-glycoprotein 2-beta-N-acetylglucosaminyltransferase & 0 & 0 & 1 \\
\hline Mgst3 & Q9CPU4 & Microsomal glutathione S-transferase 3 & 0 & 0 & 1 \\
\hline Mif & P34884 & Macrophage migration inhibitory factor & 0 & 1 & 0 \\
\hline Milr1 & Q3TB92 & Allergin-1 & 1 & 0 & 0 \\
\hline Mnda & P0DOV1 & Interferon-activable protein $205-\mathrm{B}$ & 1 & 0 & 0 \\
\hline Mospd2 & Q9CWP6 & Motile sperm domain-containing protein 2 & 0 & 1 & 0 \\
\hline Mov10 & P23249 & Putative helicase MOV-10 & 1 & 0 & 0 \\
\hline Mpeg1 & A1L314 & Macrophage-expressed gene 1 protein & 1 & 0 & 0 \\
\hline Mpi & Q924M7 & Mannose-6-phosphate isomerase & 0 & 0 & -1 \\
\hline Mras & O08989 & Ras-related protein M-Ras & 0 & 0 & -1 \\
\hline Mrc1 & Q61830 & Macrophage mannose receptor 1 & 0 & -1 & 0 \\
\hline Mrpl40 & Q9Z2Q5 & 39S ribosomal protein L40, mitochondrial & 0 & 0 & 1 \\
\hline Msmo1 & Q9CRA4 & Methylsterol monooxygenase 1 & 0 & 0 & 1 \\
\hline Mthfs & Q9D110 & 5-formyltetrahydrofolate cyclo-ligase & 0 & 0 & 1 \\
\hline Mto1 & Q923Z3 & Protein MTO1 homolog, mitochondrial & 0 & 0 & 1 \\
\hline Mtr & A6H5Y3 & Methionine synthase & 0 & 0 & -1 \\
\hline Mvb12b & Q6KAU4 & Multivesicular body subunit 12B & 0 & 0 & -1 \\
\hline Myo1b & P46735 & Unconventional myosin-Ib & 0 & 0 & -1 \\
\hline Myo1g & Q5SUA5 & Unconventional myosin-Ig & 0 & 0 & -1 \\
\hline Myo5a & Q99104 & Unconventional myosin- $\mathrm{Va}$ & 0 & 0 & 1 \\
\hline Мyо9а & Q8C170 & Unconventional myosin-IXa & 0 & 0 & -1 \\
\hline $\mathrm{Naa} 25$ & Q8BWZ3 & N-alpha-acetyltransferase $25, \mathrm{NatB}$ auxiliary subunit & 0 & 0 & 1 \\
\hline Naaa & Q9D7V9 & $\mathrm{N}$-acylethanolamine-hydrolyzing acid amidase & 0 & -1 & 0 \\
\hline Nampt & Q99KQ4 & Nicotinamide phosphoribosyltransferase & 0 & 1 & 0 \\
\hline Ncan & P55066 & Neurocan core protein & 0 & 0 & 1 \\
\hline Nceh1 & Q8BLF1 & Neutral cholesterol ester hydrolase 1 & 0 & 1 & 0 \\
\hline $\mathrm{Ncl}$ & P09405 & Nucleolin & 0 & 0 & 1 \\
\hline Ndrg2 & Q9QYG0 & Protein NDRG2 & 0 & 0 & 1 \\
\hline
\end{tabular}




\begin{tabular}{|c|c|c|c|c|c|}
\hline \multirow[b]{2}{*}{$\begin{array}{l}\text { Gene } \\
\text { Name }\end{array}$} & \multirow[b]{2}{*}{$\begin{array}{l}\text { UniProt } \\
\text { Accession }\end{array}$} & \multirow[b]{2}{*}{ Protein Name } & \multicolumn{3}{|c|}{ MARPs (up: +1; down: -1) } \\
\hline & & & $\begin{array}{c}\text { Early } \\
\text { MARP }\end{array}$ & $\begin{array}{l}\text { Middle } \\
\text { MARP }\end{array}$ & $\begin{array}{c}\text { Advanced } \\
\text { MARP }\end{array}$ \\
\hline Nenf & Q9CQ45 & Neudesin & 0 & 0 & 1 \\
\hline $\mathrm{Neu} 4$ & Q8BZL1 & Sialidase-4 & 0 & 0 & -1 \\
\hline Nfatc1 & O88942 & Nuclear factor of activated T-cells, cytoplasmic 1 & 0 & 0 & -1 \\
\hline Nfatc2 & Q60591 & Nuclear factor of activated T-cells, cytoplasmic 2 & 0 & 0 & -1 \\
\hline Nfkbib & Q60778 & NF-kappa-B inhibitor beta & 0 & 0 & -1 \\
\hline $\mathrm{Ngp}$ & O08692 & Neutrophilic granule protein & 0 & 0 & -1 \\
\hline Nipsnap3b & Q9CQE1 & Protein NipSnap homolog 3B & 0 & 0 & 1 \\
\hline Nit1 & Q8VDK1 & Nitrilase homolog 1 & 0 & 0 & -1 \\
\hline Nkiras2 & Q9CR56 & NF-kappa-B inhibitor-interacting Ras-like protein 2 & 0 & 0 & 1 \\
\hline No66 & Q9JJF3 & Bifunctional lysine-specific demethylase and histidyl-hydroxylase NO66 & 0 & 0 & 1 \\
\hline Nop10 & Q9CQS2 & H/ACA ribonucleoprotein complex subunit 3 & 1 & 0 & 0 \\
\hline $\mathrm{Npc} 2$ & Q9Z0J0 & Epididymal secretory protein E1 & 1 & 0 & 0 \\
\hline Nras & P08556 & GTPase NRas & 0 & 0 & -1 \\
\hline Nrbf2 & Q8VCQ3 & Nuclear receptor-binding factor 2 & 1 & 0 & 0 \\
\hline Nsdhl & Q9R1J0 & Sterol-4-alpha-carboxylate 3-dehydrogenase, decarboxylating & 0 & 0 & 1 \\
\hline Nucb1 & Q02819 & Nucleobindin-1 & 0 & 0 & 1 \\
\hline Nucb2 & P81117 & Nucleobindin-2 & 1 & 0 & 0 \\
\hline Numb & Q9QZS3 & Protein numb homolog & 0 & -1 & 0 \\
\hline Numbl & O08919 & Numb-like protein & 0 & -1 & 0 \\
\hline Nup155 & Q99P88 & Nuclear pore complex protein Nup155 & 0 & 0 & 1 \\
\hline Oas1a & P11928 & 2'-5'-oligoadenylate synthase $1 \mathrm{~A}$ & 1 & 0 & 0 \\
\hline Olfml3 & Q8BK62 & Olfactomedin-like protein 3 & 0 & 0 & -1 \\
\hline Omg & Q63912 & Oligodendrocyte-myelin glycoprotein & -1 & 0 & 0 \\
\hline Ophn1 & Q99J31 & Oligophrenin-1 & 0 & 0 & -1 \\
\hline ORF11 & Q9ERY9 & Probable ergosterol biosynthetic protein 28 & 0 & 0 & 1 \\
\hline Os9 & Q8K2C7 & Protein OS-9 & 0 & 1 & 0 \\
\hline Osbpl3 & Q9DBS9 & Oxysterol-binding protein-related protein 3 & 0 & 0 & 1 \\
\hline Osbpl8 & B9EJ86 & Oxysterol-binding protein-related protein 8 & 0 & 0 & 1 \\
\hline $\mathrm{P} 2 \mathrm{rx} 4$ & Q9JJX6 & $\mathrm{P} 2 \mathrm{X}$ purinoceptor 4 & 0 & 0 & 1 \\
\hline $\mathrm{P} 2 \mathrm{rx} 7$ & Q9Z1M0 & $\mathrm{P} 2 \mathrm{X}$ purinoceptor 7 & 0 & 0 & -1 \\
\hline
\end{tabular}




\begin{tabular}{|c|c|c|c|c|c|}
\hline \multirow[b]{2}{*}{$\begin{array}{l}\text { Gene } \\
\text { Name }\end{array}$} & \multirow[b]{2}{*}{$\begin{array}{l}\text { UniProt } \\
\text { Accession }\end{array}$} & \multirow[b]{2}{*}{ Protein Name } & \multicolumn{3}{|c|}{ MARPs (up: +1; down: -1) } \\
\hline & & & $\begin{array}{c}\text { Early } \\
\text { MARP }\end{array}$ & $\begin{array}{l}\text { Middle } \\
\text { MARP }\end{array}$ & $\begin{array}{c}\text { Advanced } \\
\text { MARP }\end{array}$ \\
\hline P2ry12 & Q9CPV9 & P2Y purinoceptor 12 & 0 & -1 & 0 \\
\hline $\mathrm{P} 2 \mathrm{yr} 13$ & Q9D8I2 & P2Y purinoceptor 13 & 0 & 0 & -1 \\
\hline Pacsin 1 & Q61644 & Protein kinase $\mathrm{C}$ and casein kinase substrate in neurons protein 1 & 0 & 0 & 1 \\
\hline Pacsin 2 & Q9WVE8 & Protein kinase $\mathrm{C}$ and casein kinase substrate in neurons protein 2 & 0 & 0 & -1 \\
\hline Paf1 & Q8K2T8 & RNA polymerase II-associated factor 1 homolog & 0 & 0 & 1 \\
\hline Pclo & Q9QYX7 & Protein piccolo & 0 & 0 & -1 \\
\hline Pcna & P17918 & Proliferating cell nuclear antigen & 1 & 0 & 0 \\
\hline Pde $3 b$ & Q61409 & cGMP-inhibited 3',5'-cyclic phosphodiesterase B & 0 & -1 & 0 \\
\hline Pdia4 & P08003 & Protein disulfide-isomerase A4 & 0 & 0 & 1 \\
\hline Pdlim4 & P70271 & PDZ and LIM domain protein 4 & 0 & -1 & 0 \\
\hline Pdlim5 & Q8CI51 & PDZ and LIM domain protein 5 & 0 & -1 & 0 \\
\hline Pdxdc1 & Q99K01 & Pyridoxal-dependent decarboxylase domain-containing protein 1 & 0 & 1 & 0 \\
\hline Pfkl & $\mathrm{P} 12382$ & ATP-dependent 6-phosphofructokinase, liver type & 0 & 1 & 0 \\
\hline Pgam1 & Q9DBJ1 & Phosphoglycerate mutase 1 & 0 & 0 & 1 \\
\hline Pgam2 & O70250 & Phosphoglycerate mutase 2 & 0 & 1 & 0 \\
\hline Pgap1 & Q3UUQ7 & GPI inositol-deacylase & 0 & 0 & 1 \\
\hline Pgk1 & P09411 & Phosphoglycerate kinase 1 & 0 & 1 & 0 \\
\hline Pgm1 & Q9D0F9 & Phosphoglucomutase-1 & 0 & 0 & 1 \\
\hline Phf11 & A6H5X4 & PHD finger protein 11 & 1 & 0 & 0 \\
\hline Phyhd1 & Q9DB26 & Phytanoyl-CoA dioxygenase domain-containing protein 1 & 0 & 0 & -1 \\
\hline $\mathrm{Pi} 4 \mathrm{k} 2 \mathrm{a}$ & Q2TBE6 & Phosphatidylinositol 4-kinase type 2-alpha & 1 & 0 & 0 \\
\hline Pid1 & Q3UBG2 & PTB-containing, cubilin and LRP1-interacting protein & 0 & 0 & -1 \\
\hline Pik3ap1 & Q9EQ32 & Phosphoinositide 3-kinase adapter protein 1 & 0 & 0 & -1 \\
\hline Pik3r5 & Q5SW28 & Phosphoinositide 3-kinase regulatory subunit 5 & 0 & 0 & -1 \\
\hline Pik3r6 & Q3U6Q4 & Phosphoinositide 3-kinase regulatory subunit 6 & 0 & 0 & -1 \\
\hline Pikfyve & Q9Z1T6 & 1-phosphatidylinositol 3-phosphate 5-kinase & 0 & 0 & 1 \\
\hline Pip4k2a & O70172 & Phosphatidylinositol 5-phosphate 4-kinase type-2 alpha & -1 & 0 & 0 \\
\hline Pip4k2b & Q80XI4 & Phosphatidylinositol 5-phosphate 4-kinase type-2 beta & 0 & -1 & 0 \\
\hline $\mathrm{Pkm}$ & P52480 & Pyruvate kinase PKM & 0 & 1 & 0 \\
\hline Pkn1 & P70268 & Serine/threonine-protein kinase N1 & 0 & 0 & -1 \\
\hline
\end{tabular}




\begin{tabular}{|c|c|c|c|c|c|}
\hline \multirow[b]{2}{*}{$\begin{array}{l}\text { Gene } \\
\text { Name } \\
\end{array}$} & \multirow[b]{2}{*}{$\begin{array}{l}\text { UniProt } \\
\text { Accession }\end{array}$} & \multirow[b]{2}{*}{ Protein Name } & \multicolumn{3}{|c|}{ MARPs (up: +1; down: -1) } \\
\hline & & & $\begin{array}{c}\text { Early } \\
\text { MARP }\end{array}$ & $\begin{array}{l}\text { Middle } \\
\text { MARP }\end{array}$ & $\begin{array}{c}\text { Advanced } \\
\text { MARP }\end{array}$ \\
\hline Plcb3 & P51432 & 1-phosphatidylinositol 4,5-bisphosphate phosphodiesterase beta-3 & 0 & 0 & -1 \\
\hline $\mathrm{Plcl} 2$ & Q8K394 & Inactive phospholipase C-like protein 2 & 0 & 0 & -1 \\
\hline Pld4 & Q8BG07 & Phospholipase D4 & 0 & 0 & -1 \\
\hline Plekha1 & Q8BUL6 & Pleckstrin homology domain-containing family A member 1 & 0 & 0 & 1 \\
\hline Plekho1 & Q9JIY0 & Pleckstrin homology domain-containing family $\mathrm{O}$ member 1 & 0 & 0 & -1 \\
\hline Plgrkt & Q9D3P8 & Plasminogen receptor (KT) & 0 & 1 & 0 \\
\hline Plp2 & Q9R1Q7 & Proteolipid protein 2 & 0 & 1 & 0 \\
\hline Plpp3 & Q99JY8 & Phospholipid phosphatase 3 & 0 & 0 & 1 \\
\hline Plrg1 & Q922V4 & Pleiotropic regulator 1 & 0 & 0 & 1 \\
\hline Plscr3 & Q9JIZ9 & Phospholipid scramblase 3 & 0 & -1 & 0 \\
\hline Plxnb2 & B2RXS4 & Plexin-B2 & 0 & 0 & -1 \\
\hline Pml & Q60953 & Protein PML & 1 & 0 & 0 \\
\hline Pnp & P23492 & Purine nucleoside phosphorylase & 0 & -1 & 0 \\
\hline Pofut2 & Q8VHI3 & GDP-fucose protein O-fucosyltransferase 2 & 0 & 1 & 0 \\
\hline Ppig & A2AR02 & Peptidyl-prolyl cis-trans isomerase $\mathrm{G}$ & 0 & -1 & 0 \\
\hline Ppp1r18 & Q8BQ30 & Phostensin & 0 & 0 & -1 \\
\hline Praf2 & Q9JIG8 & PRA1 family protein 2 & 0 & 0 & 1 \\
\hline Prdx1 & $\mathrm{P} 35700$ & Peroxiredoxin-1 & 0 & 0 & 1 \\
\hline $\operatorname{Prdx} 4$ & O08807 & Peroxiredoxin-4 & 1 & 0 & 0 \\
\hline Prdx6 & O08709 & Peroxiredoxin-6 & 0 & 0 & 1 \\
\hline Prkab1 & Q9R078 & 5'-AMP-activated protein kinase subunit beta-1 & 0 & 0 & -1 \\
\hline Prkcd & P28867 & Protein kinase $\mathrm{C}$ delta type & 0 & -1 & 0 \\
\hline Prpf40a & Q9R1C7 & Pre-mRNA-processing factor 40 homolog A & 0 & 0 & -1 \\
\hline Prpf8 & Q99PV0 & Pre-mRNA-processing-splicing factor 8 & 0 & 0 & -1 \\
\hline Psat1 & Q99K85 & Phosphoserine aminotransferase & 1 & 0 & 0 \\
\hline Ptp4a2 & $\mathrm{O} 70274$ & Protein tyrosine phosphatase type IVA 2 & 0 & 0 & -1 \\
\hline Ptp4a3 & Q9D658 & Protein tyrosine phosphatase type IVA 3 & 0 & 0 & -1 \\
\hline Ptprj & Q64455 & Receptor-type tyrosine-protein phosphatase eta & 0 & 0 & -1 \\
\hline Ptrf & O54724 & Polymerase I and transcript release factor & 0 & -1 & 0 \\
\hline Pts & Q9R1Z7 & 6-pyruvoyl tetrahydrobiopterin synthase & 0 & 0 & -1 \\
\hline
\end{tabular}




\begin{tabular}{|c|c|c|c|c|c|}
\hline \multirow[b]{2}{*}{$\begin{array}{l}\text { Gene } \\
\text { Name } \\
\end{array}$} & \multirow[b]{2}{*}{$\begin{array}{l}\text { UniProt } \\
\text { Accession }\end{array}$} & \multirow[b]{2}{*}{ Protein Name } & \multicolumn{3}{|c|}{ MARPs (up: +1; down: -1) } \\
\hline & & & $\begin{array}{c}\text { Early } \\
\text { MARP }\end{array}$ & $\begin{array}{l}\text { Middle } \\
\text { MARP }\end{array}$ & $\begin{array}{c}\text { Advanced } \\
\text { MARP }\end{array}$ \\
\hline Pxk & Q8BX57 & PX domain-containing protein kinase-like protein & 0 & -1 & 0 \\
\hline Pxn & Q8VI36 & Paxillin & 0 & 0 & -1 \\
\hline Pyhin1 & Q8BV49 & Pyrin and HIN domain-containing protein 1 & 1 & 0 & 0 \\
\hline Rab39a & Q8BHD0 & Ras-related protein Rab-39A & 0 & 0 & -1 \\
\hline Rab3d & $\mathrm{P} 35276$ & Ras-related protein Rab-3D & 0 & 0 & 1 \\
\hline Rab3il1 & Q8VDV3 & Guanine nucleotide exchange factor for Rab-3A & 0 & 0 & -1 \\
\hline $\operatorname{Rac} 2$ & Q05144 & Ras-related C3 botulinum toxin substrate 2 & 0 & 0 & -1 \\
\hline Rala & P63321 & Ras-related protein Ral-A & 0 & -1 & 0 \\
\hline Ralgapb & Q8BQZ4 & Ral GTPase-activating protein subunit beta & 0 & 0 & 1 \\
\hline Rap1b & Q99JI6 & Ras-related protein Rap-1b & 0 & 0 & -1 \\
\hline Rap2b & P61226 & Ras-related protein Rap-2b & 0 & 0 & 1 \\
\hline Rap2c & Q8BU31 & Ras-related protein Rap-2c & 0 & 0 & -1 \\
\hline Rassf2 & Q8BMS9 & Ras association domain-containing protein 2 & 0 & 0 & -1 \\
\hline Rbbp9 & O88851 & Putative hydrolase RBBP9 & 0 & 0 & -1 \\
\hline Rbm39 & Q8VH51 & RNA-binding protein 39 & 0 & -1 & 0 \\
\hline Rcc1 & Q8VE37 & Regulator of chromosome condensation & 0 & -1 & 0 \\
\hline Rcsd1 & Q3UZA1 & CapZ-interacting protein & 0 & 0 & -1 \\
\hline Rer1 & Q9CQU3 & Protein RER1 & 0 & 1 & 0 \\
\hline Rgs10 & Q9CQE5 & Regulator of G-protein signaling 10 & 0 & 0 & -1 \\
\hline Rgs19 & Q9CX84 & Regulator of G-protein signaling 19 & 0 & 0 & -1 \\
\hline Rhoc & Q62159 & Rho-related GTP-binding protein RhoC & 0 & 1 & 0 \\
\hline Rhog & P84096 & Rho-related GTP-binding protein RhoG & 0 & 0 & -1 \\
\hline Rhoq & Q8R527 & Rho-related GTP-binding protein RhoQ & 0 & 0 & -1 \\
\hline Rnaseh2a & Q9CWY8 & Ribonuclease $\mathrm{H} 2$ subunit $\mathrm{A}$ & 0 & 0 & 1 \\
\hline Rnaseh2c & Q9CQ18 & Ribonuclease $\mathrm{H} 2$ subunit $\mathrm{C}$ & 0 & 1 & 0 \\
\hline Rnf130 & Q8VEM1 & E3 ubiquitin-protein ligase RNF130 & 0 & 0 & -1 \\
\hline Rp2 & Q9EPK2 & Protein XRP2 & 0 & 0 & -1 \\
\hline Rpl13a & P19253 & 60S ribosomal protein L13a & 1 & 0 & 0 \\
\hline Rpl38 & Q9JJI8 & $60 S$ ribosomal protein L38 & -1 & 0 & 0 \\
\hline Rpl7 & $\mathrm{P} 14148$ & 60S ribosomal protein $\mathrm{L} 7$ & 1 & 0 & 0 \\
\hline
\end{tabular}




\begin{tabular}{|c|c|c|c|c|c|}
\hline \multirow[b]{2}{*}{$\begin{array}{l}\text { Gene } \\
\text { Name }\end{array}$} & \multirow[b]{2}{*}{$\begin{array}{l}\text { UniProt } \\
\text { Accession }\end{array}$} & \multirow[b]{2}{*}{ Protein Name } & \multicolumn{3}{|c|}{ MARPs (up: +1; down: -1) } \\
\hline & & & $\begin{array}{c}\text { Early } \\
\text { MARP }\end{array}$ & $\begin{array}{l}\text { Middle } \\
\text { MARP }\end{array}$ & $\begin{array}{c}\text { Advanced } \\
\text { MARP }\end{array}$ \\
\hline Rps15 & P62843 & 40S ribosomal protein $\mathrm{S} 15$ & 1 & 0 & 0 \\
\hline Rps27a & P62983 & Ubiquitin-40S ribosomal protein $\mathrm{S} 27 \mathrm{a}$ & 0 & 0 & 1 \\
\hline Rps6ka1 & P18653 & Ribosomal protein S6 kinase alpha-1 & 0 & -1 & 0 \\
\hline Rps6ka3 & P18654 & Ribosomal protein S6 kinase alpha-3 & 0 & 0 & -1 \\
\hline Rras2 & P62071 & Ras-related protein R-Ras2 & 0 & 0 & -1 \\
\hline Rtn4 & Q99P72 & Reticulon-4 & 0 & -1 & 0 \\
\hline Scly & Q9JLI6 & Selenocysteine lyase & 0 & 0 & 1 \\
\hline Scpep1 & Q920A5 & Retinoid-inducible serine carboxypeptidase & 0 & 0 & 1 \\
\hline Sdcbp & O08992 & Syntenin-1 & 1 & 0 & 0 \\
\hline Sec1412 & Q99J08 & SEC14-like protein 2 & 0 & 0 & 1 \\
\hline Sec23ip & Q6NZC7 & SEC23-interacting protein & 0 & 1 & 0 \\
\hline Sec61a1 & P61620 & Protein transport protein Sec61 subunit alpha isoform 1 & 0 & 0 & 1 \\
\hline Sel11 & Q9Z2G6 & Protein sel-1 homolog 1 & 0 & 0 & 1 \\
\hline Serpinc1 & P32261 & Antithrombin-III & 0 & -1 & 0 \\
\hline Serpini 1 & O35684 & Neuroserpin & 0 & 0 & -1 \\
\hline Sf3b5 & Q923D4 & Splicing factor $3 \mathrm{~B}$ subunit 5 & 0 & 0 & -1 \\
\hline Sh3bgrl & Q9JJU8 & SH3 domain-binding glutamic acid-rich-like protein & 0 & 0 & 1 \\
\hline Sh3bp1 & P55194 & SH3 domain-binding protein 1 & 0 & 0 & -1 \\
\hline Sil1 & Q9EPK6 & Nucleotide exchange factor SIL1 & 1 & 0 & 0 \\
\hline Sirpa & P97797 & Tyrosine-protein phosphatase non-receptor type substrate 1 & 0 & 0 & -1 \\
\hline Slc16a1 & P53986 & Monocarboxylate transporter 1 & 0 & 0 & 1 \\
\hline Slc17a7 & Q3TXX4 & Vesicular glutamate transporter 1 & 0 & 0 & 1 \\
\hline Slc23a2 & Q9EPR4 & Solute carrier family 23 member 2 & 0 & 1 & 0 \\
\hline Slc2a5 & Q9WV38 & Solute carrier family 2 , facilitated glucose transporter member 5 & 0 & -1 & 0 \\
\hline Slc30a3 & P97441 & Zinc transporter 3 & 0 & 0 & 1 \\
\hline Slc30a6 & Q8BJM5 & Zinc transporter 6 & 1 & 0 & 0 \\
\hline Slc35b1 & P97858 & Solute carrier family 35 member B1 & 0 & 0 & 1 \\
\hline Slc35b2 & Q91ZN5 & Adenosine 3'-phospho 5'-phosphosulfate transporter 1 & 0 & 1 & 0 \\
\hline Slc35e1 & Q8CD26 & Solute carrier family 35 member E1 & 0 & 1 & 0 \\
\hline Slc37a2 & Q9WU81 & Glucose-6-phosphate exchanger SLC37A2 & 0 & 0 & 1 \\
\hline
\end{tabular}




\begin{tabular}{|c|c|c|c|c|c|}
\hline \multirow[b]{2}{*}{$\begin{array}{l}\text { Gene } \\
\text { Name } \\
\end{array}$} & \multirow[b]{2}{*}{$\begin{array}{l}\text { UniProt } \\
\text { Accession }\end{array}$} & \multirow[b]{2}{*}{ Protein Name } & \multicolumn{3}{|c|}{ MARPs (up: +1; down: -1) } \\
\hline & & & $\begin{array}{c}\text { Early } \\
\text { MARP }\end{array}$ & $\begin{array}{l}\text { Middle } \\
\text { MARP }\end{array}$ & $\begin{array}{c}\text { Advanced } \\
\text { MARP }\end{array}$ \\
\hline Slc38a10 & Q5I012 & Putative sodium-coupled neutral amino acid transporter 10 & 0 & 1 & 0 \\
\hline Slc4a4 & O88343 & Electrogenic sodium bicarbonate cotransporter 1 & 0 & 0 & 1 \\
\hline Slc9a1 & Q61165 & Sodium/hydrogen exchanger 1 & 0 & 0 & -1 \\
\hline Slco2b1 & Q8BXB6 & Solute carrier organic anion transporter family member 2B1 & 0 & 0 & -1 \\
\hline Slmap & Q3URD3 & Sarcolemmal membrane-associated protein & 0 & 0 & -1 \\
\hline Smad1 & P70340 & Mothers against decapentaplegic homolog 1 & 0 & -1 & 0 \\
\hline Smad2 & Q62432 & Mothers against decapentaplegic homolog 2 & 0 & 0 & -1 \\
\hline Smad3 & Q8BUN5 & Mothers against decapentaplegic homolog 3 & 0 & -1 & 0 \\
\hline Smim1 & $\mathrm{P} 0 \mathrm{C} 8 \mathrm{~K} 7$ & Small integral membrane protein 1 & 0 & -1 & 0 \\
\hline Smox & Q99K82 & Spermine oxidase & 0 & 0 & -1 \\
\hline Smpdl3a & P70158 & Acid sphingomyelinase-like phosphodiesterase $3 \mathrm{a}$ & 0 & -1 & 0 \\
\hline Smpdl3b & P58242 & Acid sphingomyelinase-like phosphodiesterase 3b & 0 & -1 & 0 \\
\hline Snx17 & Q8BVL3 & Sorting nexin-17 & 0 & 0 & -1 \\
\hline Snx18 & Q91ZR2 & Sorting nexin-18 & 0 & 0 & -1 \\
\hline Snx 9 & Q91VH2 & Sorting nexin-9 & 0 & 0 & -1 \\
\hline Soat1 & Q61263 & Sterol O-acyltransferase 1 & 1 & 0 & 0 \\
\hline Soga1 & E1U8D0 & Protein SOGA1 & 0 & 0 & -1 \\
\hline Sort1 & Q6PHU5 & Sortilin & 0 & 0 & -1 \\
\hline Sp100 & O35892 & Nuclear autoantigen Sp-100 & 1 & 0 & 0 \\
\hline Sp3 & O70494 & Transcription factor $\mathrm{Sp} 3$ & 0 & 0 & -1 \\
\hline Sparc & P07214 & SPARC & 0 & 0 & -1 \\
\hline Sparcl1 & P70663 & SPARC-like protein 1 & 0 & -1 & 0 \\
\hline Spg20 & Q8R1X6 & Spartin & 0 & 0 & -1 \\
\hline Spg21 & Q9CQC8 & Maspardin & 1 & 0 & 0 \\
\hline Spock2 & Q9ER58 & Testican-2 & 0 & -1 & 0 \\
\hline Sqrdl & Q9R112 & Sulfide:quinone oxidoreductase, mitochondrial & 0 & -1 & 0 \\
\hline Srbd1 & Q497V5 & S1 RNA-binding domain-containing protein 1 & 0 & 1 & 0 \\
\hline Srgap2 & Q91Z67 & SLIT-ROBO Rho GTPase-activating protein 2 & 0 & -1 & 0 \\
\hline Srpk2 & O54781 & SRSF protein kinase 2 & 1 & 0 & 0 \\
\hline Ssr1 & Q9CY50 & Translocon-associated protein subunit alpha & 0 & 1 & 0 \\
\hline
\end{tabular}




\begin{tabular}{|c|c|c|c|c|c|}
\hline \multirow[b]{2}{*}{$\begin{array}{l}\text { Gene } \\
\text { Name } \\
\end{array}$} & \multirow[b]{2}{*}{$\begin{array}{l}\text { UniProt } \\
\text { Accession }\end{array}$} & \multirow[b]{2}{*}{ Protein Name } & \multicolumn{3}{|c|}{ MARPs (up: +1; down: -1) } \\
\hline & & & $\begin{array}{c}\text { Early } \\
\text { MARP }\end{array}$ & $\begin{array}{l}\text { Middle } \\
\text { MARP }\end{array}$ & $\begin{array}{c}\text { Advanced } \\
\text { MARP }\end{array}$ \\
\hline Ssr4 & Q62186 & Translocon-associated protein subunit delta & 0 & 0 & 1 \\
\hline Stab1 & Q8R4Y4 & Stabilin-1 & 0 & -1 & 0 \\
\hline Stard3nl & Q9DCI3 & MLN64 N-terminal domain homolog & 0 & 0 & -1 \\
\hline Stat1 & P42225 & Signal transducer and activator of transcription 1 & 1 & 0 & 0 \\
\hline Stat2 & Q9WVL2 & Signal transducer and activator of transcription 2 & 1 & 0 & 0 \\
\hline Stk10 & O55098 & Serine/threonine-protein kinase 10 & 0 & 0 & -1 \\
\hline Stk26 & Q99JT2 & Serine/threonine-protein kinase 26 & 0 & 0 & -1 \\
\hline Sts & P50427 & Steryl-sulfatase & 0 & 0 & 1 \\
\hline Stt3b & Q3TDQ1 & Dolichyl-diphosphooligosaccharide--protein glycosyltransferase subunit STT3B & 0 & 0 & 1 \\
\hline Sult1a1 & P52840 & Sulfotransferase 1A1 & 0 & 0 & -1 \\
\hline Susd3 & Q9D176 & Sushi domain-containing protein 3 & 0 & -1 & 0 \\
\hline Syk & P48025 & Tyrosine-protein kinase SYK & 0 & -1 & 0 \\
\hline Syngr1 & O55100 & Synaptogyrin-1 & 0 & 0 & 1 \\
\hline Tamm41 & Q3TUH1 & Phosphatidate cytidylyltransferase, mitochondrial & -1 & 0 & 0 \\
\hline Taok1 & Q5F2E8 & Serine/threonine-protein kinase TAO1 & 0 & 0 & -1 \\
\hline Tap2 & P36371 & Antigen peptide transporter 2 & 1 & 0 & 0 \\
\hline Tapbp & Q9R233 & Tapasin & 1 & 0 & 0 \\
\hline Tbc1d10b & Q8BHL3 & TBC1 domain family member $10 \mathrm{~B}$ & -1 & 0 & 0 \\
\hline Tbc1d22a & Q8R5A6 & TBC1 domain family member $22 \mathrm{~A}$ & 0 & 0 & 1 \\
\hline Tbc1d4 & Q8BYJ6 & TBC1 domain family member 4 & 0 & 0 & 1 \\
\hline Tfap2a & P34056 & Transcription factor AP-2-alpha & 0 & 0 & -1 \\
\hline Tfe3 & Q64092 & Transcription factor E3 & 0 & 0 & -1 \\
\hline Tfeb & Q9R210 & Transcription factor EB & 0 & 0 & -1 \\
\hline Tgfbr1 & Q64729 & TGF-beta receptor type- 1 & 0 & 0 & -1 \\
\hline Tgm2 & P21981 & Protein-glutamine gamma-glutamyltransferase 2 & 0 & -1 & 0 \\
\hline Them6 & Q80ZW2 & Protein THEM6 & 0 & 0 & 1 \\
\hline Tigar & Q8BZA9 & Fructose-2,6-bisphosphatase TIGAR & 0 & 0 & 1 \\
\hline Tjp1 & P39447 & Tight junction protein $\mathrm{ZO}-1$ & 0 & 0 & -1 \\
\hline Tkt & $\mathrm{P} 40142$ & Transketolase & 0 & 1 & 0 \\
\hline Tlk2 & O55047 & Serine/threonine-protein kinase tousled-like 2 & 0 & 0 & 1 \\
\hline
\end{tabular}




\begin{tabular}{|c|c|c|c|c|c|}
\hline \multirow[b]{2}{*}{$\begin{array}{l}\text { Gene } \\
\text { Name }\end{array}$} & \multirow[b]{2}{*}{$\begin{array}{l}\text { UniProt } \\
\text { Accession }\end{array}$} & \multirow[b]{2}{*}{ Protein Name } & \multicolumn{3}{|c|}{ MARPs (up: +1; down: -1) } \\
\hline & & & $\begin{array}{c}\text { Early } \\
\text { MARP }\end{array}$ & $\begin{array}{l}\text { Middle } \\
\text { MARP }\end{array}$ & $\begin{array}{c}\text { Advanced } \\
\text { MARP }\end{array}$ \\
\hline Tlr2 & Q9QUN7 & Toll-like receptor 2 & 1 & 0 & 0 \\
\hline Tlr3 & Q99MB1 & Toll-like receptor 3 & 0 & 0 & -1 \\
\hline Tlr9 & Q9EQU3 & Toll-like receptor 9 & 0 & -1 & 0 \\
\hline Tm6sf1 & P58749 & Transmembrane 6 superfamily member 1 & 0 & -1 & 0 \\
\hline Tm9sf1 & Q9DBU0 & Transmembrane 9 superfamily member 1 & 0 & 1 & 0 \\
\hline Tm9sf3 & Q9ET30 & Transmembrane 9 superfamily member 3 & 0 & 1 & 0 \\
\hline Tm9sf4 & Q8BH24 & Transmembrane 9 superfamily member 4 & 0 & 0 & 1 \\
\hline Tmed10 & Q9D1D4 & Transmembrane emp24 domain-containing protein 10 & 0 & 1 & 0 \\
\hline Tmed3 & Q78IS1 & Transmembrane emp24 domain-containing protein 3 & 0 & 0 & 1 \\
\hline Tmed4 & Q8R1V4 & Transmembrane emp24 domain-containing protein 4 & 0 & 1 & 0 \\
\hline Tmed 9 & Q99KF1 & Transmembrane emp24 domain-containing protein 9 & 0 & 1 & 0 \\
\hline Tmem100 & Q9CQG9 & Transmembrane protein 100 & 0 & -1 & 0 \\
\hline Tmem119 & Q8R138 & Transmembrane protein 119 & 0 & -1 & 0 \\
\hline Tmem163 & Q8C996 & Transmembrane protein 163 & 0 & 0 & 1 \\
\hline Tmem167a & Q9CR64 & Protein kish-A & 0 & 0 & 1 \\
\hline Tmem173 & Q3TBT3 & Stimulator of interferon genes protein & 0 & 0 & -1 \\
\hline Tmem205 & Q91XE8 & Transmembrane protein 205 & 0 & 0 & 1 \\
\hline Tmem214 & Q8BM55 & Transmembrane protein 214 & 0 & 0 & 1 \\
\hline Tmem38b & Q9DAV9 & Trimeric intracellular cation channel type B & 0 & 0 & 1 \\
\hline Tmsb10 & Q6ZWY8 & Thymosin beta-10 & 0 & 0 & 1 \\
\hline Tnfaip812 & Q9D8Y7 & Tumor necrosis factor alpha-induced protein 8 -like protein 2 & 0 & -1 & 0 \\
\hline Top2b & Q64511 & DNA topoisomerase 2-beta & 0 & 0 & 1 \\
\hline Tpcn1 & Q9EQJ0 & Two pore calcium channel protein 1 & 0 & 0 & -1 \\
\hline Tpd52 & Q62393 & Tumor protein D52 & 0 & 1 & 0 \\
\hline Tpi1 & $\mathrm{P} 17751$ & Triosephosphate isomerase & 0 & 1 & 0 \\
\hline Tpmt & O55060 & Thiopurine S-methyltransferase & 0 & 0 & -1 \\
\hline Trem2 & Q99NH8 & Triggering receptor expressed on myeloid cells 2 & 0 & 1 & 0 \\
\hline Trim3 & Q9R1R2 & Tripartite motif-containing protein 3 & 0 & 0 & -1 \\
\hline Trim47 & Q8C0E3 & Tripartite motif-containing protein 47 & 0 & 0 & -1 \\
\hline Trim65 & Q8BFW4 & Tripartite motif-containing protein 65 & 0 & 0 & -1 \\
\hline
\end{tabular}




\begin{tabular}{|c|c|c|c|c|c|}
\hline \multirow[b]{2}{*}{$\begin{array}{l}\text { Gene } \\
\text { Name }\end{array}$} & \multirow[b]{2}{*}{$\begin{array}{l}\text { UniProt } \\
\text { Accession }\end{array}$} & \multirow[b]{2}{*}{ Protein Name } & \multicolumn{3}{|c|}{ MARPs (up: +1; down: -1) } \\
\hline & & & $\begin{array}{c}\text { Early } \\
\text { MARP }\end{array}$ & $\begin{array}{l}\text { Middle } \\
\text { MARP }\end{array}$ & $\begin{array}{c}\text { Advanced } \\
\text { MARP }\end{array}$ \\
\hline Trio & Q0KL02 & Triple functional domain protein & 0 & 0 & -1 \\
\hline Triobp & Q99KW3 & TRIO and F-actin-binding protein & 0 & 1 & 0 \\
\hline Trp53i11 & Q4QQM4 & Tumor protein p53-inducible protein 11 & 0 & -1 & 0 \\
\hline Tsc22d1 & P62500 & TSC22 domain family protein 1 & 0 & 0 & 1 \\
\hline Ttc38 & A3KMP2 & Tetratricopeptide repeat protein 38 & 0 & 0 & -1 \\
\hline Ttc39b & Q8BYY4 & Tetratricopeptide repeat protein $39 \mathrm{~B}$ & 0 & 0 & 1 \\
\hline Ttyh1 & Q9D3A9 & Protein tweety homolog 1 & 0 & 0 & 1 \\
\hline Tubb5 & P99024 & Tubulin beta- 5 chain & 0 & 0 & -1 \\
\hline Ube2d1 & P61080 & Ubiquitin-conjugating enzyme E2 D1 & 0 & 0 & -1 \\
\hline Ubl4a & $\mathrm{P} 21126$ & Ubiquitin-like protein 4A & 0 & 0 & 1 \\
\hline Upk1b & Q9Z2C6 & Uroplakin-1b & 0 & -1 & 0 \\
\hline Usp24 & B1AY13 & Ubiquitin carboxyl-terminal hydrolase 24 & 0 & 0 & -1 \\
\hline Vamp4 & $\mathrm{O} 70480$ & Vesicle-associated membrane protein 4 & 0 & 0 & 1 \\
\hline Vasp & P70460 & Vasodilator-stimulated phosphoprotein & 0 & 0 & -1 \\
\hline Vat1 & Q62465 & Synaptic vesicle membrane protein VAT-1 homolog & 0 & 0 & 1 \\
\hline Vav2 & Q60992 & Guanine nucleotide exchange factor VAV2 & 0 & 0 & -1 \\
\hline Vim & P20152 & Vimentin & 0 & 0 & 1 \\
\hline Vps13c & Q8BX70 & Vacuolar protein sorting-associated protein $13 \mathrm{C}$ & 0 & 1 & 0 \\
\hline Vrk1 & Q80X41 & Serine/threonine-protein kinase VRK1 & 0 & -1 & 0 \\
\hline Vtn & P29788 & Vitronectin & 0 & 1 & 0 \\
\hline Was & P70315 & Wiskott-Aldrich syndrome protein homolog & 0 & 0 & -1 \\
\hline Wasf2 & Q8BH43 & Wiskott-Aldrich syndrome protein family member 2 & 0 & 0 & -1 \\
\hline Wdfy2 & Q8BUB4 & WD repeat and FYVE domain-containing protein 2 & 0 & 0 & -1 \\
\hline Wdr37 & Q8CBE3 & WD repeat-containing protein 37 & 0 & -1 & 0 \\
\hline Wls & Q6DID7 & Protein wntless homolog & 0 & 0 & 1 \\
\hline Wnk1 & P83741 & Serine/threonine-protein kinase WNK1 & 0 & 0 & -1 \\
\hline Xdh & Q00519 & Xanthine dehydrogenase/oxidase & 0 & 0 & 1 \\
\hline Xpo5 & Q924C1 & Exportin-5 & 0 & 0 & 1 \\
\hline Yes1 & Q04736 & Tyrosine-protein kinase Yes & 0 & 0 & -1 \\
\hline Yif1a & Q91XB7 & Protein YIF1A & 0 & 0 & 1 \\
\hline
\end{tabular}




\begin{tabular}{|c|c|c|c|c|c|}
\hline & & & MAI & lp: $+1 ; d$ & $n:-1)$ \\
\hline $\begin{array}{l}\text { Gene } \\
\text { Name }\end{array}$ & \begin{tabular}{|l} 
UniProt \\
Accession
\end{tabular} & Protein Name & $\begin{array}{c}\text { Early } \\
\text { MARP }\end{array}$ & $\begin{array}{l}\text { Middle } \\
\text { MARP }\end{array}$ & $\begin{array}{c}\text { Advanced } \\
\text { MARP }\end{array}$ \\
\hline Yipf3 & Q3UDR8 & Protein YIPF3 & 1 & 0 & 0 \\
\hline Zadh2 & Q8BGC4 & Prostaglandin reductase- 3 & 1 & 0 & 0 \\
\hline Zfpl1 & Q9DB43 & Zinc finger protein-like 1 & 0 & 0 & 1 \\
\hline Znf335 & A2A5K6 & Zinc finger protein 335 & 0 & 0 & 1 \\
\hline Znf652 & Q5DU09 & Zinc finger protein 652 & 0 & 0 & -1 \\
\hline Znf691 & Q3TDE8 & Zinc finger protein 691 & 0 & 0 & -1 \\
\hline Zyx & Q62523 & Zyxin & 0 & 0 & -1 \\
\hline & Q91V76 & Ester hydrolase C11orf54 homolog & 0 & 0 & -1 \\
\hline & Q9CRC3 & UPF0235 protein C15orf40 homolog & 0 & 0 & -1 \\
\hline & Q99K99 & Uncharacterized protein C4orf19 homolog & 0 & 0 & -1 \\
\hline & P01864 & Ig gamma-2A chain $\mathrm{C}$ region secreted form & 0 & -1 & 0 \\
\hline & Q9CXL3 & Uncharacterized protein C7orf50 homolog & 1 & 0 & 0 \\
\hline
\end{tabular}


Suppl. Table 5: Relative quantification of proteins from seven AD risk genes in APPPS1 (A) or APP-KI (B) versus $\mathrm{WT}$ microglia. The protein $\mathrm{LFQ}$ ratios and $\mathrm{p}$-values of $\mathrm{AD}$ risk genes are presented. P-values less than 0.05 are indicated in red.

A

\begin{tabular}{|l|r|r|r|r|r|r|r|r|}
\hline & \multicolumn{4}{|c|}{ Ratio APPPS1 vs WT } & \multicolumn{4}{c|}{ p-value APPPS1 vs WT } \\
\hline Gene Name & 1 month & 3 months & 6 months & 12 months & 1 month & 3 months & 6 months & 12 months \\
\hline APOE & 1.01 & 2.44 & 4.20 & 9.25 & $8.59 \mathrm{E}-01$ & $2.45 \mathrm{E}-02$ & $4.47 \mathrm{E}-03$ & $4.37 \mathrm{E}-05$ \\
\hline TREM2 & 0.94 & 1.40 & 2.20 & 2.88 & $1.50 \mathrm{E}-01$ & $1.09 \mathrm{E}-02$ & $4.82 \mathrm{E}-03$ & $7.36 \mathrm{E}-06$ \\
\hline CLU & 1.15 & 0.97 & 1.07 & 1.87 & $5.70 \mathrm{E}-03$ & $6.81 \mathrm{E}-01$ & $6.36 \mathrm{E}-01$ & $1.11 \mathrm{E}-03$ \\
\hline INPP5D & 1.10 & 1.38 & 1.80 & 1.71 & $2.66 \mathrm{E}-02$ & $4.91 \mathrm{E}-04$ & $2.86 \mathrm{E}-03$ & $9.29 \mathrm{E}-05$ \\
\hline PLCG2 & 0.99 & 1.05 & 0.99 & 0.86 & $7.01 \mathrm{E}-01$ & $2.27 \mathrm{E}-01$ & $8.45 \mathrm{E}-01$ & $1.39 \mathrm{E}-01$ \\
\hline ABI3 & 1.00 & 1.05 & 0.90 & 0.52 & $9.56 \mathrm{E}-01$ & $4.72 \mathrm{E}-01$ & $4.39 \mathrm{E}-01$ & $1.44 \mathrm{E}-03$ \\
\hline BIN1 & 0.95 & 1.03 & 0.74 & 0.40 & $3.93 \mathrm{E}-01$ & $7.08 \mathrm{E}-01$ & $7.62 \mathrm{E}-02$ & $2.85 \mathrm{E}-04$ \\
\hline
\end{tabular}

B

\begin{tabular}{|l|r|r|r|r|r|r|r|r|}
\hline & \multicolumn{4}{|c|}{ Ratio APP-KI vs WT } & \multicolumn{4}{c|}{ p-value APP-KI vs WT } \\
\hline Gene Name & 1 month & 3 months & 6 months & 12 months & 1 month & 3 months & 6 months & 12 months \\
\hline APOE & 1.06 & 1.22 & 2.88 & 15.03 & $3.29 \mathrm{E}-01$ & $3.04 \mathrm{E}-02$ & $7.66 \mathrm{E}-04$ & $3.09 \mathrm{E}-05$ \\
\hline TREM2 & 0.99 & 1.12 & 1.44 & 3.85 & $9.16 \mathrm{E}-01$ & $5.55 \mathrm{E}-01$ & $6.38 \mathrm{E}-03$ & $6.40 \mathrm{E}-04$ \\
\hline CLU & 0.84 & 1.10 & 0.76 & 0.72 & $2.84 \mathrm{E}-01$ & $3.95 \mathrm{E}-01$ & $1.80 \mathrm{E}-01$ & $8.13 \mathrm{E}-02$ \\
\hline INPP5D & 0.94 & 1.08 & 1.26 & 1.34 & $1.68 \mathrm{E}-01$ & $4.30 \mathrm{E}-01$ & $2.43 \mathrm{E}-02$ & $5.14 \mathrm{E}-05$ \\
\hline PLCG2 & 0.97 & 0.99 & 0.74 & 0.66 & $2.33 \mathrm{E}-01$ & $9.27 \mathrm{E}-01$ & $1.31 \mathrm{E}-01$ & $1.12 \mathrm{E}-02$ \\
\hline ABI3 & 0.95 & 0.95 & 0.67 & 0.53 & $6.55 \mathrm{E}-01$ & $6.83 \mathrm{E}-01$ & $1.08 \mathrm{E}-02$ & $1.78 \mathrm{E}-03$ \\
\hline BIN1 & 0.99 & 0.97 & 0.72 & 0.59 & $7.39 \mathrm{E}-01$ & $7.90 \mathrm{E}-01$ & $5.49 \mathrm{E}-03$ & $1.05 \mathrm{E}-03$ \\
\hline
\end{tabular}

